\title{
A Comparison of Airway Dimensions among Different Skeletal Craniofacial Patterns
}

Ronnie J. Sparks

West Virginia University

Follow this and additional works at: https://researchrepository.wvu.edu/etd

\section{Recommended Citation}

Sparks, Ronnie J., "A Comparison of Airway Dimensions among Different Skeletal Craniofacial Patterns" (2012). Graduate Theses, Dissertations, and Problem Reports. 4921.

https://researchrepository.wvu.edu/etd/4921

This Thesis is protected by copyright and/or related rights. It has been brought to you by the The Research Repository @ WVU with permission from the rights-holder(s). You are free to use this Thesis in any way that is permitted by the copyright and related rights legislation that applies to your use. For other uses you must obtain permission from the rights-holder(s) directly, unless additional rights are indicated by a Creative Commons license in the record and/ or on the work itself. This Thesis has been accepted for inclusion in WVU Graduate Theses, Dissertations, and Problem Reports collection by an authorized administrator of The Research Repository @ WVU. For more information, please contact researchrepository@mail.wvu.edu. 


\title{
A Comparison of Airway Dimensions among Different Skeletal Craniofacial Patterns
}

\author{
Ronnie J. Sparks, D.D.S.
}

\author{
A THESIS \\ Submitted to: \\ The School of Dentistry \\ at West Virginia University \\ in partial fulfillment of the requirements \\ for the degree of \\ Master of Science \\ In \\ Orthodontics
}

Peter Ngan, D.M.D., Chair

Chris Martin, D.D.S., M.S.

Thomas Razmus, D.D.S., M.S.

Department of Orthodontics

Morgantown, West Virginia

2012 


\title{
ABSTRACT \\ A Comparison of Airway Dimensions among Different Skeletal Craniofacial Patterns
}

\author{
Ronnie Sparks, D.D.S.
}

Background and Objectives: Much attention has been given to the association of craniofacial skeletal morphology, upper airway dimension, and respiratory function with patients suffering from obstructive sleep apnea. However, much of the information gathered on the aforementioned has been established with the use of 2-Dimensional lateral cephalometry. The objective of this study was to investigate upper airway dimensions among different skeletal patterns using cone-beam computed tomography (CBCT). Methods: A sample of 279 patients who sought orthodontic treatment at the University of Nevada Las Vegas School of Dentistry Department of Orthodontics was included in this study. Pre-treatment multi-slice CBCT scans of these subjects were divided into three sagittal groups: Class I subjects with an ANB angle $0^{\circ}$ to $5^{\circ}$, Class II subjects with an ANB angle $>5^{\circ}$, and Class III subjects with an ANB angle $<0^{\circ}$. The CBCT scans were also divided into three vertical groups: normodivergent subjects with a mandibular plane angle $22^{\circ}$ to $30^{\circ}$, hyperdivergent subjects with a mandibular plane angle $>30^{\circ}$, and hypodivergent subjects with a mandibular plane angle $<22^{\circ}$. The sagittal and vertical groups were analyzed individually ( 6 groups) and together ( 9 groups) to determine if the various combination of skeletal patterns has any effects on airway volume, minimum cross sectional area (CSA), and airway shape. CBCT scans were analyzed using Dolphin Imaging 10.5 Premium and Anatomage InVivoDental ${ }^{\mathrm{TM}}$ software version 5.1. Data were analyzed using ANOVA, Tukey-Kramer, Student $t$ test, and Wilcoxon/Kruskal-Wallis tests. Results: Significant differences were found among the sagittal groups for airway volume and minimum CSA, $p<.05$. Class III subjects were found to have the largest airway volume and minimum CSA while Class II subjects were found to have the smallest airway volume and minimum CSA. Minimum CSA was found to have an increasing function of airway volume. CSA increased by $10.23 \mathrm{~mm}^{2}$ for every cc increase in airway volume. No significant differences were found among the vertical groups. However, Class II subjects with hyperdivergent skeletal pattern were found to have the smallest airway volume and minimum CSA. No associations were found between the airway shapes and airway volume when evaluating sagittal and/or vertical skeletal patterns. However, wide airway shapes were shown to have the largest airway volume while long airway shapes were shown to have the smallest airways.

Conclusions: Airway dimensions can be affected by craniofacial skeletal pattern. Patients with Class II hyperdivergent skeletal pattern may be more prone to obstructive sleep apnea problems. 


\section{DEDICATIONS}

To my wife, soul mate, and confidant, Jade, for your continual love, support, and patience as I embarked on this journey. You have been with me every step of the way, through all the good times and the bad. I dedicate this thesis to you for teaching me that even the largest task can be accomplished if it is done one step at a time. I love you.

To my son ses Logan and Noah, thank you for your unconditional love. Your smiles were all I needed to melt away the frustration of the day. I love you.

To my parents, Donnie and Terry Sparks, who helped channel my eagerness for learning. Thank you for your source of encouragement and inspiration throughout my life. I dedicate this thesis to you for the myriad of ways in which you have actively supported me in my determination to find and realize my potential. Your love and sacrifice have been beyond comprehension, and I endlessly thank you for supporting me. I love you.

To my brother, Corey, for your love and support. Thank you for the laughs, the fights, and everything in between...

To my Lord and Savior, Jesus Christ, thank you for this unbelievable path you have placed me on in my life. You have blessed me beyond belief, far more than I could have ever asked. I love you. 


\section{ACKNOWLEDGEMENTS}

There are a number of people without whom this thesis might not have been written, and to whom I am greatly indebted. I would like to take this opportunity to thank not only the individuals who have contributed to my thesis, but also those who have assisted me throughout my specialty training.

Dr. Peter Ngan, for being the chairman of my thesis committee, for your countless hours of dedication to this program, and for your endless commitment to me both personally and professionally. You have been a mentor, educator, and friend. You have believed in me since the onset of my career and I am truly indebted. Your heart is full of love and support and I thank you.

Dr. Chris Martin, for being a member of my thesis committee, for being a full-time adviser, and for guiding me through my educational journey. I have learned an innumerable amount of knowledge from you, all the while making me laugh on a daily basis. I thank you.

Dr. Thomas Razmus, for being a member of my thesis committee and guiding me throughout this process. I thank you.

Dr. James Mah, for your contribution of CBCT scans of subjects utilized throughout this research project and for your continued dedication and drive to produce evidenced based studies. I thank you.

Dr. Erdogen Gunel, for your time and effort in preparing and interpreting the statistical analyses conducted throughout this project. I thank you.

Drs. Glenn Boyles, John Dempsey, Dan Foley, Jeff Gilmore, Mike Hazey, Tom Jarrett, Kerry Kirsch, Ned McFarland, Rajia Sebbahi, and Tim Tremont, for your time and enthusiasm granted to this program. You are great examples of our young orthodontic profession and set a standard in which to aspire. I am thankful that I was given the opportunity to learn from you. Each of you have gifted me a different piece of knowledge in preparing me for the unbelievable journey that I am about to embark. Without hesitation, I thank you.

Karen Pacilli, Marsha Scott, and Leona Wolfe, for your support and special assistance offered in clinic. You are an asset and I am so grateful to have gotten the opportunity to work with you. I thank you.

Hillary Jordan and Carrie Trejo, for your organizational support and assistance with patient scheduling. You are an asset and I am so grateful to have gotten the opportunity to work with you. I thank you.

Holly Eppard and Jung Mee Kim - my fellow classmates, for your support you have 
shown me throughout our time here at West Virginia University. Good luck to each of you in your future endeavors and I thank you.

Kolin, Mike, Dean, Rob, Erica, and Maggie - my former fellow residents, for being great leaders, role models, and teachers. Most importantly, however, were the friendships we developed throughout the course of this residency. The previous two years were quite an experience and you all made it one of the most memorable times of my life. I miss all of you and I thank you.

Chad, Doyoung, Alice, Lance, Nicole, and Deepa - my fellow residents, for being insightful, giving, and willing to listen when I needed it most. Like the previous residents listed above, we too have sparked friendships that I know will be everlasting. Good luck to each of you in your future endeavors and I thank you. 


\section{TABLE OF CONTENTS}

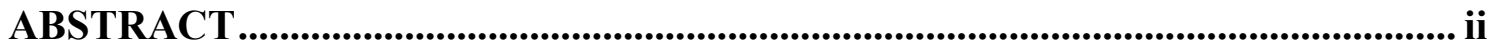

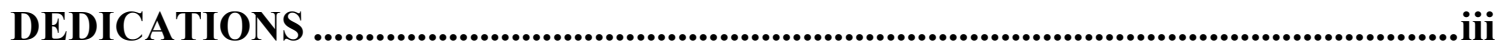

ACKNOWLEDGEMENTS ..................................................................................... iv

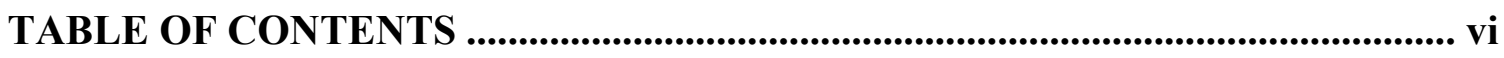

LIST OF TABLES ........................................................................................................ viii

LIST OF FIGURES ................................................................................................ ix

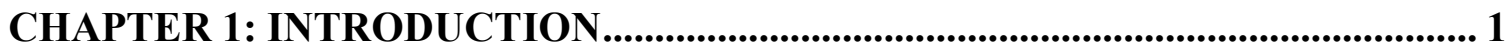

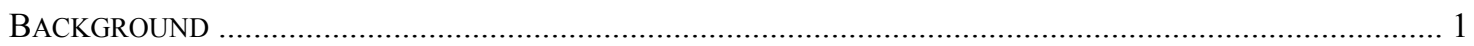

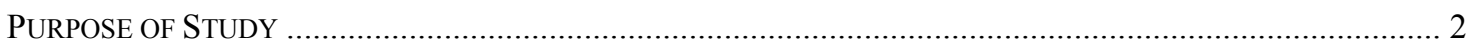

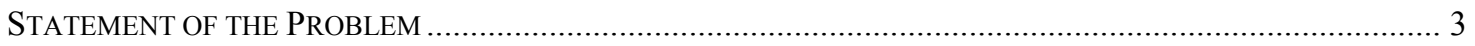

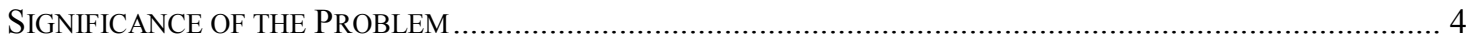

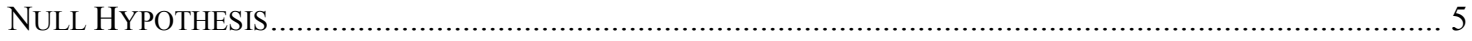

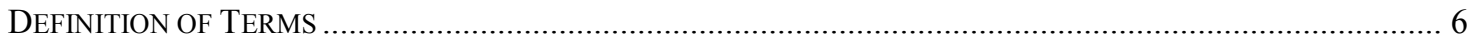

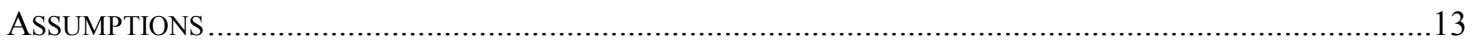

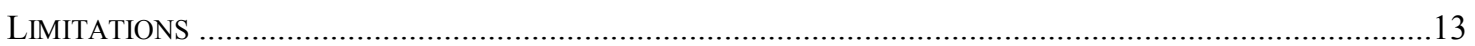

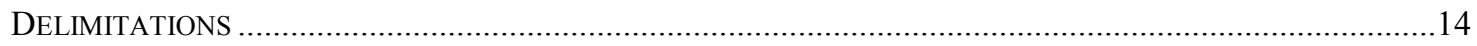

CHAPTER 2: REVIEW OF THE LITERATURE................................................ 15

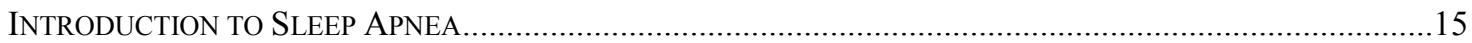

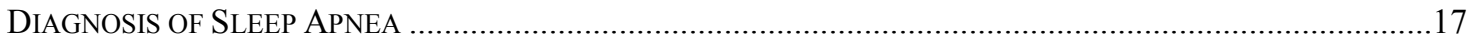

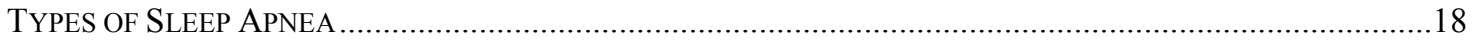

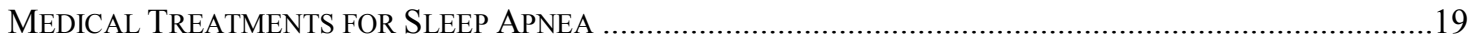

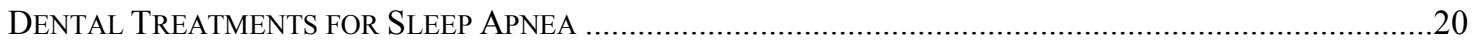

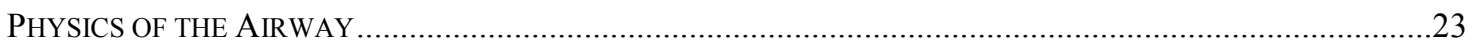

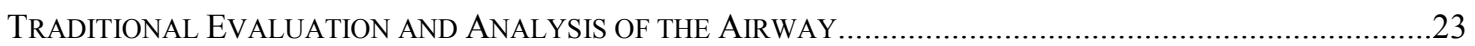

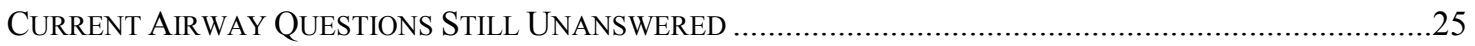

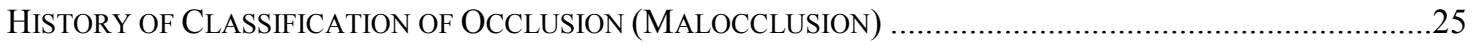

RELATIONSHIP OF MALOCCLUSION TO CRANIOFACIAL MORPHOLOGY ..................................................26

EFFECTS OF SLEEP APNEA ON CRANIOFACIAL MORPHOLOGY AND MALOCCLUSION ...............................27

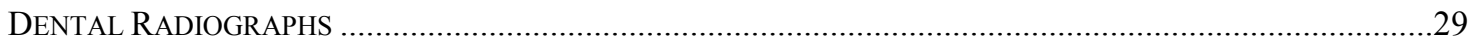

TRADITIONAL CRANIOFACIAL IMAGING FOR THE EVALUATION OF AIRWAY .............................................29

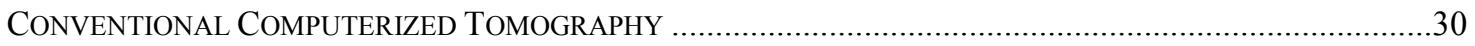

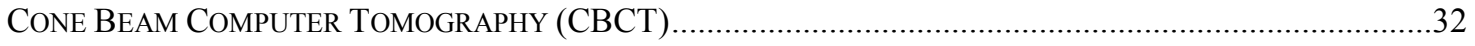

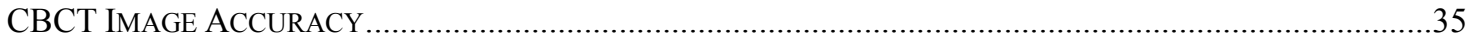

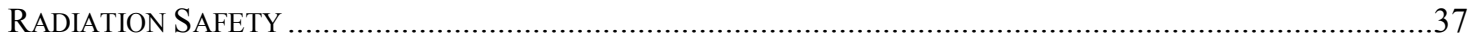

CBCT BENEFITS, LIMITATIONS, AND APPLICATIONS WITHIN ORTHODONTICS ..........................................

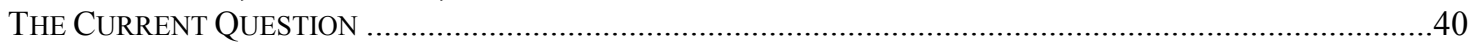

CHAPTER 3: EXPERIMENTAL DESIGN AND METHODS............................... 41

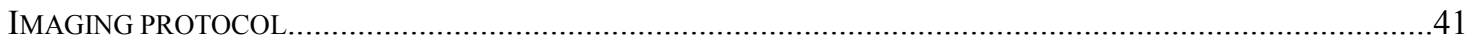

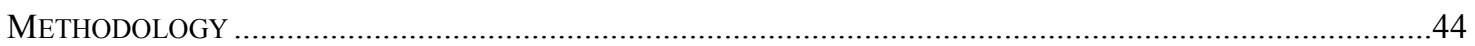

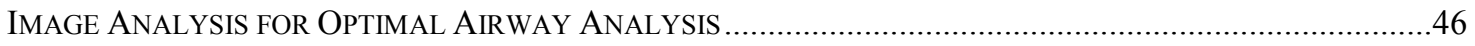

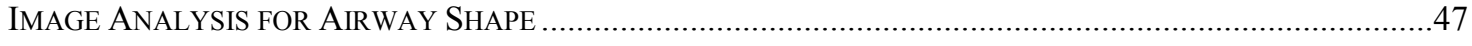

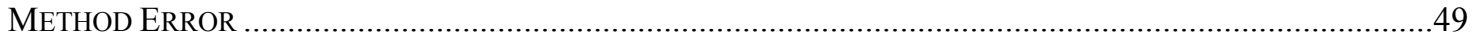

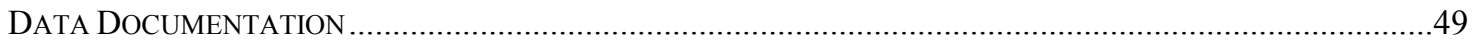

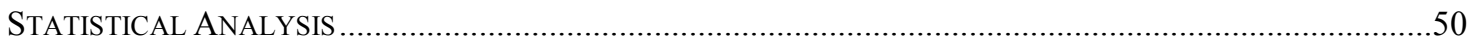

CHAPTER 4: RESULTS ...................................................................................................... 51

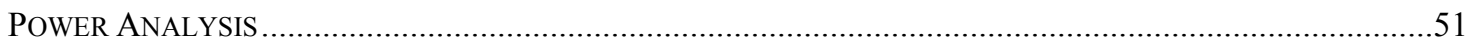

AIRWAY VOLUME BY ANTEROPOSTERIOR SKELETAL PATTERN ..........................................................52

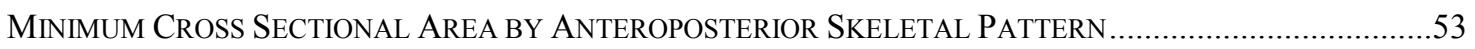

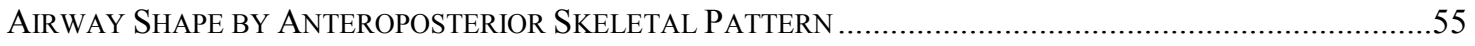

AIRWAY VOLUME BY VERTICAL SKELETAL PATTERN .........................................................................56

Minimum CRosS SECTIONAL AREA BY VERTICAL SKELETAL PATTERN .................................................57 


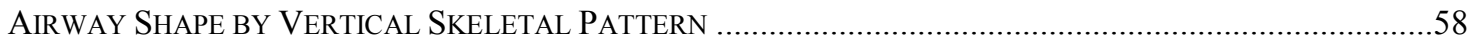

AIRWAY VOLUME BY ANTEROPOSTERIOR / VERTICAL SKELETAL SUBGROUPS ……….................................58

Minimum Cross SECTIONAL AREA BY ANTEROPOSTERIOR / VERTICAL SKELETAL SUBGROUPS ..............60

AIRWAY SHAPE BY ANTEROPOSTERIOR / VERTICAL SKELETAL SUBGROUPS..........................................61

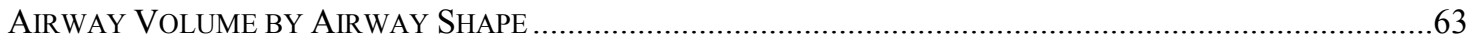

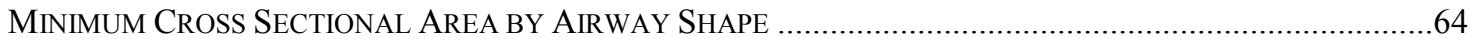

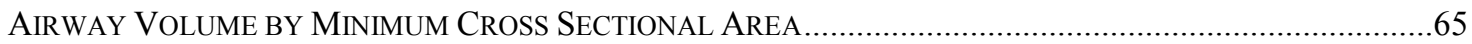

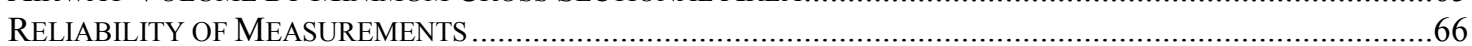

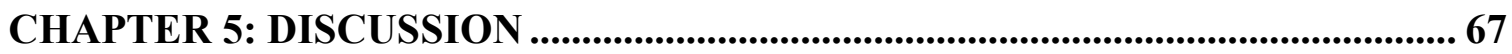

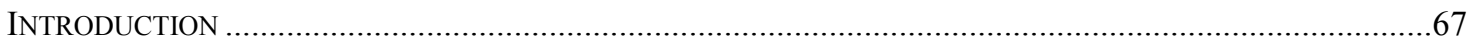

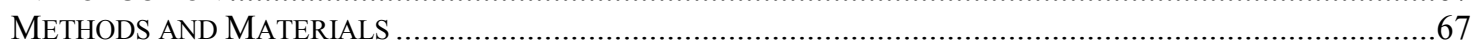

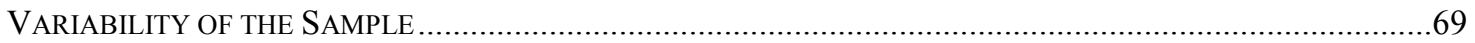

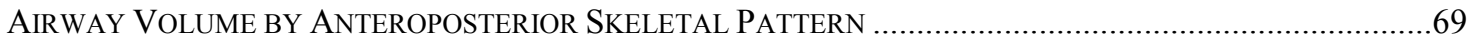

Minimum CrosS SECTIONAL AREA BY ANTEROPOSTERIOR SKELETAL PATTERN......................................70

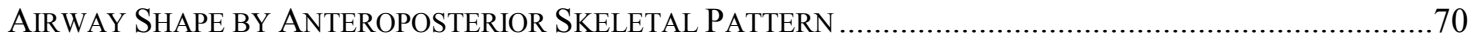

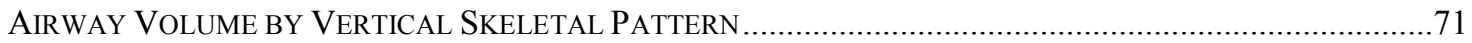

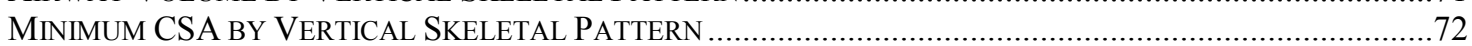

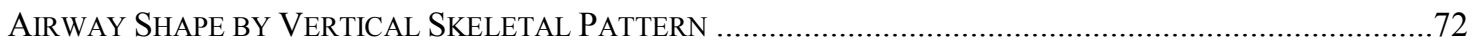

AIRWAY VOLUME BY ANTEROPOSTERIOR / VERTICAL SKELETAL SUBGROUPS ..........................................73

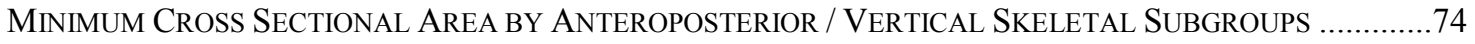

AIRWAY SHAPE BY ANTEROPOSTERIOR / VERTICAL SKELETAL SUBGROUPS............................................74

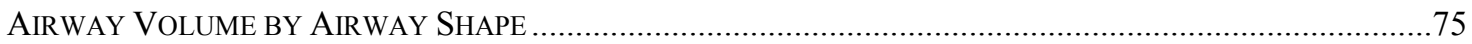

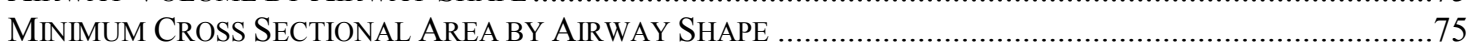

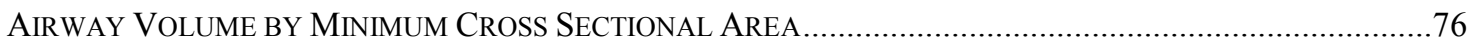

CHAPTER 6: SUMMARY AND CONCLUSIONS .................................................... 77

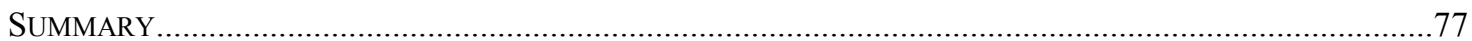

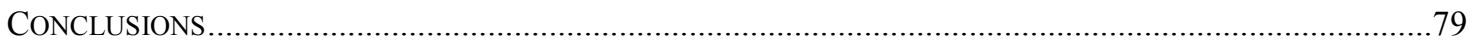

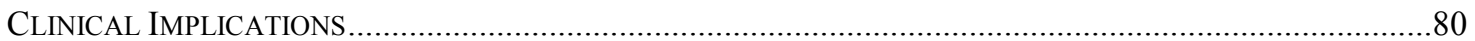

CHAPTER 7: RECOMMENDATIONS FOR FUTURE RESEARCH.................... 82

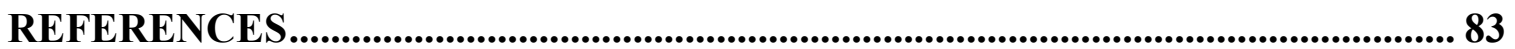

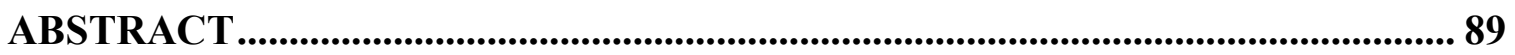

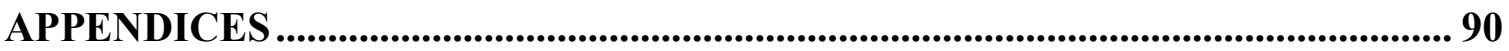

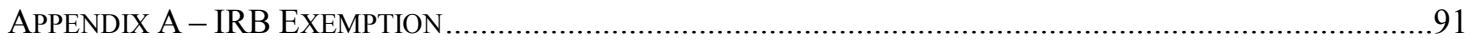

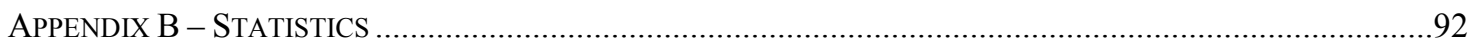

CURRICULUM VITAE................................................................................ 115 


\section{LIST OF TABLES}

Table 1. Summary of Radiograph Exposure Comparison (mSv).

Table 2. Airway Volume, Minimum CSA, and Airway Shape of Subjects with Differing Vertical Class I

Patterns.

Table 3. Airway Volume, Minimum CSA, and Airway Shape of Subjects with Differing Vertical Class II

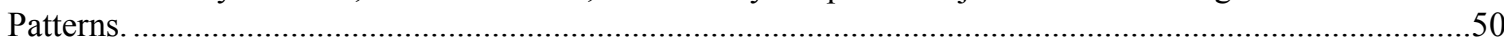

Table 4. Airway Volume, Minimum CSA, and Airway Shape of Subjects with Differing Vertical Class III

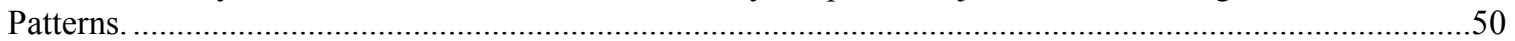

Table 5. Airway Volume (cc) Based on Anteroposterior Skeletal Pattern $(\mathrm{n}=279)$. ...................................53

Table 6. Minimum CSA $\left(\mathrm{mm}^{2}\right)$ Based on Anteroposterior Skeletal Pattern $(\mathrm{n}=279) \ldots \ldots \ldots \ldots \ldots \ldots \ldots \ldots \ldots \ldots \ldots . . . .55$

Table 7. Contingency Table of Airway Shapes By Anteroposterior Skeletal Patterns $(\mathrm{n}=279) \ldots \ldots \ldots \ldots \ldots . . .55$

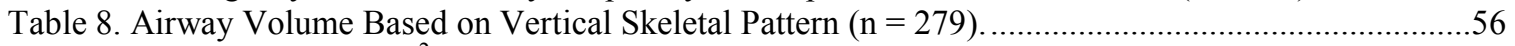

Table 9. Minimum CSA $\left(\mathrm{mm}^{2}\right)$ Based on Vertical Skeletal Pattern $(\mathrm{n}=279) \ldots \ldots \ldots \ldots \ldots \ldots \ldots \ldots \ldots \ldots \ldots \ldots \ldots \ldots . . . . . .57$

Table 10. Contingency Table of Airway Shapes By Vertical Skeletal Patterns $(\mathrm{n}=279)$. ..........................58

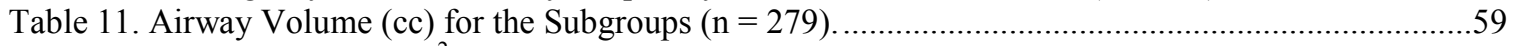

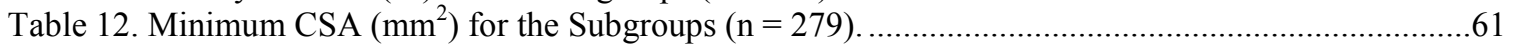

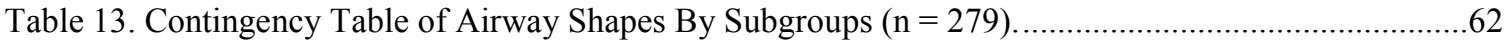

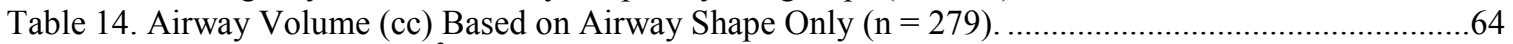

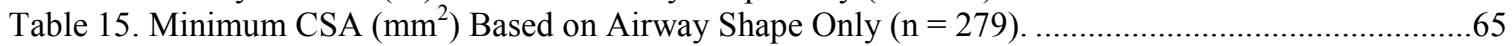




\section{LIST OF FIGURES}

Figure 1. Pixel and voxel components of a computerized tomographic radiograph. ${ }^{14} \ldots \ldots \ldots \ldots \ldots \ldots \ldots \ldots \ldots \ldots . .13$

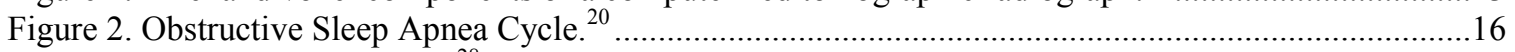

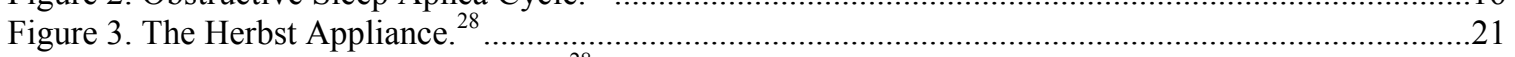

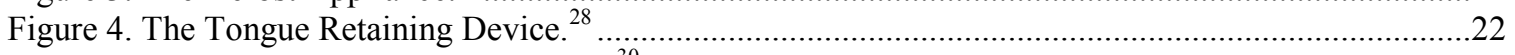

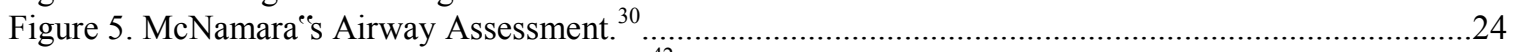

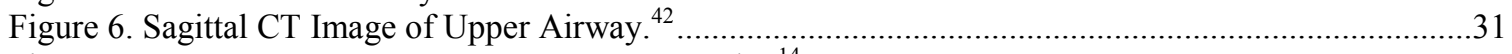

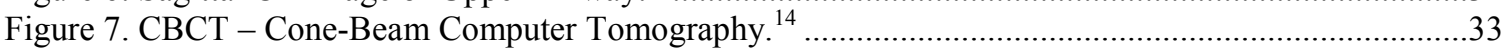

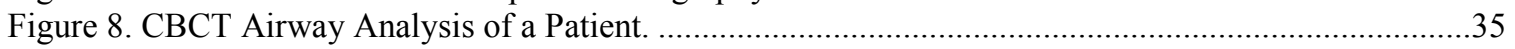

Figure 9. Patient Determined to Have a Class II Skeletal Pattern. ............................................................42

Figure 10. Patient Determined to Have a Hyperdivergent Skeletal Pattern..................................................43

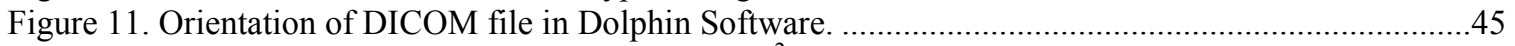

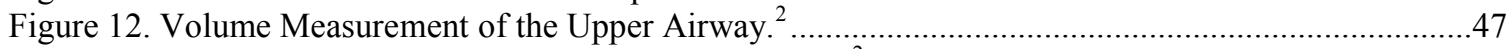

Figure 13. Oropharyngeal Cross Section at Bilateral Gonion. ${ }^{2}$..............................................................48

Figure 14. Three Possible Airway Shapes Viewed in Cross Section at the Level of Bilateral Gonion.........49

Figure 15. Mean Airway Volume (cc) for the Anteroposterior Skeletal Groups $(\mathrm{n}=279)$.............................52

Figure 16. Mean Minimum CSA $\left(\mathrm{mm}^{2}\right)$ for the Anteroposterior Skeletal Groups $(\mathrm{n}=279)$.............................54

Figure 17. Mean Airway Volume $(\mathrm{cc})$ for the Vertical Skeletal Groups $(\mathrm{n}=279) \ldots \ldots \ldots \ldots \ldots \ldots \ldots \ldots \ldots \ldots \ldots \ldots \ldots . . . .56$

Figure 18. Mean Minimum CSA $\left(\mathrm{mm}^{2}\right)$ for the Vertical Skeletal Groups $(\mathrm{n}=279)$...................................57

Figure 19. Mean Airway Volume $(\mathrm{cc})$ for the Subgroups $(\mathrm{n}=2279)$.......................................................5

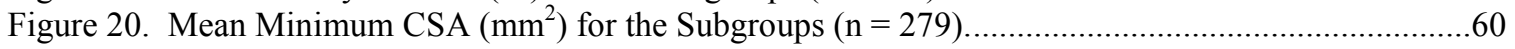

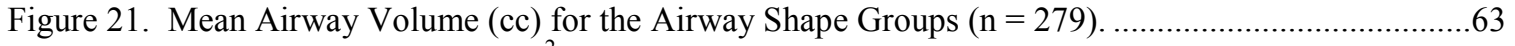

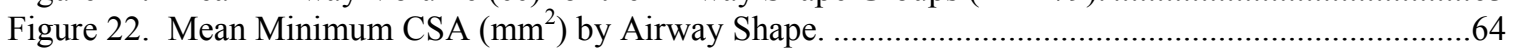

Figure 23. Bivariate Fit of Airway Volume by Minimum CSA. .............................................................66

Figure 24. Percentage of each Airway Shape Irrespective of Skeletal Pattern..............................................73 


\section{CHAPTER 1: INTRODUCTION}

\section{Background}

One disorder not often associated with dentistry, but one that is truly related to the surrounding anatomy, is obstructive sleep apnea. Simply stated, obstructive sleep apnea is caused by a narrowing or blocking of the airway due to collapse of soft tissues in the pharynx. The importance of understanding this obstruction in the development of both childhood and adult health problems has become increasingly documented. ${ }^{1-4}$ As such, much attention has been given to the association among craniofacial skeletal morphology, upper airway dimension, and respiratory function..$^{5-8}$ However, much of the information gathered on the aforementioned has been established with the use of 2-Dimensional lateral cephalometry. This method of airway dimensional assessment has been deemed inadequate because only length, and not width, of the upper airway can be evaluated from a lateral cephalogram.

Researchers in previous years have been limited to lateral and frontal cephalograms to conduct cephalometric measurements and analyses. The information interpreted from these measurements is often oversimplified because information is lost or assumed when data from a 3-Dimensional object is transferred into a 2-Dimensional image. Recently, new technology entitled cone-beam computed tomography (or CBCT) has arrived which offers the orthodontist the ability to view the patient ${ }^{\text {ee }}$ s anatomical structures in 3-Dimensions. True interpretation of data can now be conducted accurately, effectively, and efficiently because all dimensions are available for assessment at any given time. ${ }^{9}$

Although, CBCT scans serve as the ideal method for evaluating airway 
dimensions, few research articles have been published utilizing this form of assessment. Instead, most information collected on airway dimension and its relationship to skeletal patterns have been with the use of traditional 2-Dimensional lateral cephalograms. ${ }^{10,11}$ For example, Joseph and Kirjavainen found Class II patients have a narrower anteroposterior pharyngeal dimension when compared to Class I patients. They also found Class II Div 1 patients can have a narrower upper airway dimension without having retrognathia. de Freitas et al. found "that the upper pharyngeal width in the subjects with Class I and Class II malocclusions and vertical growth patterns was statistically significantly narrower than in the normal growth-pattern groups." 12 Important to remember is that these studies summarized data based on 2-Dimensional assessments.

Since the advent of cone-beam computed tomography, a number of companies have produced software, including InVivoDental ${ }^{\mathrm{TM}}$ by Anatomage USA, which allow for manipulation and comparison of volumetric images. Now, high-resolution 3-

Dimensional scans can be studied quantitatively which will allow researchers to revisit the question of whether true differences in airway volume, minimum cross sectional area (CSA), and airway shape are noticeably and statically different when comparing all types of skeletal patterns. Only by understanding true airway dimension and its variations among patients with different skeletal patterns can better treatment modalities be achieved for patients diagnosed with obstructive sleep apnea.

\section{Purpose of Study}

The aim of this study is to investigate upper airway dimensions among different 
skeletal patterns by using cone-beam computed tomography (CBCT). Intra-operator reliability will be evaluated to confirm accuracy of results. In addition to this study providing researchers with information regarding the usage of 3-Dimensional analysis to quantitatively determine morphologic airway dimensions, the results of this study will establish normative airway volumes for patients with high and low angle Class I, II, and III skeletal patterns and will serve as a standard to compare patients to when determining normal airway size. Additionally, minimum cross sectional area (CSA) and airway shape will be documented. This will allow one to determine whether any differences exists among airway volume, minimum CSA, and airway shape when evaluating facial skeletal patterns.

\section{Statement of the Problem}

Establishment of cephalometric norms for upper airway size has been

predominately based on lateral cephalograms. ${ }^{10,11,13}$ As such, true normative airway dimensions of patients with differing facial skeletal patterns, that is high and low angle Class I, II, and III malocclusions, could only be assumed. With the advent of cone-beam computer tomography, this study will attempt to determine these normative airway dimensions. Additionally, researchers have been unable to adequately determine if correlations exist between true airway volume and facial skeletal patterns. For example, do skeletal Class III patients with a high mandibular plane angle have statistically larger airway volumes than patients with a skeletal Class II pattern with a low mandibular plane angle? Do skeletal Class II patients with a high mandibular plane angle have statistically smaller airway volumes than patients with a skeletal Class I pattern with a normal 
mandibular plane angle? To date, no study found has tried to answer these compounded questions with the use of CBCT. Some previous studies have tried to determine whether anteroposterior patterns alone (Class I, II and III) affect airway size. However, no current studies found have tried to determine if vertical skeletal patterns (normodivergent, hyperdivergent, and hypodivergent), separate or in combination with anteroposterior skeletal patterns, affect airway volume, minimum CSA, or airway shape. Most studies that have evaluated anteroposterior skeletal pattern"s effect on the variables previously mentioned have mainly done so with the use of 2-Dimensional radiography. Only with the use of $\mathrm{CBCT}$ images can one truly determine the answer to these questions.

\section{Significance of the Problem}

Little to no documentation exists on true airway volume, minimum CSA, or airway shape and their correlation to craniofacial skeletal patterns. This information could be used to develop new treatment modalities for patients suffering from obstructive sleep apnea. Much more information is needed to understand these variables effect on obstructive sleep apnea when clinically evaluating a patient and determining his or her course of treatment. Without first establishing normal airway dimensions, choosing the correct treatment modality for a patient cannot be determined adequately.

Ultimately, this investigation hopes to determine whether anteroposterior and vertical skeletal patterns may be contributory factors in the variation of oropharyngeal airway volume, minimum CSA, or airway shape. This may determine whether patients with certain skeletal deficiencies are predisposed to upper airway obstruction. This investigation intends to add to the current information about airway volume and in fact 
intends to serve as a reference of normative airway dimensions when evaluating the airway of a patient.

\section{Null Hypothesis}

1. There is no significant difference in airway volume among the three anteroposterior groups (Class I, Class II, and Class III) of untreated adult orthodontic patients.

2. There is no significant difference in airway volume among the three vertical groups (normodivergent, hyperdivergent, and hypodivergent) of untreated adult orthodontic patients.

3. There is no significant difference in airway volume among the nine anteroposterior / vertical subgroups (Class I normodivergent, Class I hyperdivergent, Class I hypodivergent, etc.) of untreated adult orthodontic patients.

4. There is no significant difference in minimum cross sectional area (CSA) among the three anteroposterior groups (Class I, Class II, and Class III) of untreated adult orthodontic patients.

5. There is no significant difference in minimum CSA among the three vertical groups (normodivergent, hyperdivergent, and hypodivergent) of untreated adult orthodontic patients.

6. There is no significant difference in minimum CSA among the nine anteroposterior / vertical subgroups (Class I normodivergent, Class I hyperdivergent, Class I hypodivergent, etc.) of untreated adult orthodontic 
patients.

7. There is no significant difference in airway shape among the three anteroposterior groups (Class I, Class II, and Class III) of untreated adult orthodontic patients.

8. There is no significant difference in airway shape among the three vertical groups (normodivergent, hyperdivergent, and hypodivergent) of untreated adult orthodontic patients.

9. There is no significant difference in airway shape among the nine anteroposterior / vertical subgroups (Class I normodivergent, Class I hyperdivergent, Class I hypodivergent, etc.) of untreated adult orthodontic patients.

10. There is no significant difference in airway volume in differently observed airway shapes (wide, long, and square) in untreated adult orthodontic patients.

11. There is no significant difference in minimum CSA in differently observed airway shapes (wide, long, and square) in untreated adult orthodontic patients.

12. There is no correlation in airway volume and minimum cross sectional area (CSA) in untreated adult orthodontic patients.

\section{Definition of Terms}

- 2D - Two Dimensional (2-Dimensional)

- Refers to objects that are rendered visually on paper, film or on screen in two planes ( $\mathrm{X}$ and $\mathrm{Y}$; width and height). Two-dimensional structures or images are used to simulate 3D objects. In the computer, a 2D drawing program can be used to illustrate a $3 \mathrm{D}$ object; however, in order to interactively rotate an object in all axes, it must be created as a 3D 
drawing in a 3D drawing program.

- 3D - Three Dimensional (3-Dimensional)

- Refers to objects that are rendered visually on paper, film or on screen in three planes (X, Y and $\mathrm{Z}) .3 \mathrm{D}$ images are true representations of 3D objects.

- Central Sleep Apnea

- Cessation of breathing due to the central nervous system failing to send a signal to the muscles to enact breathing. Causes of this type of sleep apnea include head trauma, stroke, and tumor.

- Cephalogram

○ Synonym for a cephalometric radiograph

- Cephalometric analysis

- An analysis made on a radiograph of the head (cephalometric radiograph) comprised of referents and landmarks used to describe relationships of skeletal and dental components, usually compared to a norm.

- Cephalometric radiograph

- A radiograph of the head made with reproducible relationships between the x-ray source, the subject, and the film.

- Class I skeletal pattern

- Patients with an ANB angle $0^{\circ}$ to $5^{\circ}$. This orthodontics term indicates a type of skeletal pattern in which the maxilla and mandible are in good harmonious position relative to each other. 
- Class II skeletal pattern

$\circ$ Patients with an ANB angle $>5^{\circ}$. This orthodontics term indicates a type of skeletal discrepancy in which the mandible is retrusive, relative to the maxilla.

- Class III skeletal pattern

$\circ$ Patients with an ANB angle $<0^{\circ}$. This orthodontics term indicates a type of skeletal discrepancy in which the mandible is protrusive, relative to the maxilla.

- Computed tomography (CT)

- A series of radiographs (flat, two-dimensional grayscale images) that are analyzed and rendered via computer to produce a three-dimensional volumetric or surface mapped image.

- Cone Beam Computed Tomography (CBCT)

- A computed tomography scan utilizing an x-ray beam in the shape of a cone to provide images of bony structures. Data is captured by a flat receiver that detects pulses of cone shaped beam radiation. The result is a stack of two-dimensional grayscale images of the anatomy which can be rendered into volumetric data to visualize anatomical structures in three dimensions. Also known as Cone Beam Volumetric Tomography (CBVT)

- Digital Imaging and Communications in Medicine (DICOM)

- DICOM is a standard for handling, storing, printing, and transmitting medical images. It includes a file format in which data from volumetric radiographs are stored. 
- Frankfort Horizontal Plane

- A horizontal plane represented in profile by a line between the lowest point on the margin of the orbit and the highest point on the margin of the auditory meatus.

- Frankfort - Mandibular Plane angle (FH/MP)

- The angle formed at the intersection of the Frankfort horizontal plane with the Mandibular Plane. This angle is often used to define the vertical dimension in human facial forms. This angle defines whether a patient is hyperdivergent, hypodivergent, or normodivergent.

- Hyperdivergent

$\circ$ Patients with a Frankfort - Mandibular plane angle (FH/MP) $>30^{\circ}$. This orthodontic term indicates that the patient has a vertical openbite pattern. These patients usually have longer lower facial heights and have a clockwise growth pattern.

- Hypodivergent

$\circ$ Patients with a Frankfort - Mandibular plane angle $(\mathrm{FH} / \mathrm{MP})<22^{\circ}$. This orthodontic term indicates that the patient has a horizontal deepbite pattern. These patients usually have normal to short lower facial heights and have a counter - clockwise growth pattern.

- Image intensifier

- Allows real time image feed to an analog or digital receiver for compilation or viewing of live radiographic images. 
- Landmark

- A fixed, reproducible (anatomical) point of reference on a radiograph.

- Mandibular Plane

- A plane constructed from the most anterior inferior portion of the mandible, termed mention, and the most inferior posterior boarder of the mandible termed gonion.

- Nasopharynx

○ The uppermost portion of the airway, mainly the nose. It begins with the nares, where air enters the nose, and extends back to the hard palate at the superior portion of the soft palate. This includes the nasal septum and the nasal turbinates.

- Normodivergent

- Patients with mandibular plane angle (FH/MP) of $22^{\circ}$ to $30^{\circ}$. This orthodontic term indicates that the patient has a normal vertical skeletal pattern. These patients usually have normal lower facial heights.

\section{- Obstructive Sleep Apnea}

- A sleep disorder that occurs when a person"s breathing is interrupted during sleep. It is caused by a narrowing or blocking of the airway due to the collapse of soft tissues in the pharynx and retraction of the genioglossus muscle allowing the tongue to slide further posterior than normal, thus blocking the airway.

- Oropharynx

- Includes the oral cavity, beginning with the back portion of the mouth and 
extending rearward to the base of the tongue. This segment of the posterior pharyngeal wall includes the tonsils. In this area are many muscles, both extrinsic and intrinsic, that control tongue posture: genioglossus, palatoglossus, and the superior longitudinal and transverse muscles of the tongue as examples.

- Referent

- A variable, reproducible (anatomical) point related to a landmark on a radiograph.

- Resolution

- The smallest distance between two points at which the viewer can still distinguish the two points as separate entities. Higher resolutions provide finer detail.

- $\quad$ Sievert (Sv)

- Standard international (SI) unit of radiation dose equivalent. This unit of measure reflects the biological effects of radiation (as opposed to the physical aspects which are characterized by absorbed dose measured in Grays).

- Tomogram

○ A radiograph representing a "slice" or sectioned focal area by moving an $\mathrm{X}$-ray source and the film in opposite directions during exposure.

Structures in the focal plane appear sharp, while structures in front of and behind the plane are blurred. 
- Velopharynx

- Extends from the hard palate to the inferior tip of the soft palate. Includes the uvula and the uppermost segment of the posterior pharyngeal wall. Major muscles include the tensor pallatini and levator pallatini, which elevate the soft palate, and the musculous uvulae providing elevation of the uvula.

- Volumetric

- Visual representation of an image in three dimensional space.

- Voxel

- The smallest element in building a three-dimensional image. It is similar to a "pixel" in a flat two-dimensional image display. Voxel size is important in defining the resolution of a volumetric image (smaller voxel size $=$ higher resolution). The voxel size of a CBCT image can be as small as 0.16 cubic millimeters while the voxel size of a traditional CT image is 0.32 cubic millimeters. Figure 1 demonstrates pictorially both a voxel and pixel. 
Figure 1. Pixel and voxel components of a computerized tomographic radiograph. ${ }^{14}$

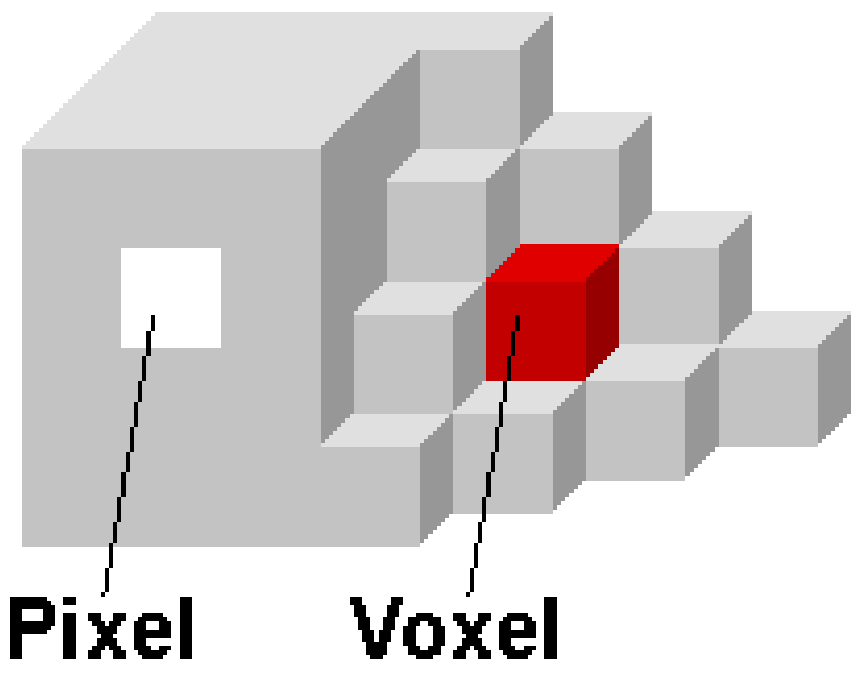

\section{Assumptions}

1. The CBCT scans are of sufficient quality with no patient movement contributing to the introduction of radiographic artifacts.

2. The operator in this study has a working knowledge of computer technology.

3. Landmarks can be accurately identified using cone-beam computed tomography technology.

4. CBCT scans on subjects are taken in centric relation as opposed to centric occlusion.

5. CBCT scans on subjects were taken prior to initiation of any type of orthodontic or orthopedic treatment.

\section{Limitations}

1. There will be gender, ethnicity, and medical history differences among the 
subjects.

2. Scans may contain artifacts depending on patient movement and machine calibration.

3. Measurements are limited to the researcheres ability to accurately manipulate the cone-beam computed tomography image.

4. The study is limited to the subjects in the database Advanced Dental Imaging on the campus of University of Nevada Las Vegas School of Dentistry.

\section{Delimitations}

1. Skeletal ages of the patients comprising the sample will be adult patients with a CVM value greater than CVM - 4 .

2. One researcher will make all measurements using the 3D cone-beam computed tomography scan.

3. The study will be limited to 3D cone-beam computed tomography scans on subject ${ }^{\text {ee }}$ pre - orthodontic treatment.

4. The study is limited to the subject database at the Advanced Dental Imaging on the campus of University of Nevada Las Vegas School of Dentistry.

5. One researcher will determine all airway dimensions on the cone-beam computed tomography image. 


\section{CHAPTER 2: REVIEW OF THE LITERATURE}

\section{Introduction to Sleep Apnea}

Many believe dentistry began in barber shops approximately 200 years ago with a routine visit consisting of a haircut, beard shaving, and if one had any pain associated with the mouth, a tooth extraction. However, early written records show that interest in this field even existed approximately 7000 years ago in ancient Egypt. ${ }^{15}$ Since then, the interest in diagnosis, prevention, and treatment of ailments associated with the mouth and its surrounding anatomy has grown to form one of the most prominent fields in health sciences, dental medicine.

One disorder not often associated with dentistry, but one that is truly related to the surrounding anatomy, is obstructive sleep apnea. According to the National Sleep Foundation, some form of snoring or obstructive sleep apnea (OSA) occurs in approximately 90 million Americans. An estimated 18 million Americans have OSA and approximately 16 million go undiagnosed. ${ }^{16}$ The Cleveland Clinic defines sleep apnea as a "sleep disorder that occurs when a person"s breathing is interrupted during sleep."17 In adults, symptoms of this disorder include, but are not limited to, loud snoring, sore throat, lethargy throughout the day, morning headaches, recurrent awakenings, and waking up with a gasping or choking sensation. ${ }^{17}$ In children, clinical symptoms include failure to thrive, abnormal weight for age, acute cardiac or cardiorespiratory failure, hypertension, and frequent upper airway infections. ${ }^{18}$ Additionally, children with sleep apnea often exhibit symptoms of hyperactivity, extreme distraction, difficulty focusing, fidgetiness, impatience, and impulsiveness. Often, these symptoms are mistaken for attentiondeficit/hyperactivity disorder or ADHD. ${ }^{3}$ However, the key symptoms distinguishing 
children with sleep apnea and ADHD are loud snoring and lack of efficient sleep.

Ultimately, if one has sleep apnea, he or she ceases to breathe adequately while sleeping. This causes an improper ratio of oxygen to carbon dioxide in the blood which eventually stimulates the brain to restart breathing. The brain is then signaled to awaken so the muscles of the tongue and throat can open the airway. Following the sudden arousal and gasps for air, the oxygen/carbon dioxide ratio returns to normal, allowing one to fall back asleep. This cycle may repeat itself only a few times a night to hundreds of times a night ultimately leading to sleep and oxygen deprivation and a multitude of other medical side effects including heart disease, hypertension, and memory loss. ${ }^{19}$ This cycle is best illustrated by Figure 2 .

Figure 2. Obstructive Sleep Apnea Cycle. ${ }^{20}$

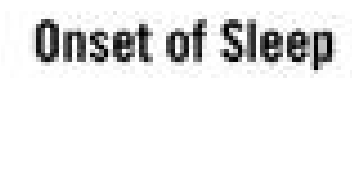

Breathing Resumed

Chemoreceptor Activation

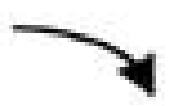

Airway Obstruction

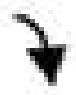

Apnea

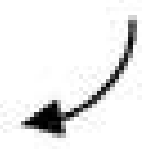




\section{Diagnosis of Sleep Apnea}

Although a diagnosis of sleep apnea will often be suspected on the basis of a patient's medical history and chief complaint, there are several tests that must be utilized to confirm the diagnosis. In order to discuss how the diagnosis of sleep apnea is achieved however, we must first define several terms. An apnea is defined as a period of time during which a patientes breathing stops or is markedly reduced. Specifically, an apnea occurs when a patient"s breathing stops for 10 seconds or more or at least a $4 \%$ drop in oxygen in the blood (called oxygen desaturation) is attained due to lack of adequate oxygen / carbon dioxide exchange in the lungs. Apneas are measured during sleep, preferably in all stages of sleep, over a two-hour period. An estimate of the severity of apnea is calculated by dividing the number of apneas by the number of hours of sleep, giving an apnea index (AI in apneas per hour). The greater the AI calculated, the more severe the apnea. ${ }^{21}$

A hypopnea is defined as a decrease in breathing that is not as severe as an apnea and is considered more like a sleep and oxygen disruption. Like apneas, hypopneas also may be defined as a $4 \%$ or greater drop in oxygen in the blood. A hypopnea index (HI) is calculated by dividing the number of hypopneas by the number of hours of sleep.

The apnea-hypopnea index (AHI) combines apneas and hypopneas giving an overall idea of sleep apnea severity. The apnea-hypopnea index, like the apnea index and hypopnea index, is calculated by dividing the number of apneas and hypopneas by the number of hours of sleep. Another index that is used to measure sleep apnea is the respiratory disturbance index (RDI). The respiratory disturbance index is similar to the apnea-hypopnea index; however, it also includes respiratory events that do not 
technically meet the definitions of apneas or hypopneas, but do disrupt sleep. ${ }^{21}$

The primary test for the diagnosis of sleep apnea is polysomnography, also referred to as a sleep study. This test measures multiple parameters while the patient is asleep ultimately giving a report containing the apnea - hypopnea index. Based on this index, a patient is diagnosed with mild obstructive sleep apnea if the AHI is between 5 15 events per hour, moderate obstructive sleep apnea if the AHI is between $15-30$ events per hour, and severe obstructive sleep apnea when more than 30 events per hour are observed. $^{21}$

\section{Types of Sleep Apnea}

According to the American Medical Association, two types of sleep apnea exist: obstructive sleep apnea or OSA and central sleep apnea or CSA. ${ }^{22}$ The more common, obstructive sleep apnea is caused by a narrowing or blocking of the airway due to the collapse of soft tissues in the pharynx and retraction of the genioglossus muscle allowing the tongue to slide further posterior than normal, thus blocking the airway. Under normal circumstances, the muscles of the throat allow the airway to remain open allowing airflow to reach the lungs. With obstructive sleep apnea, the constant opening of the throat allowing one to breathe does not occur. ${ }^{23}$ Some risk factors exist for this type of sleep apnea including large tonsils, a deviated septum, an enlarged tongue, a retrognathic mandible, obesity, smoking, and family history of sleep apnea. According to Kaplan, OSA has been reported to be associated with obesity, glucose intolerance, hypertriglyceridemia, and hypertension - known as "the deadly quartet."23 Unlike obstructive sleep apnea, in central sleep apnea, the airway does not close. 
Instead, the central nervous system fails to send a signal to the muscles to enact breathing. ${ }^{24}$ Causes of this type of sleep apnea include head trauma, stroke, and tumor. Due to the differing causes of each type of sleep apnea, treatment approaches are different.

\section{Medical Treatments for Sleep Apnea}

Conservative treatment for central sleep apnea usually consists of medication to stimulate the central nervous system regulating breathing and nightly administration of oxygen. ${ }^{24}$ Unlike CSA, a multitude of treatments exist for obstructive sleep apnea including continuous positive airway pressure or CPAP, dental, oral, and lower jaw advancement devices termed oral appliance therapy, maxillary expansion, as well as various types of surgeries including but not limited to uvulopalatopharyngoplasty, laserassisted uvulopalatoplasty, maxillomandibular osteotomy, and hyoid suspension. ${ }^{16}$

CPAP is the most widely utilized method of treating obstructive sleep apnea. This treatment involves wearing a nasal mask attached to a machine which provides constant air pressure whether one is inhaling or exhaling. Although the device is often noted for being uncomfortable, the symptoms when worn are dramatically reduced. ${ }^{16}$

The next most common medical treatment consists of surgery which removes soft tissues resulting in increased airway volume. The uvulopalatopharyngoplasty, pioneered by Dr. Fujita in 1981, is a surgical procedure utilized to enlarge the oropharyngeal area of patients with obstructive sleep apnea. The procedure involves the "removal of redundant tissues of the soft palate, uvula, tonsils, lateral and posterior pharyngeal walls." ${ }^{25}$ Studies have shown that the uvulopalatopharyngoplasty only has a fifty percent success rate and 
therefore should only be utilized when other treatments have not been successful. ${ }^{25}$ Other types of surgery consist of maxillary jaw expansion, mandibular jaw advancement, and double jaw advancement. Some studies suggest that theses surgeries may permanently correct signs and symptoms of obstructive sleep apnea. ${ }^{16}$

\section{Dental Treatments for Sleep Apnea}

Recently dentists, and specifically orthodontists, have begun to play a pivotal role in the management of patients affected by this disorder with the use of oral appliance therapy. Oral and extraoral devices have been utilized to treat obstructive sleep apnea when previous treatments are contraindicated, unavailable, or unwanted. Two main devices are utilized in the treatment: the mandibular repositioning device and the tongue retaining device. Both devices advance the mandible and/or tongue, ultimately opening the airway during sleep. ${ }^{25}$

Many studies have been conducted evaluating these appliances and have concluded that both devices reduce the symptoms of obstructive sleep apnea. The first appliance used to treat this condition was developed by Pierre Robin in 1934. In his study, infants with obstructive sleep apnea and retrognathic mandibles were treated using a mandibular repositioning device. This appliance is the most widely utilized device in the treatment of OSA. These devices "hold the mandible in an anterior and inferior position during sleep." ${ }^{25}$ When the mandible is advanced, the base of the genioglossus muscle increases and the tongue advances forward. The contraction of the genioglossus muscle moves the tongue forward increasing the volume of air in the pharynx.

Bonham et al. conducted a study on twelve patients exhibiting sleep apnea 
utilizing a mandibular repositioning device. ${ }^{18}$ The results indicated seventy-five percent of all patients had a reduction in daytime sleepiness and sixty-seven percent reported a reduction in excessive snoring. Nearly half of the patients found the device to be a success. Another study evaluating the nocturnal airway patency appliance, developed by Dr. Peter George, found a reduction in sleep apnea in at least fifty percent of all patients. ${ }^{26}$ Clark also found similar results using a mandibular repositioning device. ${ }^{27}$

One commercially available mandibular repositioning device is the Herbst appliance, "a custom-made appliance that is made of a heat-sensitive acrylic and is reinforced by a metal framework." 28 Figure 3 shows a picture of the Herbst appliance.

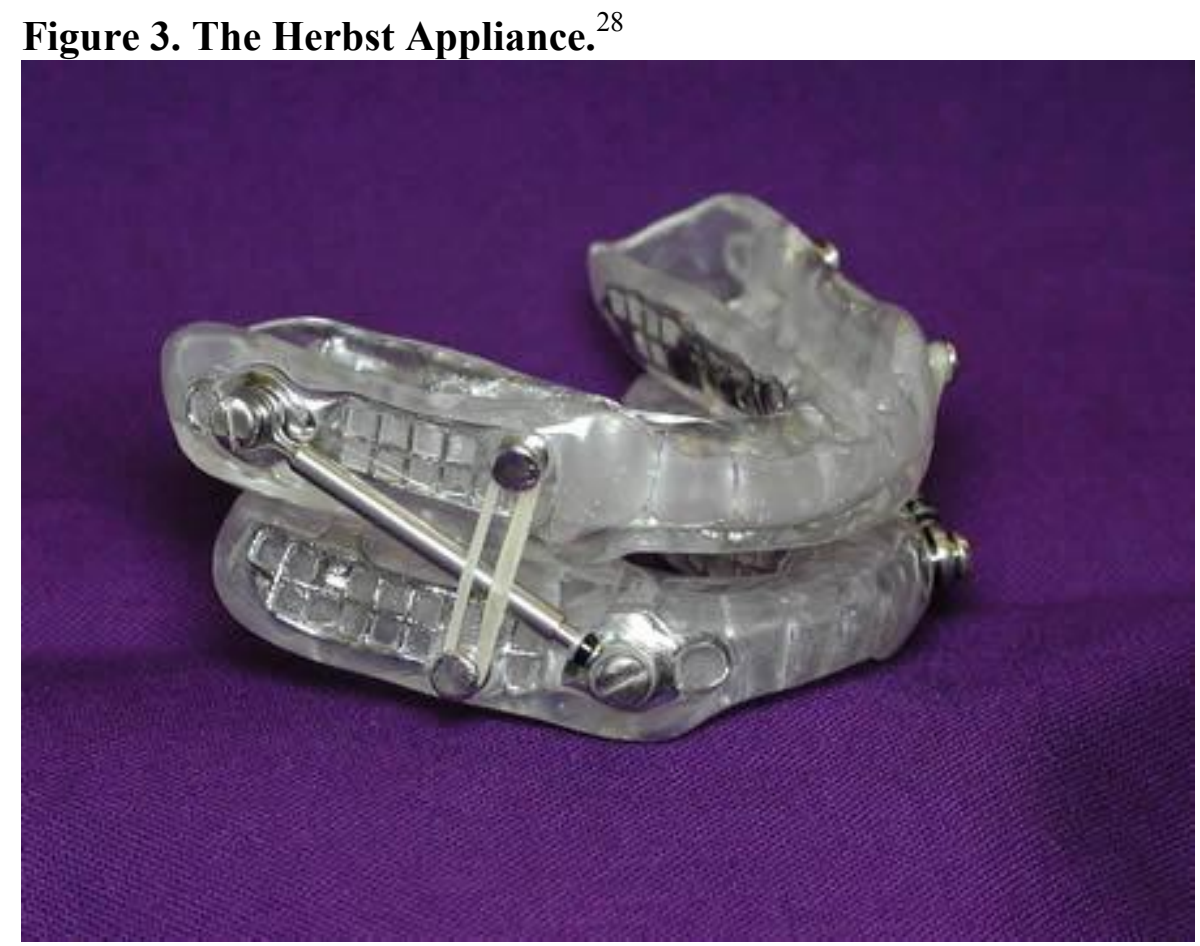

The Herbst appliance consists of pistons on both sides of the appliance that slide within a tube. Jaw position is adjusted using small rings that slide over the piston. Elastics are utilized to prevent the jaw from falling open at night. 
The tongue retaining device or TRD is separated from the mandibular repositioning device because this device actively holds the tongue forward while sleeping. "The tongue is placed in a compartment (bubble) which projects outward between the upper and lower lips" being held in position by surface tension or suction. ${ }^{28}$ Although shown to be successful, many find this device too bulky due to the inability to freely move the tongue. Often breathing tubes are placed on the device to accommodate oral breathing. Figure 4 shows a picture of the TRD.

\section{Figure 4. The Tongue Retaining Device. ${ }^{28}$}

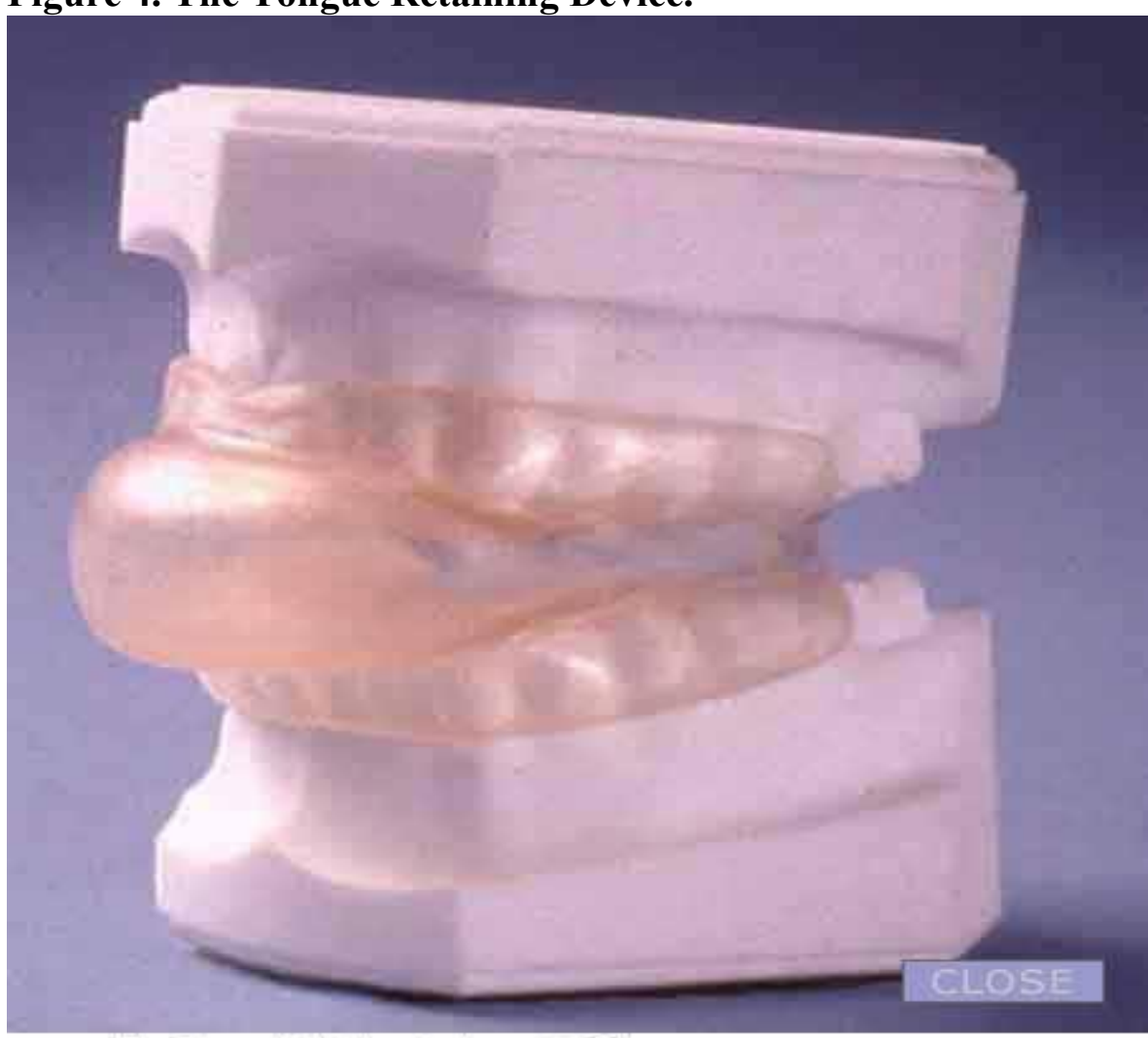

The Tongue Retaining Appliance (TRD)

A recent study on the impact of orthodontic appliances on sleep quality in young patients reported no difference in sleep efficiency with or without wearing a functional appliance. However, the authors suggested that their findings were observational only 
and further investigation with polysomnography (sleep laboratory study) and objective measurements of the duration and position of the mandible in a forward position is necessary to confirm their findings. ${ }^{3}$

\section{Physics of the Airway}

Although in most studies, symptoms of sleep apnea were reduced when wearing such appliances, the authors could only speculate of how these ,successful results were achieved. New information has now become available which can better explain the effectiveness of oral appliance therapy. Only recently has airway physics become understood. Specifically, "narrowed airways result in two long-term consequences: 1) an increase in air velocity via the Venturi effect, which imparts kinetic energy to the soft tissues of the upper airway; and 2) narrowed airways via the Bernoulli principal, in which less negative airway pressure is required to collapse, and larger negative and positive

pressures are needed to ventilate ..."16 Ultimately, the joint effects of rapid airflow and increased negative inspiratory pressure progressively elongate the soft tissues of the upper airway. Based on this information, oral appliance therapy probably works by improving airflow dynamics.

\section{Traditional Evaluation and Analysis of the Airway}

In years past, orthodontists have been faced with the challenge of evaluating a patientes airway. The most widely utilized and accepted airway analysis was conducted by McNamara in $1984^{29}$. In this analysis, two measurements are taken on a lateral cephalogram to examine the possibility of airway impairment. The first measurement 
evaluates the upper pharynx by measuring the distance between a point on the posterior outline of the soft palate to the closest point on the pharyngeal wall with the average nasopharynx being approximately $15-20 \mathrm{~mm}$ in width. A width of $2 \mathrm{~mm}$ or less in this region may indicate airway impairment. The second measurement evaluates the lower pharynx by measuring the distance between the point of intersection of the posterior border of the tongue and the inferior border of the mandible to the closest point on the posterior pharyngeal wall. The average measurement is 11 to $14 \mathrm{~mm}$, independent on age. Figure 5 best explains this analysis.

Figure 5. McNamara's Airway Assessment. ${ }^{30}$

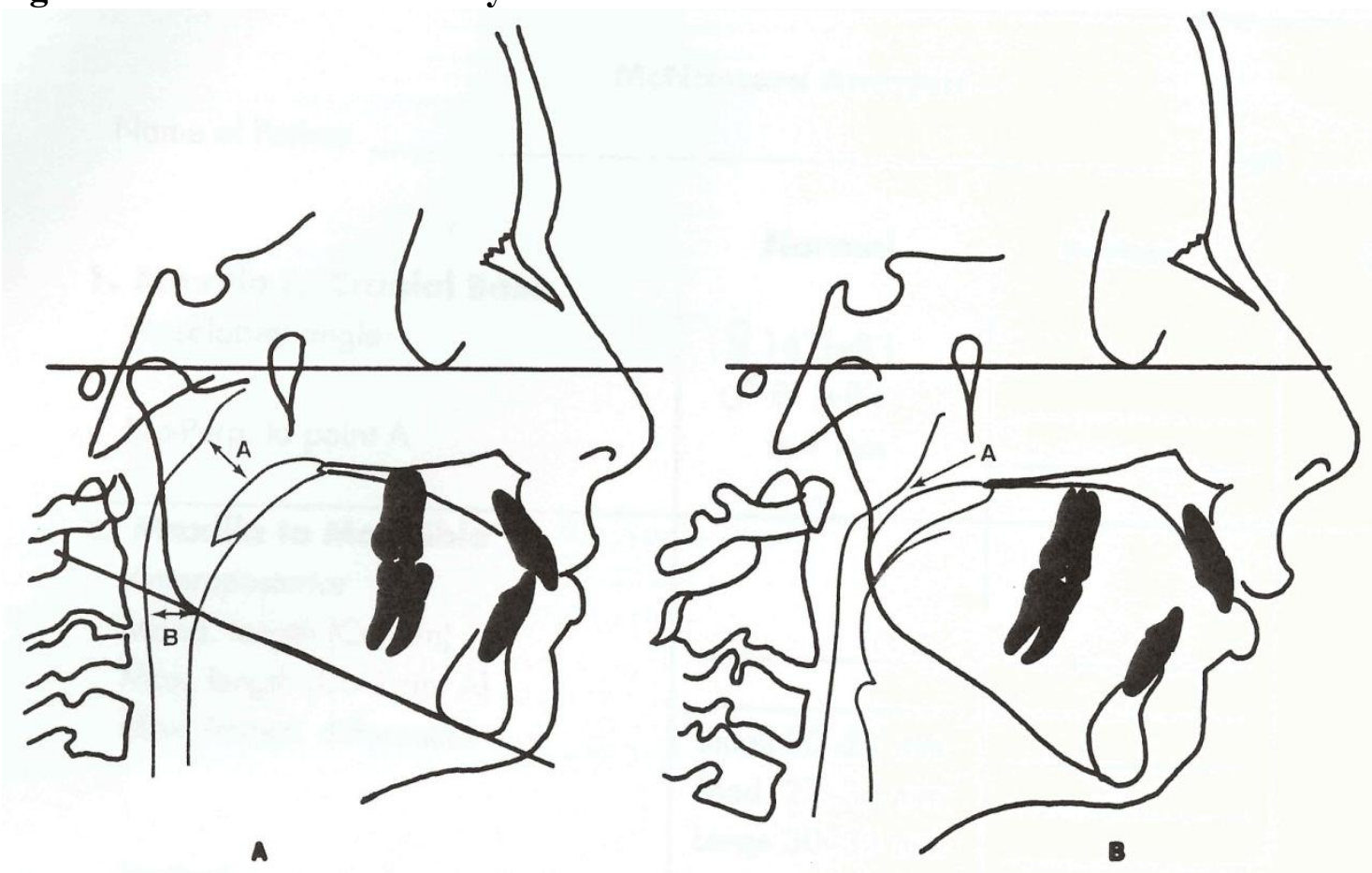

Figure 5 - A shows an average normal upper (A) and lower (B) pharyngeal airway space while Figure 5 - B shows a patient with possible airway obstruction. McNamara states that any suspicion of airway obstruction should be confirmed by a physician since a cephalogram outline of nasopharynx is a 2-Dimensional representation of a 3- 
Dimensional structure.

\section{Current Airway Questions Still Unanswered}

Traditional airway evaluation has mostly been conducted using 2-Dimensional radiography. As such, many unanswered questions still exist and can only be answered if true dimensions of the airway are assessed. For example, do patients with differing facial skeletal patterns, that is high and low angle Class I, II, and III malocclusions, have different airway dimensions? Is there a difference between adults and children when analyzing airway? Does juvenile craniofacial morphology serve as a predictor for a patient"s susceptibility to developing obstructive sleep apnea? If so, can this abnormal skeletal pattern be corrected to prevent a future breathing disorder? All these questions must be answered to treat OSA patients adequately. However, an answer to the first question will establish the foundation needed to answer the following questions. In order to understand how airway size, OSA, and skeletal patterns are related, we must first define the various types of dental malocclusions and skeletal patterns.

\section{History of Classification of Occlusion (Malocclusion)}

Before one can understand how obstructive sleep apnea relates to malocclusion and/or craniofacial skeletal patterns, we must first understand the history of classification of malocclusion. Throughout the last 1000 years of recorded history, crowded or otherwise mal-aligned teeth have been problematic for humankind. ${ }^{31}$ In 1850, Norman Kingsley was likely among the first to use force application to correct mal-aligned teeth; however at this time, no classification symptom was yet present. ${ }^{32}$ In fact, the first 
classification of malocclusion was not published until the late 1890"s. Dr. Edward Angle described the first classification of malocclusion in his published work, Treatment of malocclusion of teeth and fractures of the maxillae. ${ }^{33}$ He illustrated three types of malocclusions possible based on the position of the maxillary first molar relative to the position of the mandibular first molar. The malocclusion classification Angle presented is described below:

- Class I

- The mesiobuccal cusp of the maxillary first molar occludes with the buccal groove of the mandibular first molar, with there being a discrepancy in the line of occlusion.

- Class II

- The mesiobuccal cusp of the maxillary first molar is located mesial to the buccal groove of the mandibular first molar.

- Class III

- The mesiobuccal cusp of the maxillary first molar is located distal to the buccal groove of the mandibular first molar.

The malocclusion classification presented by Dr. Angle over 100 years ago is still the most prominent classification system used in dentistry and orthodontics today.

\section{Relationship of Malocclusion to Craniofacial Morphology}

In most cases, dental malocclusions and skeletal craniofacial morphologic aberrations (skeletal malocclusions) are a result of distortions in normal growing 
processes. Although dental malocclusion and skeletal malocclusion are two separate problems, the two are often found together in a given patient. For example, many patients that present with a Class III skeletal pattern often have a Class III dental malocclusion as well. Ultimately, skeletal craniofacial morphology often directly correlates with dental malocclusion. The primary etiologic factors associated with orthodontic malocclusion have been cited as hereditary influences and environmental influences. Specific causes cited include embryological, developmental, skeletal growth disturbances, and muscle dysfunction. ${ }^{34}$

\section{Effects of Sleep Apnea on Craniofacial Morphology and Malocclusion}

Obstructive sleep apnea is caused by a narrowing or blocking of the airway due to collapse of soft tissues in the pharynx. The importance of understanding this obstruction in the development of both childhood and adult health problems has become increasingly documented. ${ }^{1-4}$ As such, much attention has been given to the association of craniofacial skeletal morphology, upper airway dimension, and respiratory function with this disease.

Several studies report that craniofacial dysmorphism (skeletal malocclusion) can lead to obstructive sleep apnea and may involve delayed growth of the mandible, producing mandibular retrognathia. ${ }^{35}$ Additionally, high arched palates are also common in patients with obstructive sleep apnea. It is thought that high palates result from posterior tongue displacement which forces the lateral palatine processes to expand over the abnormally placed tongue before fusing at the midline. Evidence that these events may occur in patients with obstructive sleep apnea is found in Pierre Robin syndrome and Treacher Collins syndrome, in which early mandibular hypoplasia from mal-development 
of the first branchial arch results in the above sequence of events in infants. ${ }^{36-39}$

Another study conducted by Lowe found that sleep apnea subjects exhibited a posteriorly positioned maxilla and mandible, a steep occlusal plane, over erupted maxillary and mandibular teeth, and a steep mandibular plane. Additionally, these patients illustrated a large gonial angle, high upper and lower facial heights, and an anterior open bite in association with a long tongue and a posteriorly placed pharyngeal wall. ${ }^{8}$

A recent article published by Iwasaki et al. found that oropharyngeal airway shape also is an important factor that may be correlated with craniofacial malocclusion and sleep apnea. ${ }^{2}$ The author stated that children with Class III malocclusion had significantly longer and flatter oropharyngeal airways when compared to Class I patients who tended to have square shaped oropharyngeal airways. Iwasaki deduced that Class III patients probably have less obstructive sleep apnea because they have larger oropharyngeal airways when compared to Class I patients.

Clearly, evidence suggests that skeletal craniofacial morphology, skeletal patterns, and possibly airway shape are associated with obstructive sleep apnea. However, all information collected thus far has been accomplished with 2-Dimensional radiography. This investigation will determine whether anteroposterior and vertical skeletal patterns are in fact contributory factors in the variation of oropharyngeal airway volume with the use of 3-Dimensional assessment. Ultimately, this may determine whether patients with certain skeletal deficiencies are predisposed to upper airway obstruction. 


\section{Dental Radiographs}

Radiographs are necessary when evaluating, diagnosing, and treating an orthodontic patient. Most commonly found in an orthodontic practice are panoramic, cephalometric, and tomographic radiographs which provide a magnified, 2-Dimensional, projected view of a 3-Dimensional structure. Due to magnification and image superimposition of a 3-Dimensional object to produce a 2-Dimensional image, these images are subject to distortion. Often, these radiographs are utilized when analyzing the airway, TMJ, and other bony structures within the skull. More specialized imaging modalities include magnetic resonance imaging (MRI) and computed tomography (CT); however, most orthodontists decline to use such imaging systems because they can be quite expensive for the patient and/or produce higher radiation doses than those radiographs previously listed. Specialized imaging modalities suitable for the dental practice include tomography and cone beam computed tomography (CBCT). ${ }^{40}$

\section{Traditional Craniofacial Imaging for the Evaluation of Airway}

Panoramic, cephalometric, and tomographic radiographs are most commonly used in an orthodontic practice because of its availability, relatively low cost, and radiation dosage. Panoramic and cephalometric radiographs are principally used by many clinicians to assess and diagnose patients prior to and throughout the course of treatment. Included in this assessment are size and shape of a patientes airway and whether any oropharyngeal airway obstruction is present. However, identifying the area of airway obstruction has always proven to be a challenge. ${ }^{9}$

Technological advances in medical imaging have given both the clinician and 
researcher the ability to visualize and understand anatomic structures and their relative positions without invasive procedures. In the past, this information could only be ascertained with dissection and 2-Dimensional images which only lead to speculation and assumption when viewing structures on a 2-Dimensional film.

Prior to 3-Deminsional imaging, the opportunity to view the posterior pharynx and its surrounding anatomy was limited to traditional 2-Dimensional radiography which only offered a one plane view of these structures. When 3-Dimensional imaging did become available, one had to seek a hospital for its use and utilize a radiologist for interpretation. This process is not only expensive for the patient, it is also very time consuming and offers a significant amount of radiation. Additional factors bearing challenge during this endeavor included difficultly of visualizing the airway in its entirety and the inability to visualize anatomical changes following various treatment modalities. New technology entitled cone-beam computed tomography now offers the orthodontist the ability to view the patient"s oropharyngeal region in 3-Dimension while in the dental office. These scanners are compact in size and relatively low in radiation dosage. Thus, this imaging modality helps address many of the previous concerns both effectively and efficiently. ${ }^{9}$

\section{Conventional Computerized Tomography}

Computerized tomography (CT) began as "computerized axial transverse scanning” by Godfrey Hounsfield in 1972. Hounsfield produced an image from an axial cross-section of the head using a narrow moving x-ray beam. The signal view was then fed into a computer and analyzed using a mathematical algorithm. The resultant image 
that emerged was in fact data from the algorithm reconstructed by a computer to produce a tomographic image. Hence the term computer tomography was born. This revolutionary radiographic system claimed to be 100 times more sensitive than conventional $\mathrm{x}$-ray systems and had demonstrated diagnostic quality that had never been seen before in radiology. ${ }^{41}$

Figure 6 shows a picture of a reformatted sagittal CT image demonstrating the upper airway. The red arrow points to the pharynx, and a green arrow points to the trachea.

Figure 6. Sagittal CT Image of Upper Airway. ${ }^{42}$

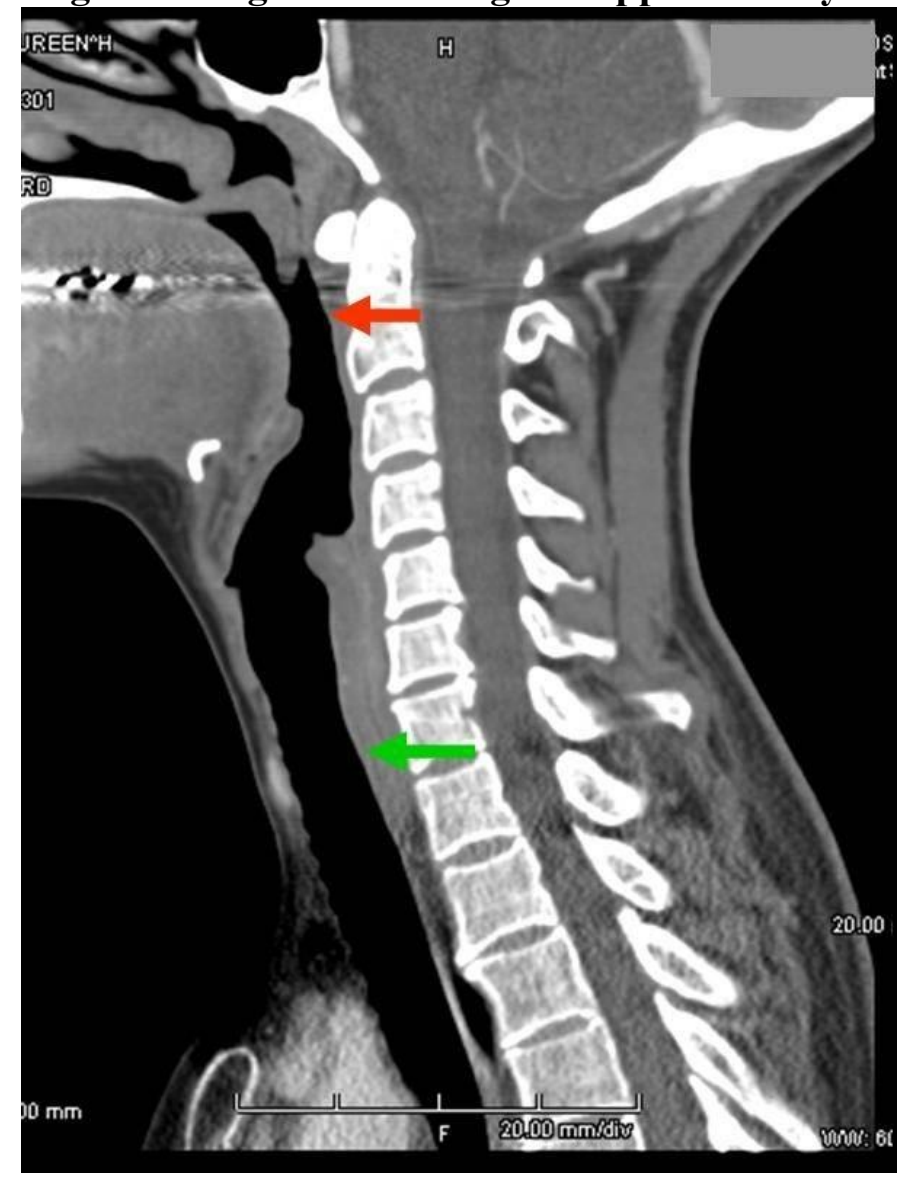




\section{Cone Beam Computer Tomography (CBCT)}

Cone-beam computer tomography scanners have been available for craniofacial imaging since 1999 in Europe and since 2001 in the United States. These scanners utilize a flat panel detector instead of an image intensifier which has been traditionally used to produce "live" radiographic images for analog or digital capture. ${ }^{43,44}$ CBCT uses a variation of conventional CT imaging techniques, but at a much lower radiation dosage than conventional medical CTs. This is because the CBCT scanners employ a round or rectangular cone-shaped $\mathrm{x}$-ray beam that pulses on and off capturing a large volume of area requiring minimal amounts of generated x-rays. Scan time ranges from 10 seconds to more than a minute depending on the size and resolution of the volume as well as the pulsing action which reduces radiation exposure to the patient and shortens scan time. Figure 7 shows a picture diagramming a CBCT image being captured and may help explain the aforementioned. 
Figure 7. CBCT - Cone-Beam Computer Tomography. ${ }^{14}$

\section{Cone Beam X-ray \& Flat Panel Detector}

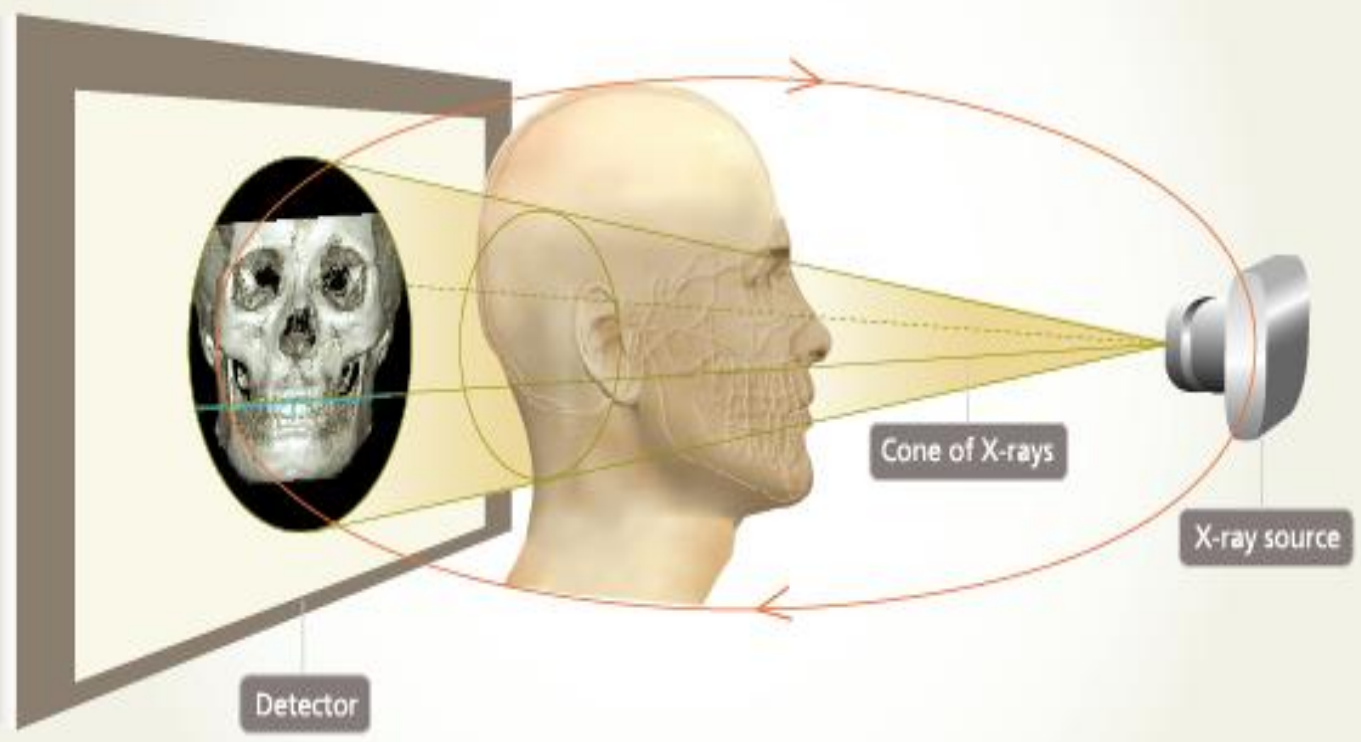

The cone-beam machine rotates $360^{\circ}$ around the head and captures static images producing raw data that requires the use of software on board a rendering computer in order to reconstruct volumetric data. This is in contrast to a conventional CT scanner that provides a set of consecutive slices of the imaged area. This reconstruction allows any three dimensional or two dimensional view in any selected plane of space. The visual resolution of a $\mathrm{CBCT}$ image varies but can be four times that of a traditional $\mathrm{CT}{ }^{41}$ Conebeam computer tomography equipment is typically less expensive than a traditional CT machine and is also less maintenance intensive.

CBCT technology now provides a major enhancement for evaluation of the upper airway with 3-Dimensional and volumetric assessments (Figure 6). As stated previously, airway analyses have been conventionally conducted utilizing lateral cephalograms. In a 
recent study comparing lateral cephalograms to CBCT imaging, the authors found moderate variation in measurements of the upper airway area and volume. This ultimately led the authors to conclude that more accurate readings were established with the cone-beam evaluation when compared to traditional cephalometric analyses. ${ }^{45}$ This type of airway analysis can only be beneficial for understanding more complex conditions such as obstructive sleep apnea and soft tissue abnormalities such as enlarged adenoids. Figure 8 shows a picture of a patient"s airway analysis being conducted utilizing CBCT technology. With only a lateral cephalogram, one would not be able to identify any possible airway lateral constriction abnormality. By means of CBCT, the airway can be segmented and analyzed volumetrically in 3 dimensions. 


\section{Figure 8. CBCT Airway Analysis of a Patient.}

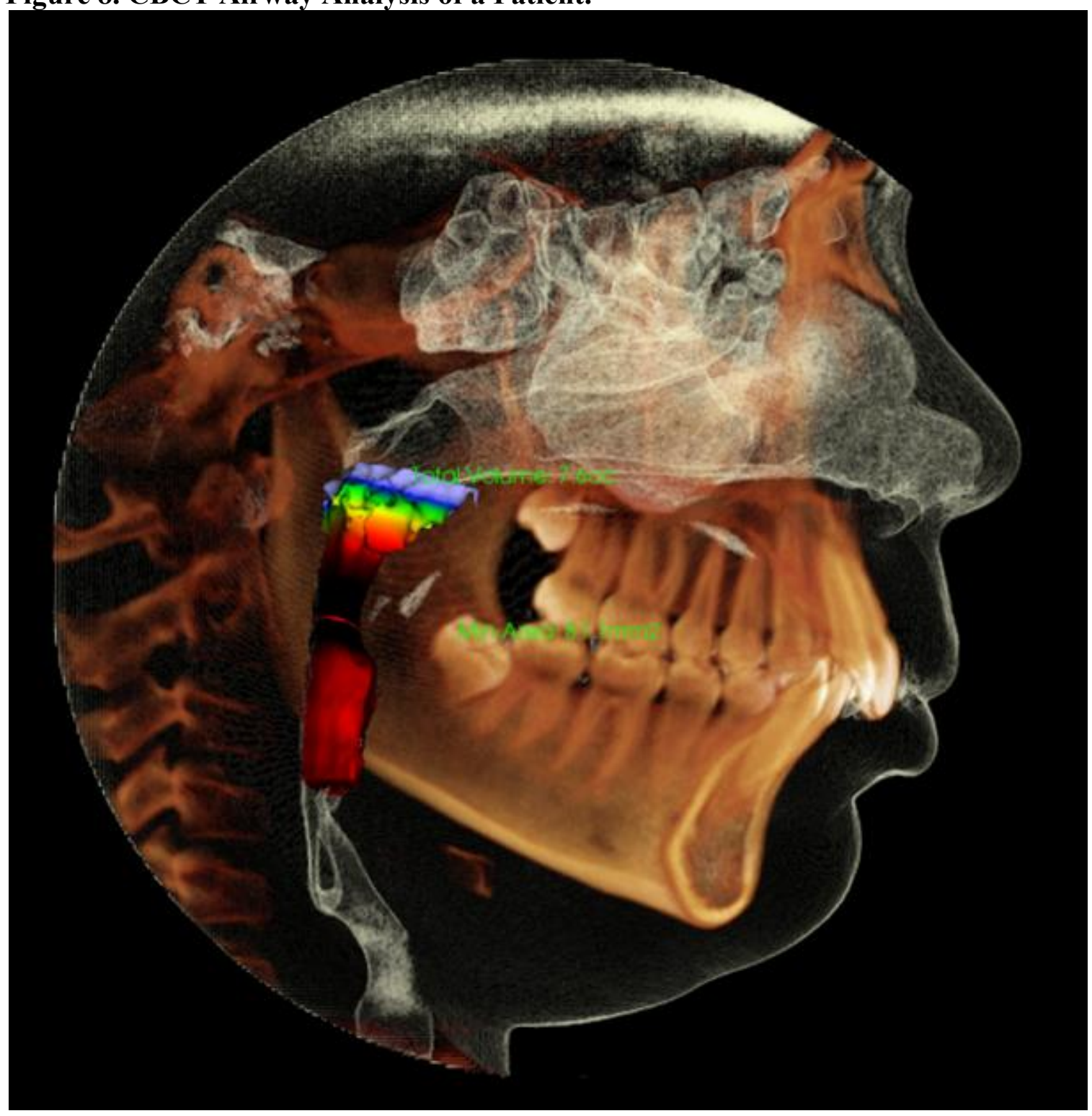

\section{CBCT Image Accuracy}

The CBCT image has a large advantage over 2-Dimensional radiography because it allows a true representation of anatomic structures in 3-Dimensions ultimately giving the clinician a better understanding of the object studied. An increased acceptance of cone-beam computer tomography in clinical orthodontics has motivated researchers to 
investigate its accuracy. Periago et al. studied the accuracy and reliability of taking linear measurements from $\mathrm{CBCT}$ images reconstructed with an orthodontic volumetric rendering program to direct measurements made on human skulls. The study found that many linear measurements taken on 3D volumetric surface rendering images may be statistically significantly different from anatomic dimensions. However, most measurements could be considered to be sufficiently clinically accurate for craniofacial analyses. ${ }^{46}$ In 2007, Moshiri et al. compared the accuracy of linear measurements taken from $\mathrm{CBCT}$ images to those measurements taken from traditional cephalometric headfilms. The investigation found that lateral cephalometric images rendered from CBCT data were more accurate than traditional lateral cephalometric headfilms. ${ }^{47}$ In a study conducted by Honey et al., five types of radiographs were taken of 37 dry skulls and were reviewed by independent observers. The five categories of radiographs were as follows:

1. Corrected angle linear tomography

2. Standard panoramic radiograph

3. TMJ-specific panoramic radiograph

4. Cone beam computed tomography (static image)

5. Cone beam computed tomography (interactive image)

The findings indicate that $\mathrm{CBCT}$ images provide more accuracy and reliability than the other types of radiographs studied including panoramic radiographs and tomograms. ${ }^{48}$ Final images from a CBCT volume may be printed on a 1:1 scale with a margin of error in geometric accuracy reported to be $2 \%$ or less. ${ }^{41}$ 


\section{Radiation Safety}

The amount of radiation one receives from an $\mathrm{x}$-ray source depends on a multitude of factors including the field of view, the current multiplied by the scan time $(\mathrm{mA})$, and the voltage $(\mathrm{kVp})$ chosen. With recent awareness from both the practitioner and the general population in regards to radiation safety, much concern over radiation dose and radiographic imaging has emerged. As such, much research has been conducted to ensure public safety.

Rustemeyer et al. compared radiation dose to low-dose dental CT protocols, standard CT protocols, and CBCT protocols. Standard dental CT protocols were found to have an effective dose of approximately $3.4 \mathrm{mSv}$ while low-dose dental CT protocols were found to produce up to nine times less radiation approximating $0.37 \mathrm{mSv}$. With CBCT protocols, the effective dose found was approximately 0.11 to $0.5 \mathrm{mSv}{ }^{49}$ Another article written by Scarfe et al. found similar results. The authors summarized that the radiation dose from CBCT scanners were approximately 15 times lower than those of conventional CT scanners (a range from 0.04 to $0.05 \mathrm{mSv}$ ) which is a reduction of up to $98 \%$ when compared to conventional dental CT scans (1.3 to $3.3 \mathrm{mSv}$ for imaging the mandible and 1.0 to $1.4 \mathrm{mSv}$ for imaging the maxilla). ${ }^{50}$ The low radiation requirements are attributed to the pulse behavior of the $\mathrm{x}$-ray beam in acquiring a cone-beam image. ${ }^{51}$ Ultimately, research has shown that $\mathrm{CBCT}$ images require much less radiation than that of conventional dental CT scans but more radiation than that of a typical panoramic or cephalometric radiograph.

Cone-beam computer tomography radiation dosages are not an industry standard and in fact depend on several variables including the manufacturer of the x-ray machine, 
the scan volume size, and the scan resolution. Higher resolution scans require more radiation and/or longer scanning times as does a larger volume size. Current published radiation dosages will continue to vary as manufacturers make strides in the continued development and refinement of CBCT imaging. Table 1 gives the estimated radiation dosage $(\mathrm{mSv})$ for several types of radiographs commonly taken in the dental office.

Table 1. Summary of Radiograph Exposure Comparison (mSv).

\begin{tabular}{|l|l|}
\hline Source Type & Estimated Radiation Dosage (mSv) \\
\hline Traditional panoramic headfilm & 0.016 \\
\hline Full mouth series (19 films) & 0.150 \\
\hline Low-dose Dental CT & 0.370 (reported as low as 0.040 in one study) \\
\hline Traditional Dental CT & 1.300 to 3.400 \\
\hline $\begin{array}{l}\text { Cone-beam CT } \\
\text { Average radiation in the United States } \\
\text { from Natural sources (per year) }\end{array}$ & 0.110 to 0.500 \\
\hline
\end{tabular}

\section{CBCT Benefits, Limitations, and Applications within Orthodontics}

Although CBCT images require more radiation than panoramic and cephalometric radiographs, many believe the information obtained from one of these scans alone prevail the risks of slightly more radiation. In fact, this radiograph is equivalent to having all of the following radiographs in one image: periapicals, panograms, cephalograms, occlusal radiographs, and temporomandibular joint series. ${ }^{23}$ If the radiation doses of each of these radiographs were cumulated, one would observe the radiation received from one CBCT scan is relatively low in comparison.

The clinical applications of the CBCT include the ability to see impacted teeth 
and oral abnormalities in three dimensions. Additionally, one can determine placement of temporary anchorage devices, alveolar bone height and density, as well as airway dimension and or obstruction. Another invaluable application of a CBCT scan is the ability to observe the temporomandibular joint morphology. This allows the clinician to observe and document any resorption present prior to the onset of treatment. ${ }^{23}$

A limitation of the CBCT scan includes a grainy appearance of the skin surface. ${ }^{53}$ To resolve this issue, some researchers have introduced 3-Dimensional photography in conjunction with the CBCT image. The design of 3-Dimensional photography utilizes three cameras set at specific angles from an individuales face allowing the individual'es entire face to be captured. A computer maps the images together and a 3-Dimentional photograph results. This is joined with the skin surface of the CBCT scan and has seemed to resolve the aforementioned dilemma. ${ }^{54}$ This technology has clinical applications mainly in orthognathic surgery with the ability to predict patient outcomes. The images that are obtained need improvement before the profession accepts the images as diagnostically acceptable. However, it should be noted that this technology is in its infancy with research and development of this specific technique and is constantly changing. 55

Future applications of CBCT scans include the addition of motion to the data collections process. This will allow the clinician to observe the patient ${ }^{\text {ee }}$ s opening and closing patterns while at the same time observe the response to movement within the temporomandibular joint space. ${ }^{56}$ Applications of CBCT scans and the use of the DICOM files in which they are stored are endless. 


\section{The Current Question}

Establishment of cephalometric norms for upper airway dimensions have been predominately based on lateral cephalograms. As such, the precise volume of the airway, minimum cross sectional area (CSA), and shape could not be established in adults. Additionally, true normative airway dimensions of patients with differing facial skeletal patterns, that is high and low angle Class I, II, and III malocclusions, is still undetermined using 3-Dimensional imaging.

Accordingly, the purpose of this study is to assess the effect of craniofacial skeletal patterns on upper airway volume, minimum cross sectional area, and shape by using cone-beam computed tomography (CBCT) and 3-Dimensional (3D) image reconstruction software. This study is significant because it will establish normative airway dimensions for patients with high and low angle Class I, II, and III malocclusions and will serve as a standard to compare patients to when determining normal airway size. Ultimately, this investigation hopes to determine whether skeletal patterns may be contributory factors in the variations of oropharyngeal airway dimensions. This may determine whether patients with certain skeletal discrepancies are predisposed to upper airway obstruction. This investigation intends to add to the current information about airway characteristics and in fact intends to serve as a reference of normative airway dimensions when evaluating the airway of a patient. 


\section{CHAPTER 3: EXPERIMENTAL DESIGN AND METHODS}

\section{Imaging protocol}

This study was in collaboration with Dr. James Mah, Associate Clinical Professor at the University of Nevada Las Vegas School of Dentistry. The DICOM files used in this study were taken at an imaging center, Advanced Dental Imaging, and were donated for this study with the intent for research. The cone-beam computer tomography scanner used to take the volumetric images was a Hitachi CB MercuRay ${ }^{\mathrm{TM}}$. Cone-beam radiographs used in this study and the experimental design were reviewed and exempted by the Institutional Review Board at West Virginia University (Appendix A).

A total of 279 subjects were divided into three anteroposterior groups according to ANB angle (Class I, II, or III). ANB angle was determined by the difference between SNA angle and SNB angle. SNA is defined as the angle formed between the lines Sella/Nasion and Nasion/A point. SNB is defined as the angle formed between the lines Sella/Nasion and Nasion/B point. Group I subjects (Class I) were patients determined to have an ANB angle range $0^{\circ}-5^{\circ}$. Group II subjects (Class II) were patients determined to have an ANB angle $>5^{\circ}$. Group III subjects (Class III) were patients determined to have an ANB angle $<0^{\circ}$. Figure 9 is an example of a patient determined to have a Class II skeletal pattern. 


\section{Figure 9. Patient Determined to Have a Class II Skeletal Pattern.}

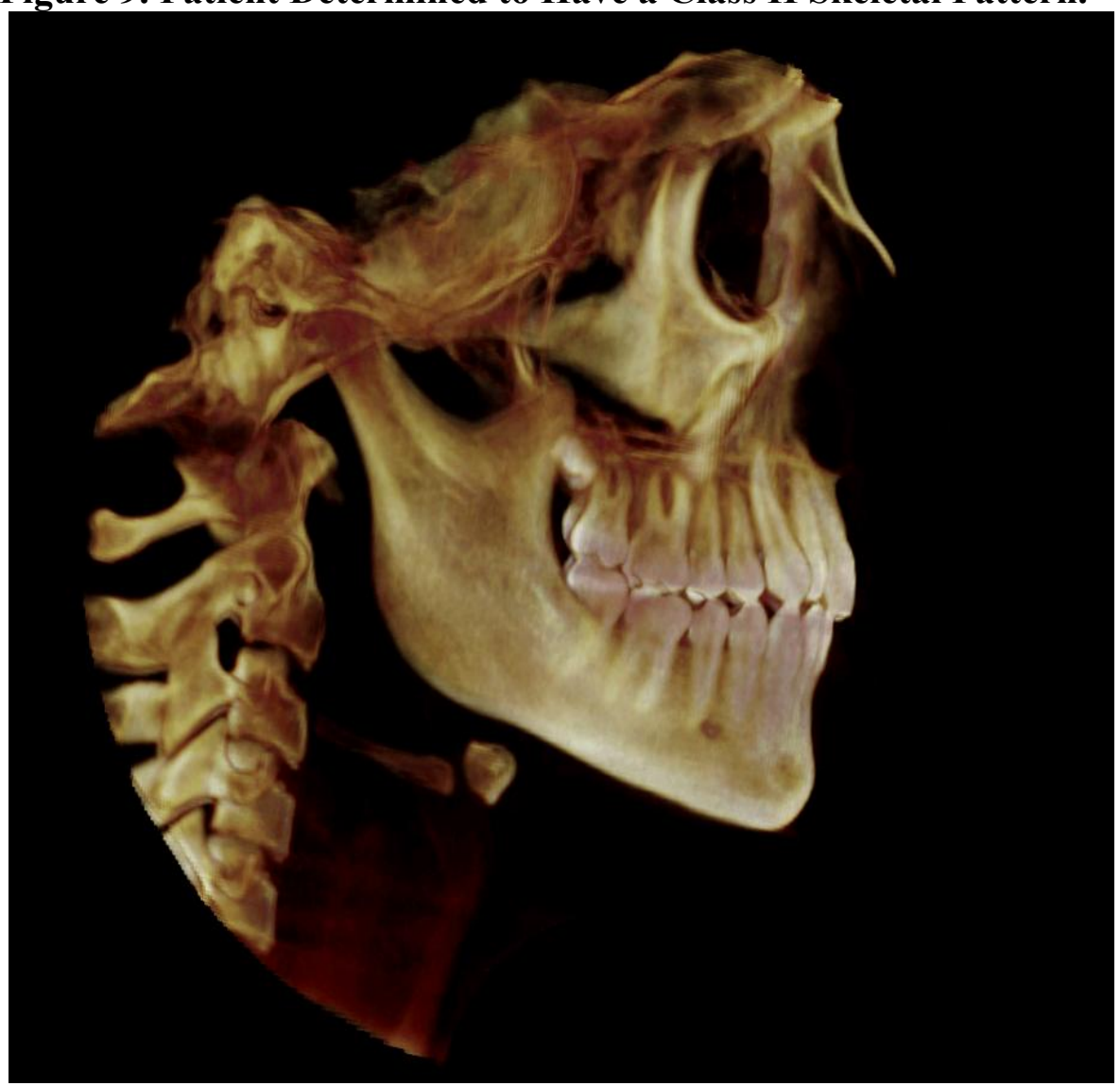

Subjects were also divided into three vertical groups by assessing the FH-MP angle (normodivergent, hyperdivergent, and hypodivergent). Frankfort Horizontal Plane is a horizontal plane represented in profile by a line between the lowest point on the margin of the orbit and the highest point on the margin of the auditory meatus. Frankfort - Mandibular Plane angle (FH/MP) is the angle formed at the intersection of the Frankfort Horizontal Plane with the Mandibular Plane.

Patients with mandibular plane angle (FH/MP) of $22^{\circ}$ to $30^{\circ}$ were classified as normodivergent. Patients with mandibular plane angle $>30^{\circ}$ were classified as hyperdivergent and patients with mandibular plane angle $<22^{\circ}$ were classified as hypodivergent. Figure 10 shows a patient with a hyperdivergent skeletal pattern. 
Figure 10. Patient Determined to Have a Hyperdivergent Skeletal Pattern.

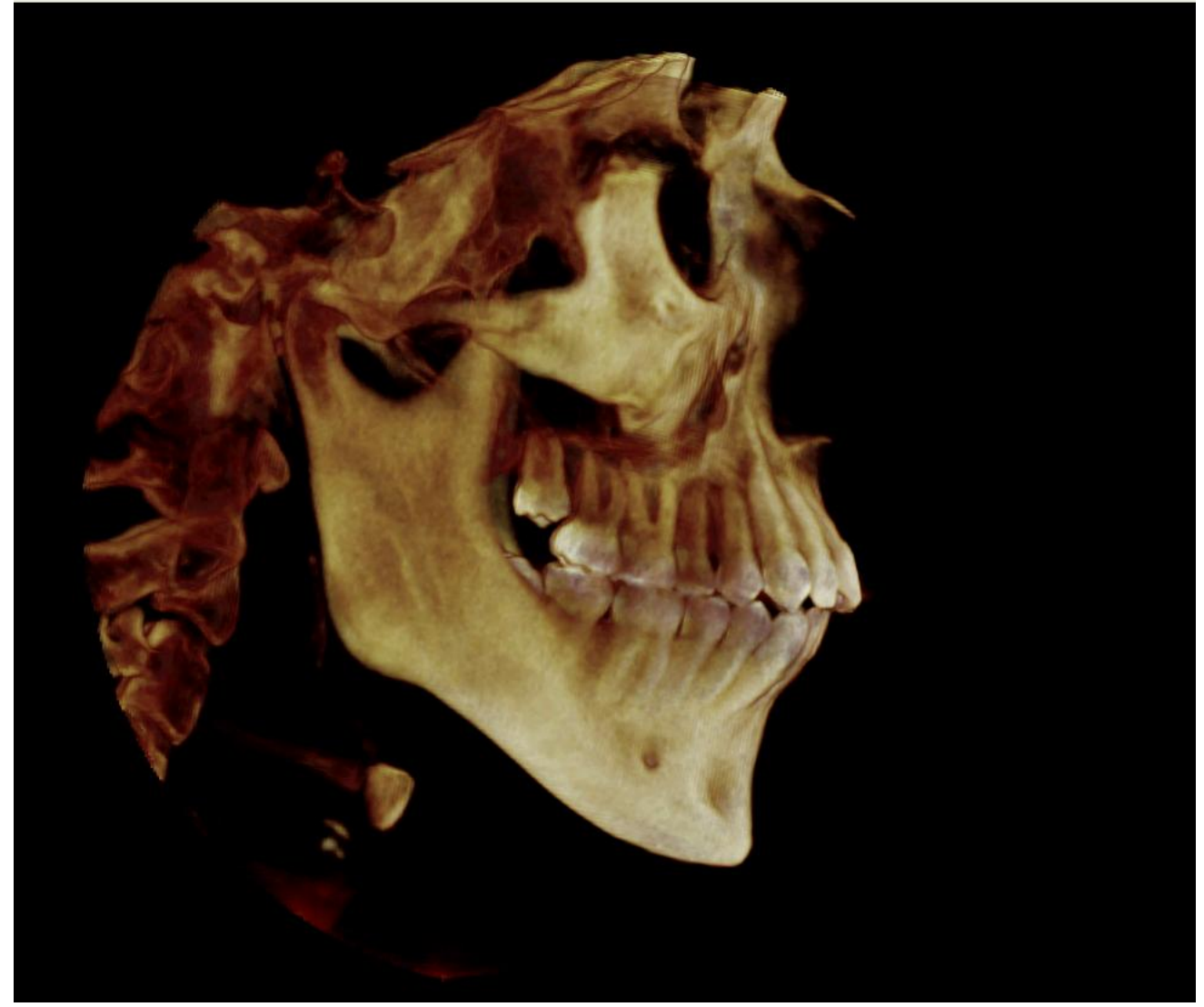

The subjects were then subdivided into nine total subgroups based on both anteroposterior and vertical skeletal patterns. The nine subgroups that resulted after classification of craniofacial skeletal pattern are listed below:

- Skeletal Class I, Normodivergent

- Skeletal Class I, Hypodivergent

- Skeletal Class I, Hyperdivergent

- Skeletal Class II, Normodivergent

- Skeletal Class II, Hypodivergent

- Skeletal Class II, Hyperdivergent

- Skeletal Class III, Normodivergent 
- Skeletal Class III, Hypodivergent

- $\quad$ Skeletal Class III, Hyperdivergent

Because airway volume is influenced by head posture, all subjects were required to posture their heads correspondingly to discount variability in airway volume due to head posture. Therefore, all subjects examined in this study had craniocervical

inclinations measured between $90^{\circ}$ and $110^{\circ}$ to ensure uniformity amongst the subjects. ${ }^{57}$

\section{Methodology}

The DICOM files were analyzed using Dolphin Imaging 10.5 Premium and Anatomage InVivoDental ${ }^{\mathrm{TM}}$ software version 5.1 licensed to West Virginia University School of Dentistry Department of Orthodontics. The subject's DICOM files were first examined in 3-Dimensional rendering mode. In this 3D mode, the subjects ${ }^{\text {ee }}$ orientation was corrected if needed to minimize variability in measurements among the sampled subjects. Horizontal orientation, also known as the Axial Plane, was determined by constructing a line through the lowest boarder of the infra - orbital rims. The vertical orientation, also known as the Mid - Sagittal Plane, was determined by constructing a line through ANS and the dental midlines as seen in Figure 11. 
Figure 11. Orientation of DICOM file in Dolphin Software.

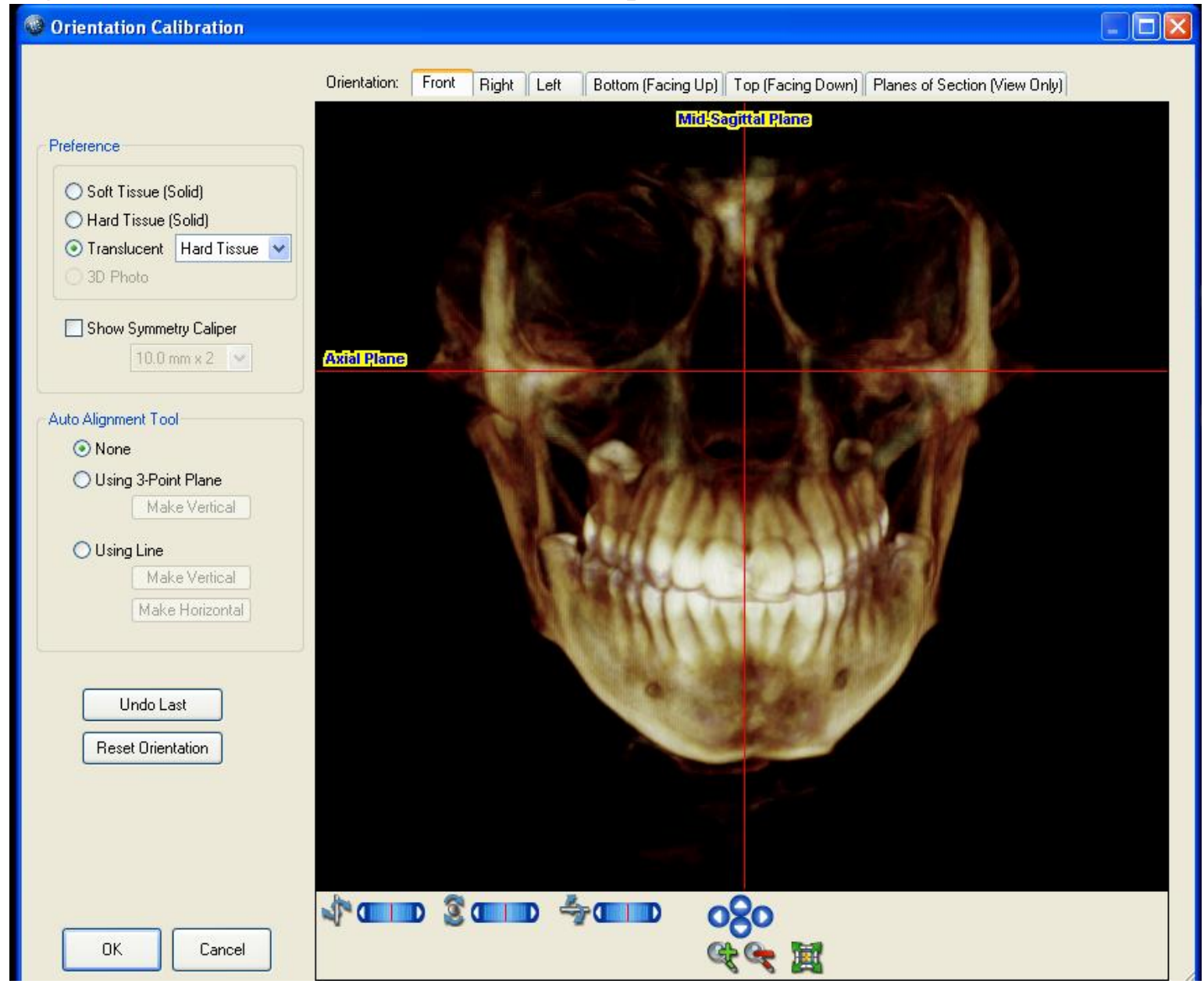

After the orientation was corrected, a 2D lateral cephalogram was generated for variable measurements. Dolphin imaging software was able to generate a "true" right and "true" left lateral cephalogram for each subject using only the data from the DICOM file for that particular side. Therefore, the cephalogram was constructed from soft and hard tissue data only from only the right side. The landmarks identified in 3D mode were then transferred automatically by the Dolphin software. 


\section{Image Analysis for Optimal Airway Analysis}

Once patients had been subdivided into nine subgroups based on skeletal pattern, analysis of airway volume and minimum cross sectional area (CSA) commenced. Anatomage InVivoDental ${ }^{\mathrm{TM}}$ software version 5.1 was used for this assessment. The upper airway volume was measured to include the airspace between the hard palate and the base of the epiglottis and the posterior pharyngeal wall and the anterior wall of the pharynx formed by the junctions of the posterior boarder of the soft palate and the posterior boarder of the tongue. The volume also included any intraoral airspace that may be present on the radiograph due to tongue position. These landmarks for airway dimensional assessment were chosen because this anatomical area is the site where most constrictions occur that lead to sleep apnea. Additionally, not only have these landmarks been used by previous authors for similar airway volume assessment, this method of assessment standardizes the procedure for data collection, thus minimizing the chances of invalid calculation. ${ }^{2,58}$ To better illustrate the anatomical sites where the airway volume analysis was conducted, see Figure 12. 
Figure 12. Volume Measurement of the Upper Airway. ${ }^{2}$

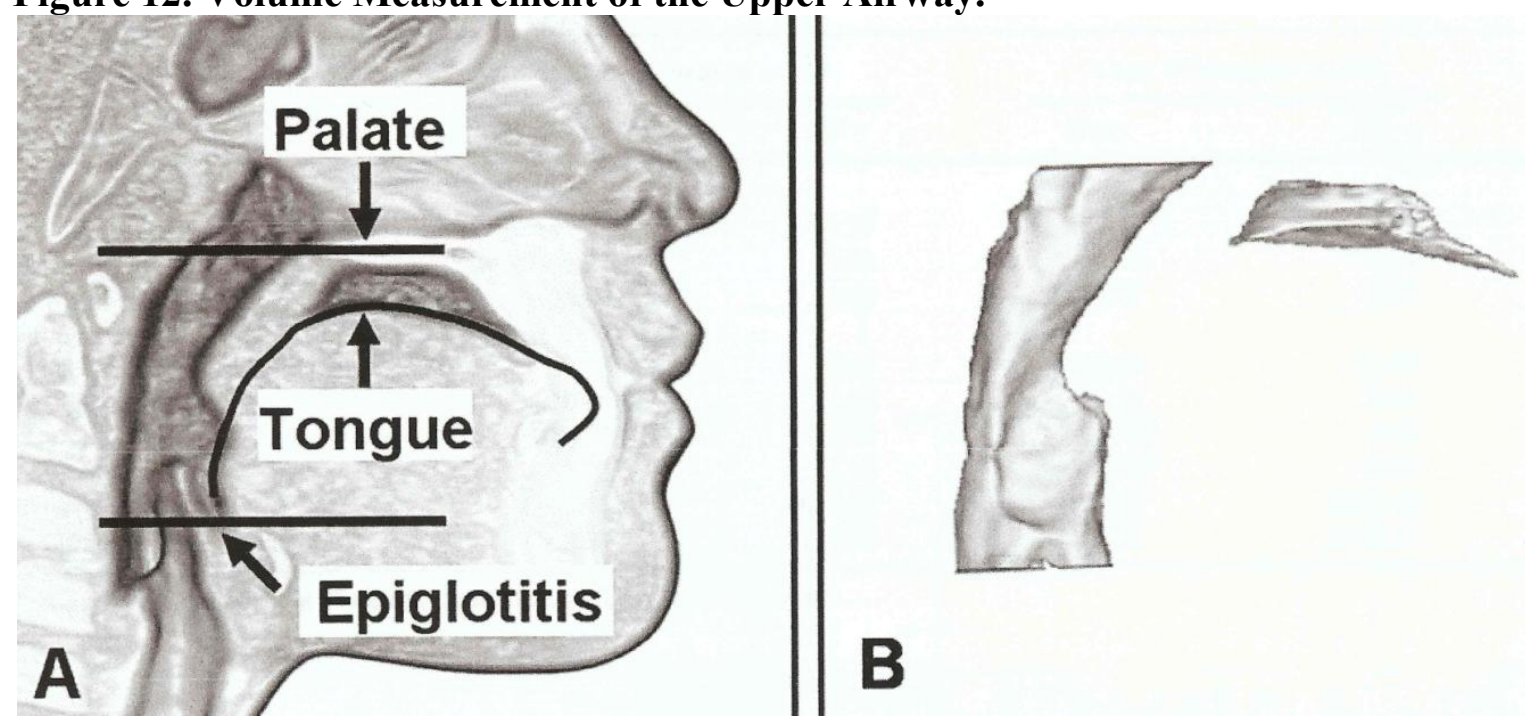

A, Upper airway volume measured between the hard palate and base of the epiglottis. B, Computer generated extraction of upper airway (left) and intraoral airway space (right).

Minimum cross sectional area (CSA) was also assessed the same time airway volume was recorded. Anatomage InVivoDental ${ }^{\mathrm{TM}}$ software version 5.1 automatically calculates the minimum CSA when calculating airway volume. Therefore, it too was recorded for later assessment to determine if this variable was affected by skeletal pattern.

\section{Image Analysis for Airway Shape}

Once upper airway volume and minimum CSA were measured and recorded, oropharyngeal airway shape was assessed. Emulating a previous study conducted by Iwasaki et al., airway shape was divided into three groups: wide, square, and long. ${ }^{2}$ The shape was assessed by taking a cross-section along the horizontal plane passing through the midpoint of bilateral gonion. Both width and depth were measured (millimeters). In the wide type, width was greater than depth. In the square type, width was equal to depth and in the long type, width was less than depth. This site for oropharyngeal airway shape 
assessment was chosen because this landmark is easily identified on all radiographs. This allows for standardized data collection, thus minimizing the chances of invalid calculation. Additionally, this location was chosen by the aforementioned authors for assessment and allows for comparison to the previous study. Figures 13 and 14 illustrate the cross section at bilateral gonion and an axial view of the three possible airway shapes.

Figure 13. Oropharyngeal Cross Section at Bilateral Gonion. ${ }^{2}$

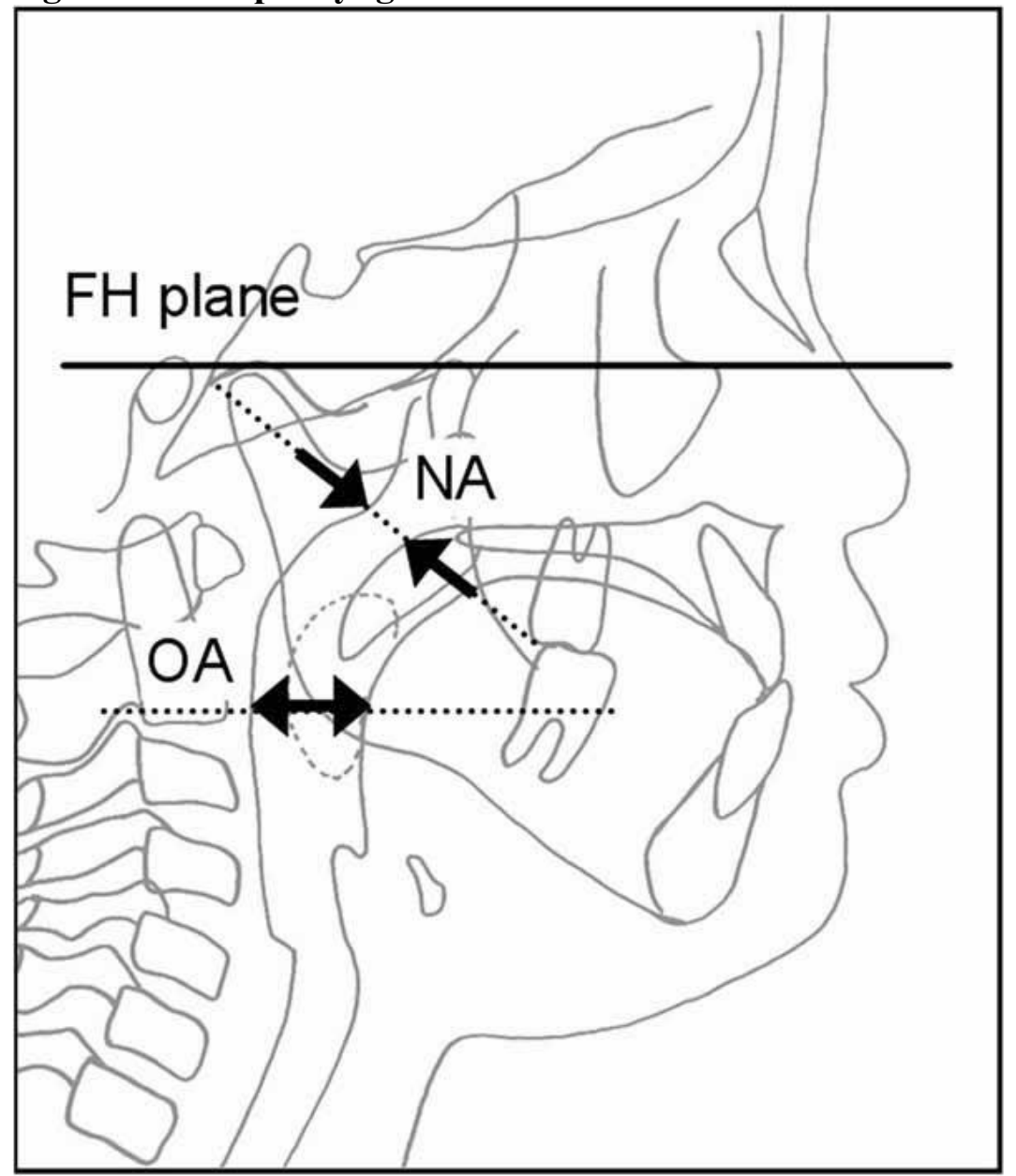

$\mathrm{NA}=$ Nasopharyngeal Airway, OA = Oropharyngeal Airway, $\mathrm{FH}=$ Frankfort Horizontal 
Figure 14. Three Possible Airway Shapes Viewed in Cross Section at the Level of Bilateral Gonion. ${ }^{2}$
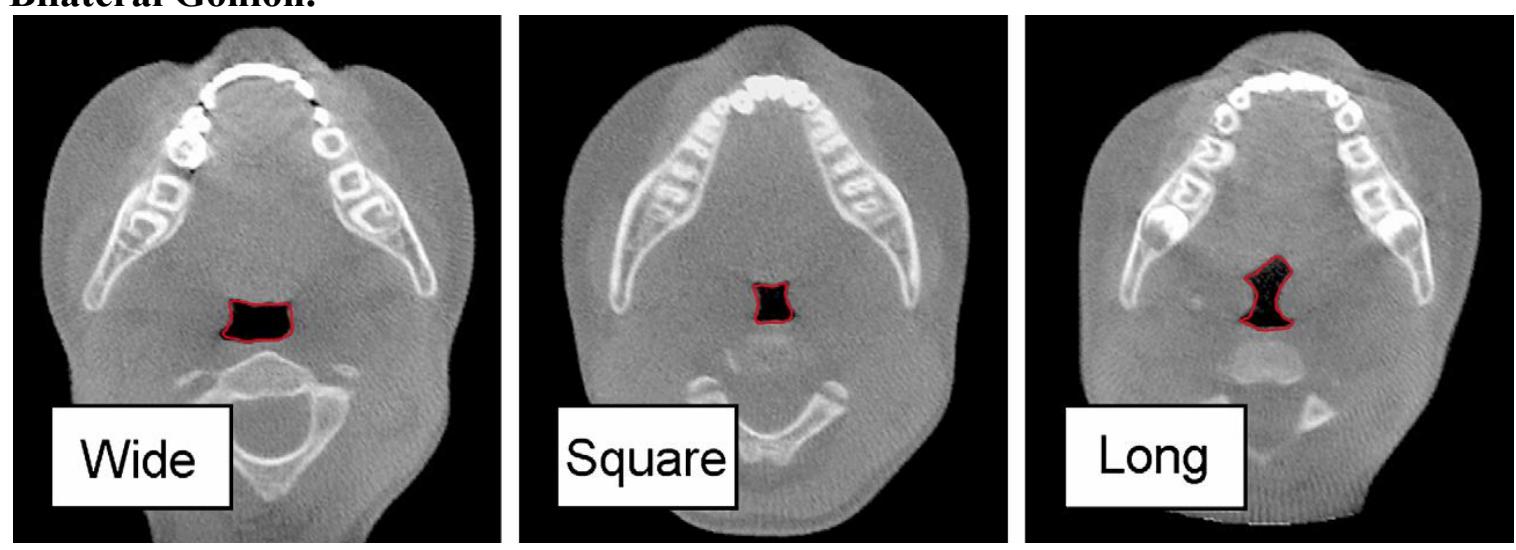

Examples of 3 airway-shape types. $W$, Width; $D$, depth. In the wide type, $\mathrm{W}>\mathrm{D}$; in the square type, $\mathrm{W}=\mathrm{D}$; in the long type, $\mathrm{W}<\mathrm{D} .^{2}$

\section{Method Error}

The reliability of this three-dimensional airway analysis was tested by investigating the error in locating and measuring the changes of all landmarks. Ten subjects were analyzed a second time two weeks after the initial tracing. For all variables, differences between the measurements recorded at the first analysis and measurements recorded at the second analysis were compared for each individual. A matched-pairs reliability test was used to statistically analyze each measurement to establish a coefficient of reliability to determine the degree of reliability of the analysis.

\section{Data Documentation}

Tables were established to document collected data using Microsoft Excel ${ }^{\mathrm{TM}}$ 2007. Example tables can be seen in Tables 2, 3, and 4 . 
Table 2. Airway Volume, Minimum CSA, and Airway Shape of Subjects with Differing Vertical Class I Patterns.

\begin{tabular}{|c|c|c|c|c|c|c|c|c|c|}
\hline & \multicolumn{3}{|c|}{$\begin{array}{l}\text { Skeletal Class I, } \\
\text { Normodivergent }\end{array}$} & \multicolumn{3}{|c|}{$\begin{array}{l}\text { Skeletal Class I, } \\
\text { Hypodivergent }\end{array}$} & \multicolumn{3}{|c|}{$\begin{array}{l}\text { Skeletal Class I, } \\
\text { Hyperdivergent }\end{array}$} \\
\hline & $\begin{array}{l}\text { Airway } \\
\text { Volume }\end{array}$ & $\begin{array}{l}\text { Minimum } \\
\text { CSA }\end{array}$ & Shape & $\begin{array}{l}\text { Airway } \\
\text { Volume }\end{array}$ & $\begin{array}{l}\text { Minimum } \\
\text { CSA }\end{array}$ & Shape & $\begin{array}{l}\text { Airway } \\
\text { Volume }\end{array}$ & $\begin{array}{l}\text { Minimum } \\
\text { CSA }\end{array}$ & Shape \\
\hline Mean & & & & & & & & & \\
\hline
\end{tabular}

Table 3. Airway Volume, Minimum CSA, and Airway Shape of Subjects with Differing Vertical Class II Patterns.

\begin{tabular}{|c|c|c|c|c|c|c|c|c|c|}
\hline & \multicolumn{3}{|c|}{$\begin{array}{l}\text { Skeletal Class II, } \\
\text { Normodivergent }\end{array}$} & \multicolumn{3}{|c|}{$\begin{array}{c}\text { Skeletal Class II, } \\
\text { Hypodivergent }\end{array}$} & \multicolumn{3}{|c|}{$\begin{array}{l}\text { Skeletal Class II, } \\
\text { Hyperdivergent }\end{array}$} \\
\hline & $\begin{array}{l}\text { Airway } \\
\text { Volume }\end{array}$ & $\begin{array}{l}\text { Minimum } \\
\text { CSA }\end{array}$ & Shape & $\begin{array}{l}\text { Airway } \\
\text { Volume }\end{array}$ & $\begin{array}{l}\text { Minimum } \\
\text { CSA }\end{array}$ & Shape & $\begin{array}{l}\text { Airway } \\
\text { Volume }\end{array}$ & $\begin{array}{l}\text { Minimum } \\
\text { CSA }\end{array}$ & Shape \\
\hline Mean & & & & & & & & & \\
\hline
\end{tabular}

Table 4. Airway Volume, Minimum CSA, and Airway Shape of Subjects with Differing Vertical Class III Patterns.

\begin{tabular}{|c|c|c|c|c|c|c|c|c|c|}
\hline & \multicolumn{3}{|c|}{$\begin{array}{c}\text { Skeletal Class III, } \\
\text { Normodivergent }\end{array}$} & \multicolumn{3}{|c|}{$\begin{array}{c}\text { Skeletal Class III, } \\
\text { Hypodivergent }\end{array}$} & \multicolumn{3}{|c|}{$\begin{array}{c}\text { Skeletal Class III, } \\
\text { Hyperdivergent }\end{array}$} \\
\hline & $\begin{array}{l}\text { Airway } \\
\text { Volume }\end{array}$ & $\begin{array}{l}\text { Minimum } \\
\text { CSA }\end{array}$ & Shape & $\begin{array}{l}\text { Airway } \\
\text { Volume }\end{array}$ & $\begin{array}{l}\text { Minimum } \\
\text { CSA }\end{array}$ & Shape & $\begin{array}{l}\text { Airway } \\
\text { Volume }\end{array}$ & $\begin{array}{c}\text { Minimum } \\
\text { CSA }\end{array}$ & Shape \\
\hline Mean & & & & & & & & & \\
\hline
\end{tabular}

\section{Statistical Analysis}

From the tables above, means were determined for the aforementioned groups and subgroups. Because multiple groups were compared to one another, a one-way analysis of variance (ANOVA) was used to analyze whether there were differences between groups and subgroups means. The Tukey-Kramer, Student t, and Wilcoxon/ KruskalWallis Tests were used to compare the means of each group and subgroup against each other. The study was prepared this way to ensure that all groups could be compared against one another to see if facial skeletal patterns significantly influence airway dimensions. All statistics were computed by a statistician. 


\section{CHAPTER 4: RESULTS}

\section{Power Analysis}

A total of 279 DICOM files were analyzed in this study. The subjects were categorized using the previously mentioned methodology into three anteroposterior groups (Class I, Class II, and Class III) with a sample size of ninety-three subjects per group. Subjects were also categorized into three vertical groups (Normodivergent, Hyperdivergent, and Hypodivergent) with a sample size of ninety-three subjects per group. The groups were then subdivided into nine subgroups (Class I Hyperdivergent, Class I Normodivergent, Class I Hypodivergent, etc.) with a sample size of thirty-one patients per subgroup. To ensure sample size was adequate giving the ability to interpret true conclusions, a power analysis was conducted using the data collected. The results of the analysis are explained below.

With ninety-three patients in each anteroposterior group (or vertical group), a difference of one standard deviation was detected between the mean airway volume (or minimum CSA) of pair of groups with power of 0.99 in a two sided test with a level of significance of 0.05 . That is, having ninety-three patients in each group, if the true difference between two groups is as large as one standard deviation, then with a probability of 0.99 , a significant difference between the groups is declared.

With thirty-one patients in each subgroup (nine total), a difference of one standard deviation was detected between the mean airway volume (or minimum CSA) of pair of groups with a power of 0.97 in a two sided test with a level of significance of 0.05 . That is, having thirty-one patients in each subgroup, if the true difference between two subgroups is as large as one standard deviation, then with a probability of 0.97 , a 
significant difference between the subgroups is declared. Therefore, a sample size of 93 was adequate for the 3 groups of anteroposterior skeletal patterns (or vertical skeletal patterns) and the 9 subgroups of anteroposterior / vertical skeletal patterns.

Sampling variability can be seen in each analysis by the standard deviation and range of airway dimensions measured.

\section{Airway Volume by Anteroposterior Skeletal Pattern}

Figure 15 and Table 5 show the mean, standard deviation, maximum airway volume attained, and the minimum airway volume attained for the three anteroposterior skeletal patterns (Class I, Class II, and Class III).

\section{Figure 15. Mean Airway Volume (cc) for the Anteroposterior Skeletal Groups} $(\mathbf{n}=\mathbf{2 7 9})$.

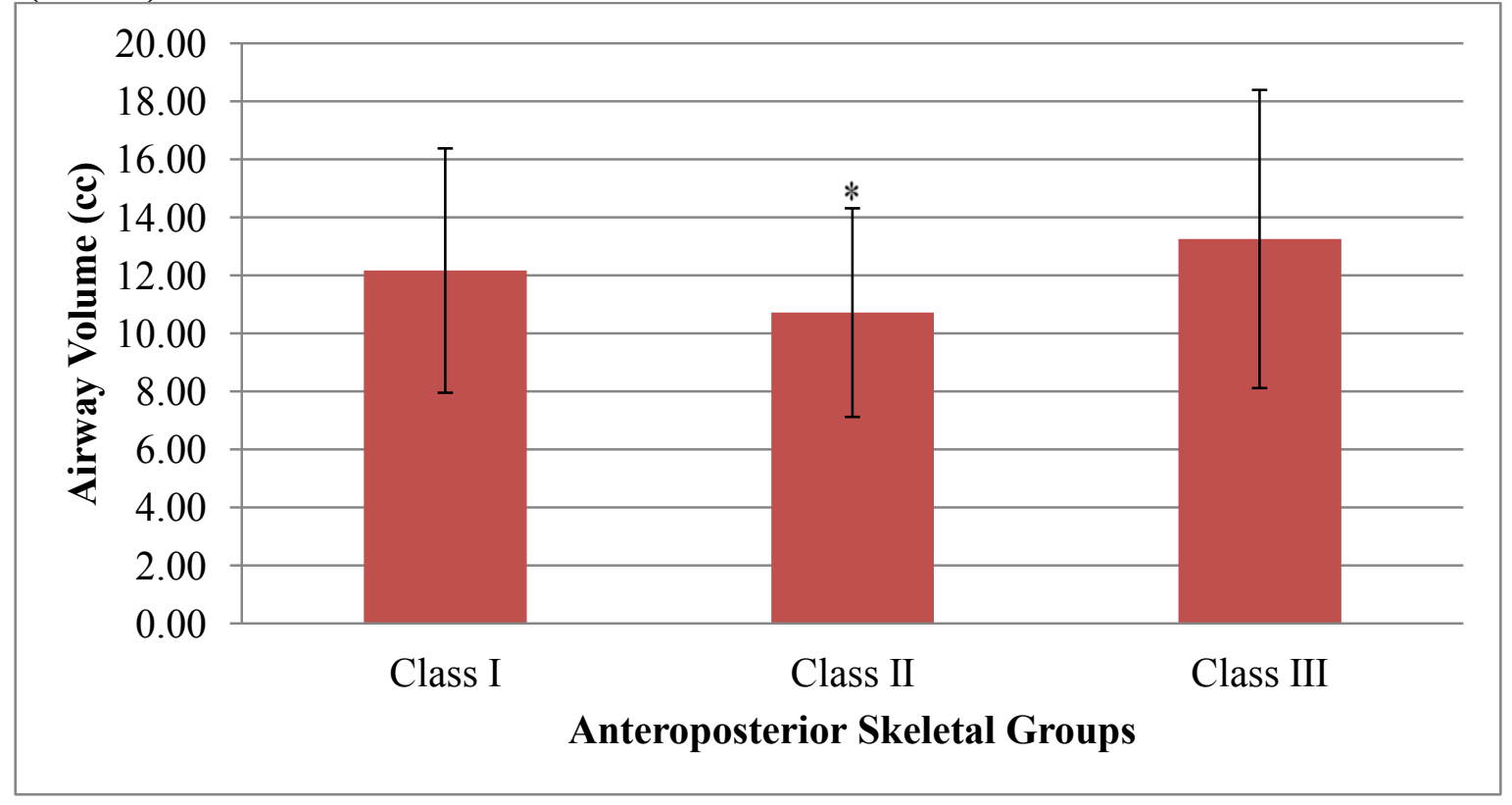

* = Significantly different from Class III at $\mathrm{p}<0.001$

Data were analyzed using a one way analysis of variance and a matched pairs Tukey-Kramer test. The study found a significant difference in airway volume between 
Class II and Class III subjects with a $\mathrm{p}<0.001$. No significant differences were found between Class I and Class II subjects and between Class I and Class III subjects.

However, a trend can be seen with Class II subjects having the smallest airway while Class III subjects having the largest airway.

Table 5. Airway Volume (cc) Based on Anteroposterior Skeletal Pattern (n= 279).

\begin{tabular}{|c|c|c|c|c|c|c|}
\hline & Mean Airway Volume (cc) & Standard Deviation & Max (cc) & Min (cc) & \multicolumn{2}{|c|}{} \\
\hline Class I & 12.17 & 4.21 & 27.1 & 4.9 & $\mathrm{~A}$ & B \\
\hline Class II & 10.72 & 3.60 & 20.6 & 4.9 & & B \\
\hline Class III & 13.26 & 5.14 & 31.4 & 4.5 & A & \\
\hline
\end{tabular}

Groups not connected by the same letter are significantly different.

\section{Minimum Cross Sectional Area by Anteroposterior Skeletal Pattern}

Figure 16 and Table 6 show the mean, standard deviation, maximum minimum cross sectional area (CSA) attained, and the minimum minimum cross sectional area attained for the three anteroposterior skeletal patterns (Class I, Class II, and Class III). 
Figure 16. Mean Minimum CSA $\left(\mathrm{mm}^{2}\right)$ for the Anteroposterior Skeletal Groups $(\mathbf{n}=\mathbf{2 7 9})$.

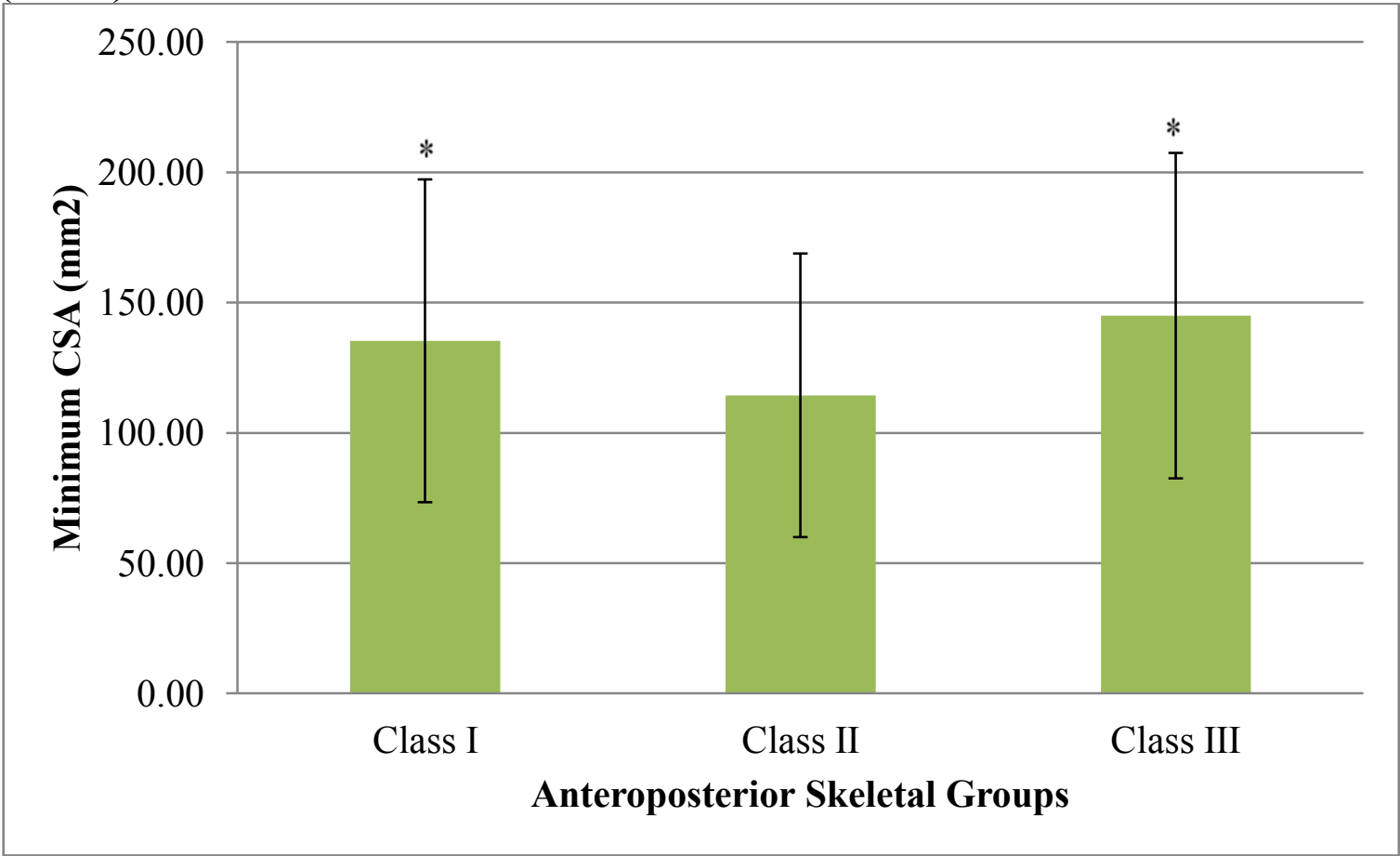

$*=$ Significantly different from Class II at $\mathrm{p}<0.01$

Data were analyzed using a one way analysis of variance and a matched pairs Tukey-Kramer test. Significant differences were found in the minimum CSA between Class I and Class II and between Class II and Class III subjects with a $\mathrm{p}<0.01$. No significant differences were found between Class I and Class III subjects. As with airway volume, a trend can be seen with Class II subjects having the smallest minimum CSA while Class III subjects having the largest minimum CSA. 
Table 6. Minimum CSA $\left(\mathrm{mm}^{2}\right)$ Based on Anteroposterior Skeletal Pattern $(\mathrm{n}=\mathbf{2 7 9})$.

\begin{tabular}{|c|c|c|c|c|c|c|}
\hline & Mean Minimum CSA $\left(\mathrm{mm}^{2}\right)$ & Standard Deviation & Max $\left(\mathrm{mm}^{2}\right)$ & Min $\left(\mathrm{mm}^{2}\right)$ & \multicolumn{1}{|c|}{} \\
\hline Class I & 135.31 & 61.94 & 327.8 & 14.2 & A & \\
\hline Class II & 114.40 & 54.42 & 273.0 & 26.8 & A & \\
\hline Class III & 144.9 & 62.45 & 319.7 & 12.2 & & B \\
\hline
\end{tabular}

Groups not connected by the same letter are significantly different.

\section{Airway Shape by Anteroposterior Skeletal Pattern}

Table 7 shows the total number and relative percentage of each airway shape attained for the three anteroposterior skeletal patterns (Class I, Class II, and Class III).

Table 7. Contingency Table of Airway Shapes By Anteroposterior Skeletal Patterns $(\mathbf{n}=\mathbf{2 7 9})$.

\begin{tabular}{|l|r|r|r|r|}
\hline Count & Long & Square & Wide & \\
Total \% & & & & \\
Col \% & & & & \\
Row \% & 11 & 15 & 67 & 33.33 \\
\hline Class I & 3.94 & 5.38 & 24.01 & \\
& 44.00 & 31.91 & 32.37 & 93 \\
& 11.83 & 16.13 & 72.04 & 33.33 \\
\hline Class II & 8 & 15 & 70 & \\
& 2.87 & 5.38 & 25.09 & 93 \\
& 32.00 & 31.91 & 33.82 & 33.33 \\
\hline Class III & 8.60 & 16.13 & 75.27 & 70 \\
& 6 & 17 & 25.09 & \\
& 2.15 & 6.09 & 33.82 & \\
& 24.00 & 36.17 & 75.27 & 207 \\
\hline
\end{tabular}

Pearson ${ }^{\text {ec }}$ chi squared test: $\mathrm{df}=4$; chi square $=1.78 ; \mathrm{p}=0.777$

Data were analyzed using a chi square analysis. No associations were found between airway shape and anteroposterior skeletal patterns. 


\section{Airway Volume by Vertical Skeletal Pattern}

Figure 17 and Table 8 show the mean, standard deviation, maximum airway volume attained, and the minimum airway volume attained for the three vertical skeletal patterns (normodivergent, hyperdivergent, and hypodivergent).

Figure 17. Mean Airway Volume (cc) for the Vertical Skeletal Groups (n=279).

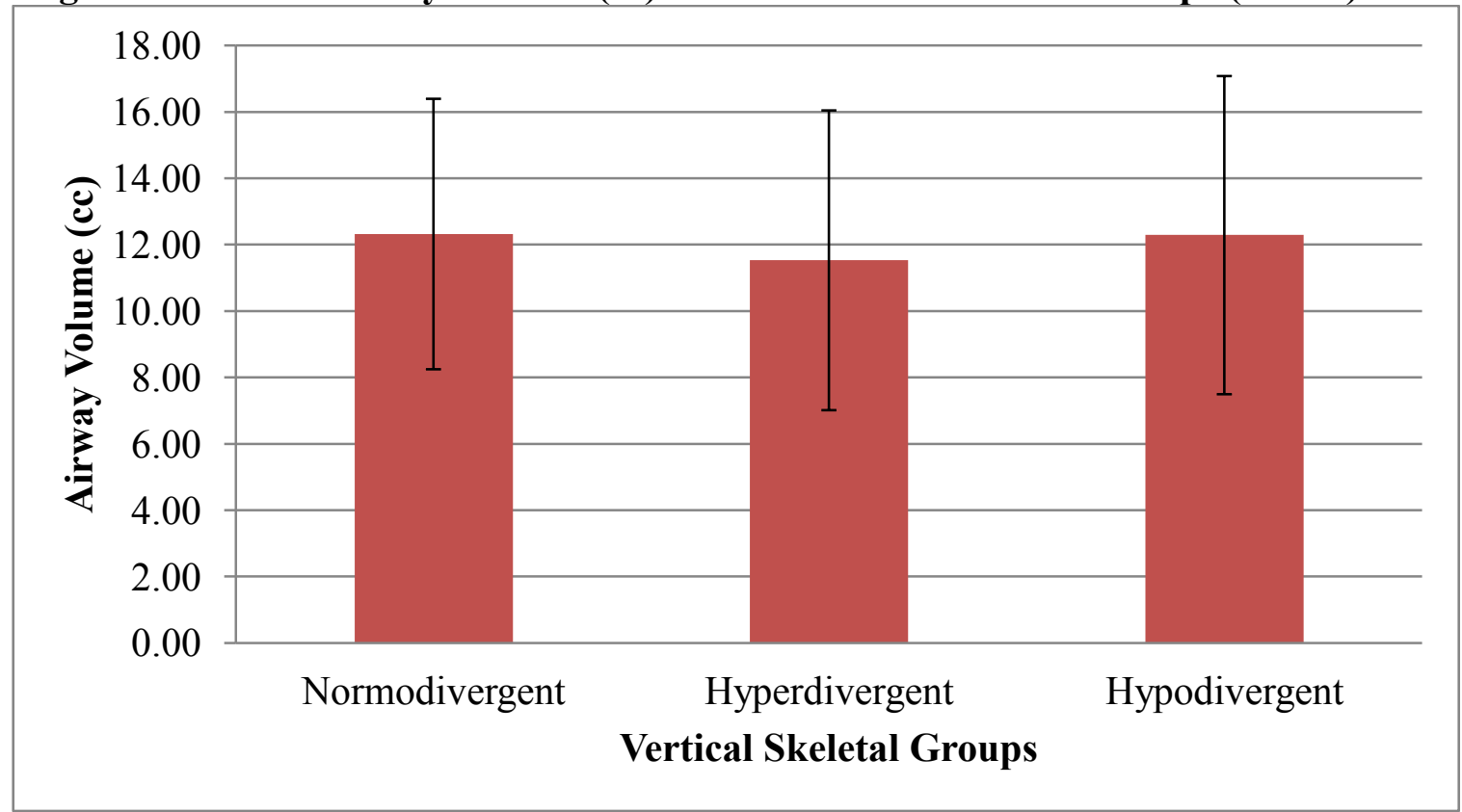

Data were analyzed using a one way analysis of variance and a matched pairs

Tukey-Kramer test. No significant differences were found in the airway volume between vertical skeletal patterns.

Table 8. Airway Volume Based on Vertical Skeletal Pattern $(n=279)$.

\begin{tabular}{|c|c|c|c|c|c|}
\hline & Mean Airway Volume (cc) & Standard Deviation & $\operatorname{Max}(\mathrm{cc})$ & $\operatorname{Min}(\mathrm{cc})$ & \\
\hline Normodivergent & 12.32 & 4.79 & 31.4 & 5.0 & A \\
\hline Hyperdivergent & 11.53 & 4.08 & 26.4 & 4.5 & A \\
\hline Hypodivergent & 12.29 & 4.52 & 27.4 & 4.9 & A \\
\hline
\end{tabular}

Groups not connected by the same letter are significantly different. 


\section{Minimum Cross Sectional Area by Vertical Skeletal Pattern}

Figure 18 and Table 9 show the mean, standard deviation, maximum minimum CSA attained, and the minimum minimum CSA attained for the three vertical skeletal patterns (normodivergent, hyperdivergent, and hypodivergent).

Figure 18. Mean Minimum CSA $\left(\mathrm{mm}^{2}\right)$ for the Vertical Skeletal Groups (n=279).

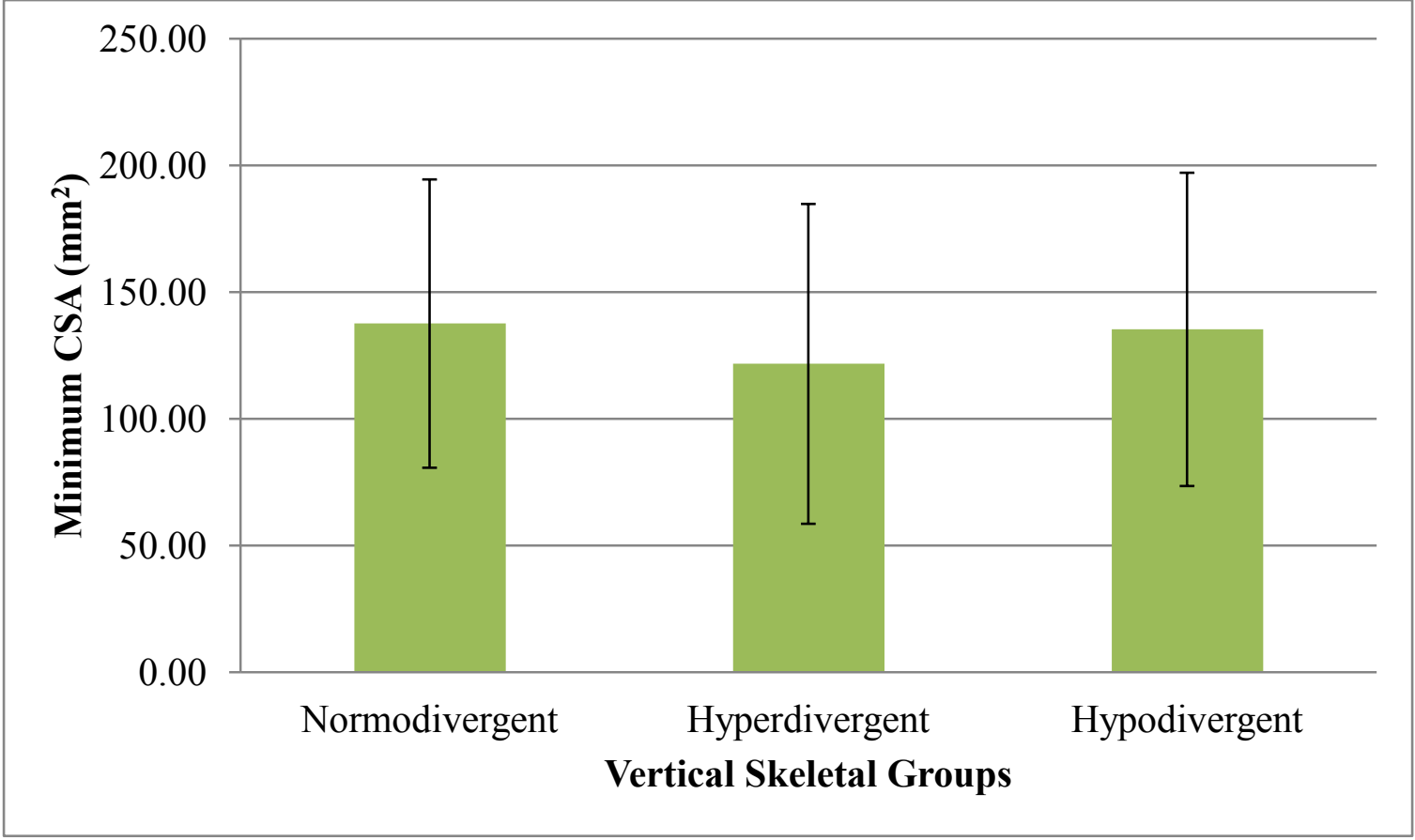

Data were analyzed using a one way analysis of variance and a matched pairs

Tukey-Kramer test. No significant differences were found in the minimum CSA between vertical skeletal patterns.

Table 9. Minimum CSA $\left(\mathrm{mm}^{2}\right)$ Based on Vertical Skeletal Pattern $(\mathrm{n}=\mathbf{2 7 9})$.

\begin{tabular}{|c|c|c|c|c|c|}
\hline & Mean Minimum CSA $\left(\mathrm{mm}^{2}\right)$ & Standard Deviation & Max $\left(\mathrm{mm}^{2}\right)$ & $\operatorname{Min}\left(\mathrm{mm}^{2}\right)$ & \\
\hline Normodivergent & 137.63 & 61.82 & 327.8 & 12.2 & $\mathrm{~A}$ \\
\hline Hyperdivergent & 121.72 & 63.12 & 298.3 & 14.2 & $\mathrm{~A}$ \\
\hline Hypodivergent & 135.34 & 56.89 & 319.7 & 39.1 & $\mathrm{~A}$ \\
\hline
\end{tabular}

Groups not connected by the same letter are significantly different. 


\section{Airway Shape by Vertical Skeletal Pattern}

Table 10 shows the total number and relative percentage of each airway shape attained for the three vertical skeletal patterns (normodivergent, hyperdivergent, and hypodivergent).

Table 10. Contingency Table of Airway Shapes By Vertical Skeletal Patterns $(n=279)$.

\begin{tabular}{|l|l|l|l|l|}
\hline $\begin{array}{l}\text { Count } \\
\text { Total \% } \\
\text { Col \% } \\
\text { Row \% }\end{array}$ & Long & Square & Wide & \\
\hline Hyperdivergent & 11 & 17 & 65 & \\
& 3.94 & 6.09 & 23.30 & 33.33 \\
& 44.00 & 36.17 & 31.40 & \\
& 11.83 & 18.28 & 69.89 & \\
\hline Hypodivergent & 6 & 15 & 72 & 93 \\
& 2.15 & 5.38 & 25.81 & 33.33 \\
& 24.00 & 31.91 & 34.78 & \\
\hline Normodivergent & 6.45 & 16.13 & 77.42 & \\
& 8 & 15 & 70 & 93 \\
& 2.87 & 5.38 & 25.09 & 33.33 \\
\hline & 32.00 & 31.91 & 33.82 & \\
\hline & 8.60 & 16.13 & 75.27 & \\
\hline & 25 & 47 & 207 & 279 \\
\hline
\end{tabular}

Pearson"s chi squared test: $\mathrm{df}=4$; chi square $=2.07 ; \mathrm{p}=0.723$

Data were analyzed using a chi square analysis. Similar to anteroposterior skeletal patterns, no associations were found between airway shape and vertical skeletal patterns.

\section{Airway Volume by Anteroposterior / Vertical Skeletal Subgroups}

Figure 19 and Table 11 show the mean, standard deviation, maximum airway volume attained, and the minimum airway volume attained for the nine subgroups (Class I Normodivergent, Class I Hyperdivergent, Class I Hypodivergent, etc.). 
Figure 19. Mean Airway Volume (cc) for the Subgroups $(n=279)$.

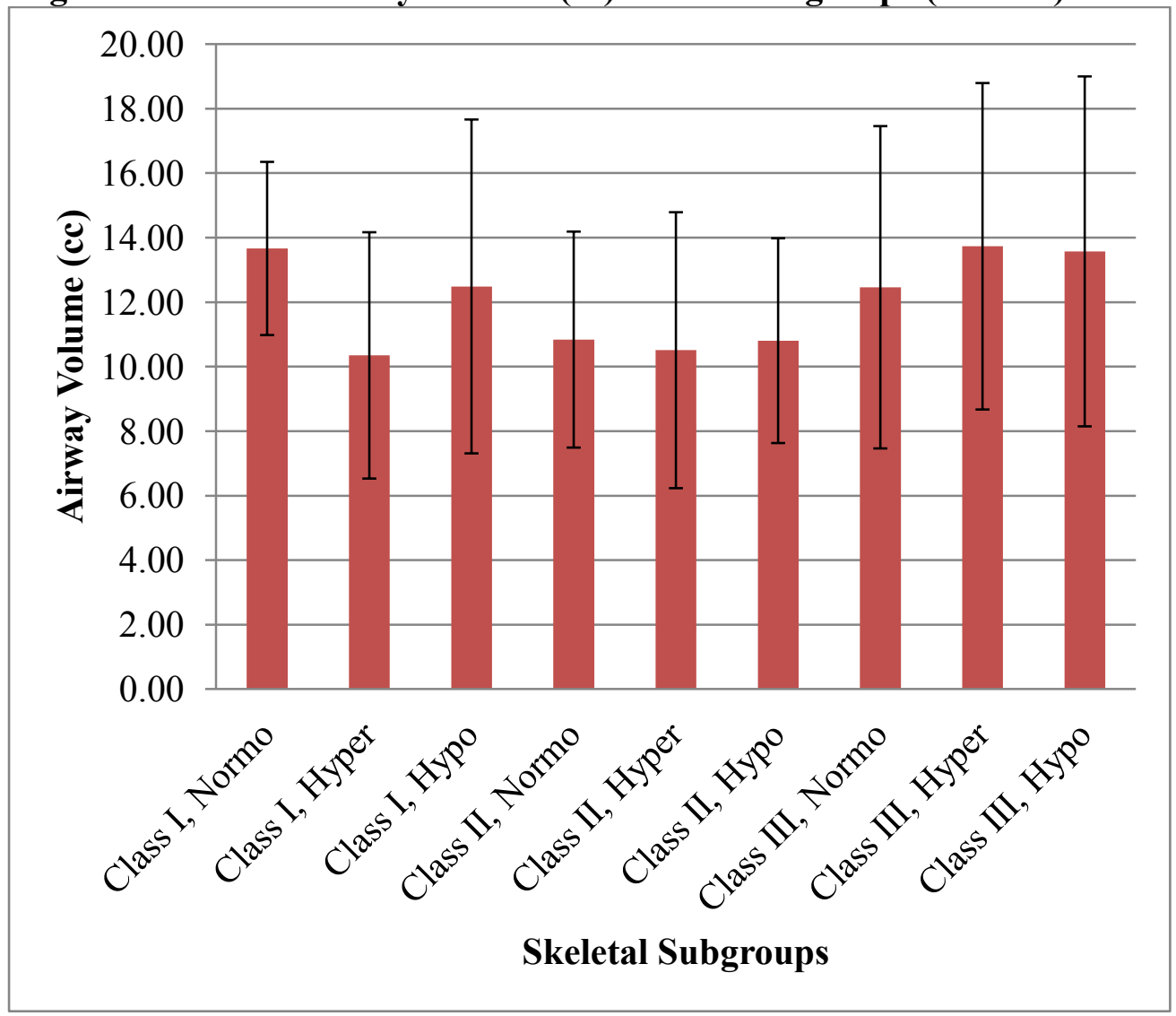

Significant differences are seen in Table 11.

Data were analyzed using a one way analysis of variance and a matched pairs Student $\mathrm{t}$ test. Significant differences are summarized in Table 11.

Table 11. Airway Volume (cc) for the Subgroups $(n=279)$.

\begin{tabular}{|l|c|c|c|c|c|c|}
\hline & Mean Airway Volume (cc) & Standard Deviation & Max (cc) & Min (cc) & & \\
\hline Class I, Normo & 13.67 & 5.18 & 27.1 & 6.0 & $\mathrm{~A}$ & \\
\hline Class I, Hyper & 10.35 & 2.69 & 17.1 & 4.9 & & $\mathrm{~B}$ \\
\hline Class I, Hypo & 12.49 & 3.82 & 19.4 & 5.5 & $\mathrm{~A}$ & $\mathrm{~B}$ \\
\hline Class II, Normo & 10.84 & 3.18 & 26.4 & 5.1 & & $\mathrm{~B}$ \\
\hline Class II, Hyper & 10.51 & 3.35 & 20.6 & 5.8 & & $\mathrm{~B}$ \\
\hline Class II, Hypo & 10.81 & 4.28 & 17.2 & 4.9 & & $\mathrm{~B}$ \\
\hline Class III, Normo & 12.46 & 5.43 & 31.4 & 5.0 & $\mathrm{~A}$ & $\mathrm{~B}$ \\
\hline Class III, Hyper & 13.73 & 5.00 & 26.4 & 4.5 & $\mathrm{~A}$ & \\
\hline Class III, Hypo & 13.57 & 5.06 & 27.4 & 7.5 & $\mathrm{~A}$ & \\
\hline
\end{tabular}

Groups not connected by the same letter are significantly different. 


\section{Minimum Cross Sectional Area by Anteroposterior / Vertical Skeletal Subgroups}

Figure 20 and Table 13 show the mean, standard deviation, maximum airway volume attained, and the minimum airway volume attained for the nine subgroups (Class I Normodivergent, Class I Hyperdivergent, Class I Hypodivergent, etc.).

Figure 20. Mean Minimum CSA $\left(\mathrm{mm}^{2}\right)$ for the Subgroups $(\mathrm{n}=\mathbf{2 7 9})$.

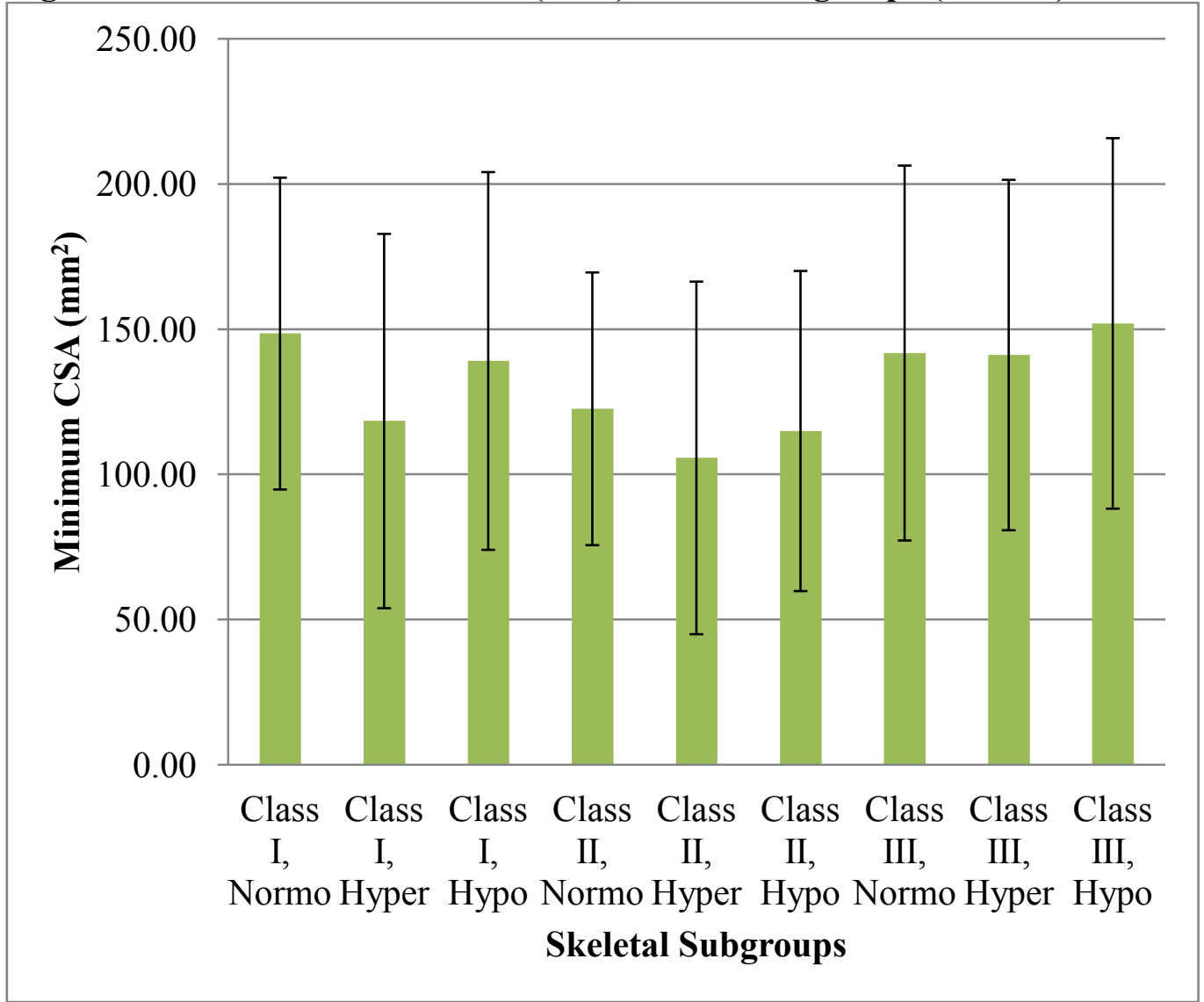

Significant differences are seen in Table 12.

Data were analyzed using a one way analysis of variance and a matched pairs Student $\mathrm{t}$ test. Significant differences are summarized in Table 12. 
Table 12. Minimum CSA $\left(\mathrm{mm}^{2}\right)$ for the Subgroups $(\mathrm{n}=\mathbf{2 7 9})$.

\begin{tabular}{|c|c|c|c|c|c|c|c|}
\hline & Mean Minimum CSA $\left(\mathrm{mm}^{2}\right)$ & Standard Deviation & $\operatorname{Max}(\mathrm{cc})$ & $\operatorname{Min}(\mathrm{cc})$ & & & \\
\hline Class I, Normo & 148.50 & 65.07 & 327.8 & 66.4 & A & & \\
\hline Class I, Hyper & 118.38 & 53.71 & 298.3 & 14.2 & & B & $\mathrm{C}$ \\
\hline Class I, Hypo & 139.07 & 64.47 & 243.4 & 43.5 & A & $\mathrm{B}$ & \\
\hline Class II, Normo & 122.59 & 55.14 & 240.1 & 41.4 & A & $\mathrm{B}$ & $\mathrm{C}$ \\
\hline Class II, Hyper & 105.67 & 46.97 & 273.0 & 26.8 & & $\mathrm{~B}$ & $\mathrm{C}$ \\
\hline Class II, Hypo & 114.94 & 60.72 & 241.2 & 39.1 & & $\mathrm{~B}$ & $\mathrm{C}$ \\
\hline Class III, Normo & 141.80 & 63.81 & 281.5 & 12.2 & $\mathrm{~A}$ & $\mathrm{~B}$ & \\
\hline Class III, Hyper & 141.11 & 64.57 & 319.7 & 31.1 & $\mathrm{~A}$ & $\mathrm{~B}$ & \\
\hline Class III, Hypo & 152.01 & 60.34 & 279.0 & 59.1 & A & & \\
\hline
\end{tabular}

Groups not connected by the same letter are significantly different.

\section{Airway Shape by Anteroposterior / Vertical Skeletal Subgroups}

Table 13 shows the total number and relative percentage of each airway shape attained for the nine subgroups (Class I Normodivergent, Class I Hyperdivergent, Class I Hypodivergent, etc.). 
Table 13. Contingency Table of Airway Shapes By Subgroups $(\mathbf{n}=\mathbf{2 7 9})$.

\begin{tabular}{|c|c|c|c|c|}
\hline $\begin{array}{l}\text { Count } \\
\text { Total \% } \\
\text { Col \% } \\
\text { Row \% }\end{array}$ & Long & Square & Wide & \\
\hline 1hyper & \begin{tabular}{|l}
6 \\
2.15 \\
24.00 \\
19.35 \\
\end{tabular} & \begin{tabular}{|l}
7 \\
2.51 \\
14.89 \\
22.58 \\
\end{tabular} & \begin{tabular}{|l|}
18 \\
6.45 \\
8.70 \\
58.06 \\
\end{tabular} & \begin{tabular}{|l|}
31 \\
11.11
\end{tabular} \\
\hline 1hypo & \begin{tabular}{|l|}
2 \\
0.72 \\
8.00 \\
6.45
\end{tabular} & \begin{tabular}{|l}
5 \\
1.79 \\
10.64 \\
16.13
\end{tabular} & \begin{tabular}{|l|}
24 \\
8.60 \\
11.59 \\
77.42
\end{tabular} & \begin{tabular}{|l}
31 \\
11.11
\end{tabular} \\
\hline 1normo & \begin{tabular}{|l|}
3 \\
1.08 \\
12.00 \\
9.68
\end{tabular} & \begin{tabular}{|l}
3 \\
1.08 \\
6.38 \\
9.68 \\
\end{tabular} & \begin{tabular}{|l}
5 \\
8.96 \\
12.08 \\
80.65 \\
\end{tabular} & \begin{tabular}{|l|}
31 \\
11.11
\end{tabular} \\
\hline 2hyper & \begin{tabular}{|l}
2 \\
0.72 \\
8.00 \\
6.45 \\
\end{tabular} & \begin{tabular}{|l}
5 \\
1.79 \\
10.64 \\
16.13 \\
\end{tabular} & \begin{tabular}{|l|}
4 \\
8.60 \\
11.59 \\
77.42 \\
\end{tabular} & \begin{tabular}{|l|}
31 \\
11.11
\end{tabular} \\
\hline 2hypo & \begin{tabular}{|l|}
4 \\
1.43 \\
16.00 \\
12.90
\end{tabular} & \begin{tabular}{|l|}
5 \\
1.79 \\
10.64 \\
16.13 \\
\end{tabular} & \begin{tabular}{|l|}
22 \\
7.89 \\
10.63 \\
70.97
\end{tabular} & \begin{tabular}{|l|}
31 \\
11.11
\end{tabular} \\
\hline 2normo & \begin{tabular}{|l|}
2 \\
0.72 \\
8.00 \\
6.45 \\
\end{tabular} & \begin{tabular}{|l|}
5 \\
1.79 \\
10.64 \\
16.13 \\
\end{tabular} & \begin{tabular}{|l|}
24 \\
8.60 \\
11.59 \\
77.42 \\
\end{tabular} & \begin{tabular}{|l|}
31 \\
11.11
\end{tabular} \\
\hline 3hyper & \begin{tabular}{|l}
3 \\
1.08 \\
12.00 \\
9.68
\end{tabular} & $\begin{array}{l}5 \\
1.79 \\
10.64 \\
16.13 \\
\end{array}$ & \begin{tabular}{|l|}
3 \\
8.24 \\
11.11 \\
74.19 \\
\end{tabular} & \begin{tabular}{|l|}
31 \\
11.11
\end{tabular} \\
\hline 3hypo & \begin{tabular}{|l|}
0 \\
0.00 \\
0.00 \\
0.00
\end{tabular} & \begin{tabular}{|l}
5 \\
1.79 \\
10.64 \\
16.13
\end{tabular} & \begin{tabular}{|l}
66 \\
9.32 \\
12.56 \\
83.87
\end{tabular} & \begin{tabular}{|l|}
31 \\
11.11
\end{tabular} \\
\hline 3normo & \begin{tabular}{|l}
3 \\
1.08 \\
12.00 \\
9.68
\end{tabular} & \begin{tabular}{|l}
7 \\
2.51 \\
14.89 \\
22.58
\end{tabular} & \begin{tabular}{|l|}
1 \\
7.53 \\
10.14 \\
67.74
\end{tabular} & \begin{tabular}{|l|}
31 \\
11.11
\end{tabular} \\
\hline & \begin{tabular}{|l|}
25 \\
8.96 \\
\end{tabular} & \begin{tabular}{|l}
47 \\
16.85 \\
\end{tabular} & \begin{tabular}{|l|}
207 \\
74.19
\end{tabular} & 279 \\
\hline
\end{tabular}

Pearson "s chi squared test: $\mathrm{df}=16$; chi square $=11.97 ; \mathrm{p}=0.746$ 
Data were analyzed using a chi square analysis. No associations were found between airway shape and the subgroups.

\section{Airway Volume by Airway Shape}

Figure 21 and Table 14 show the mean, standard deviation, maximum airway volume attained, and the minimum airway volume attained for the three airway shapes (Wide, Long and Square).

Figure 21. Mean Airway Volume (cc) for the Airway Shape Groups (n=279).

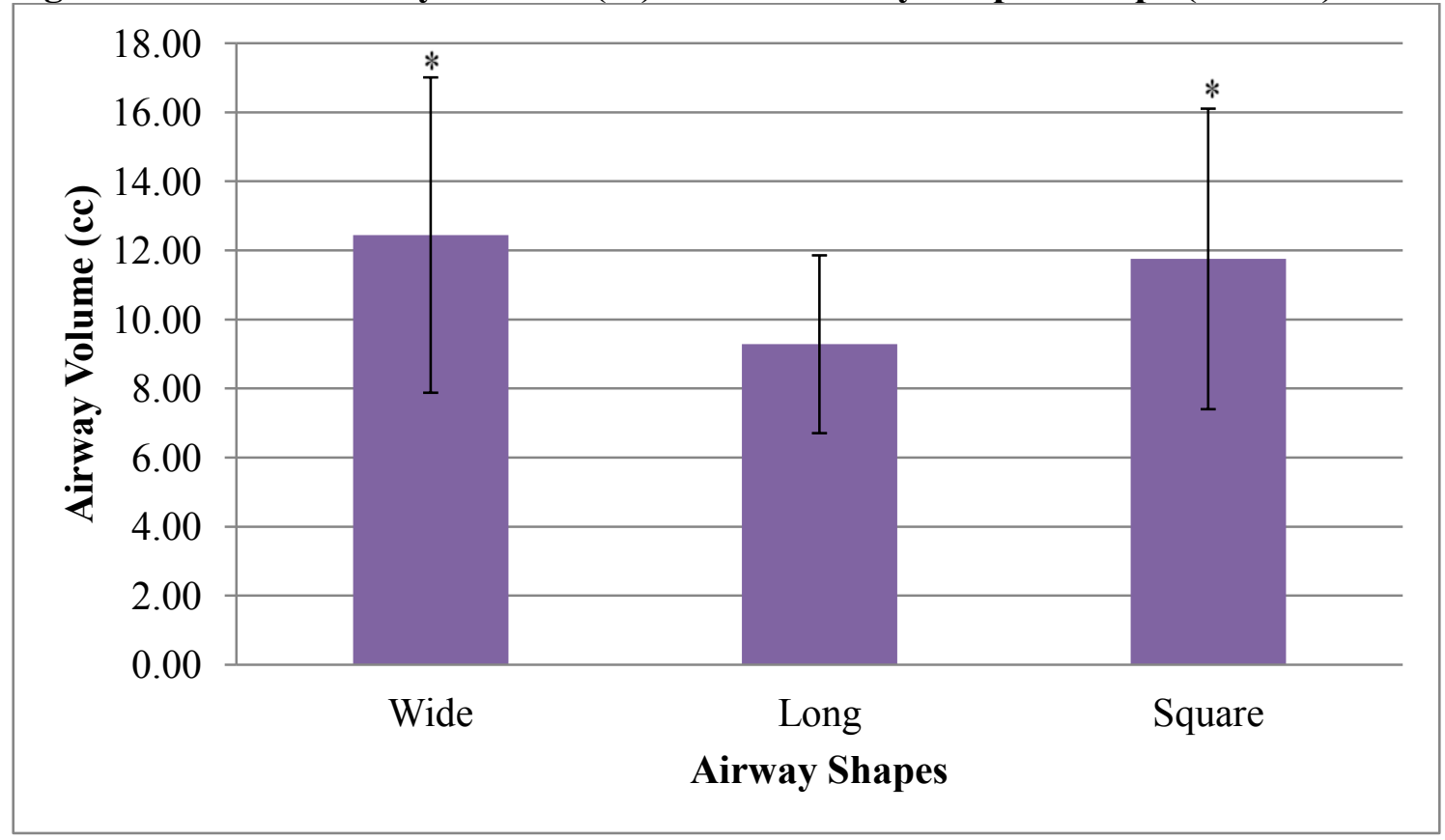

* = Significantly different from Long at $\mathrm{p}<0.01$

Data were analyzed using a one way analysis of variance and a matched pairs Student $t$ test. Significant differences were found in the airway volume between wide and long airway shapes and between square and long airway shapes with a $p<0.01$. No significant differences were found in the airway volume between wide and square airway shapes. 
Table 14. Airway Volume (cc) Based on Airway Shape Only $(n=279)$.

\begin{tabular}{|c|c|c|c|c|c|c|}
\hline & Mean Airway Volume (cc) & Standard Deviation & Max (cc) & Min (cc) & & \\
\hline Wide & 12.45 & 4.57 & 31.4 & 4.5 & $\mathrm{~A}$ & \\
\hline Square & 11.76 & 4.35 & 27.4 & 5.0 & $\mathrm{~A}$ & \\
\hline Long & 9.28 & 2.58 & 14.2 & 4.9 & & $\mathrm{~B}$ \\
\hline
\end{tabular}

Groups not connected by the same letter are significantly different.

\section{Minimum Cross Sectional Area by Airway Shape}

Figure 22 and Table 15 show the mean, standard deviation, maximum minimum CSA attained, and the minimum minimum CSA attained for the three airway shapes (Wide, Long and Square).

Figure 22. Mean Minimum CSA $\left(\mathrm{mm}^{2}\right)$ by Airway Shape.

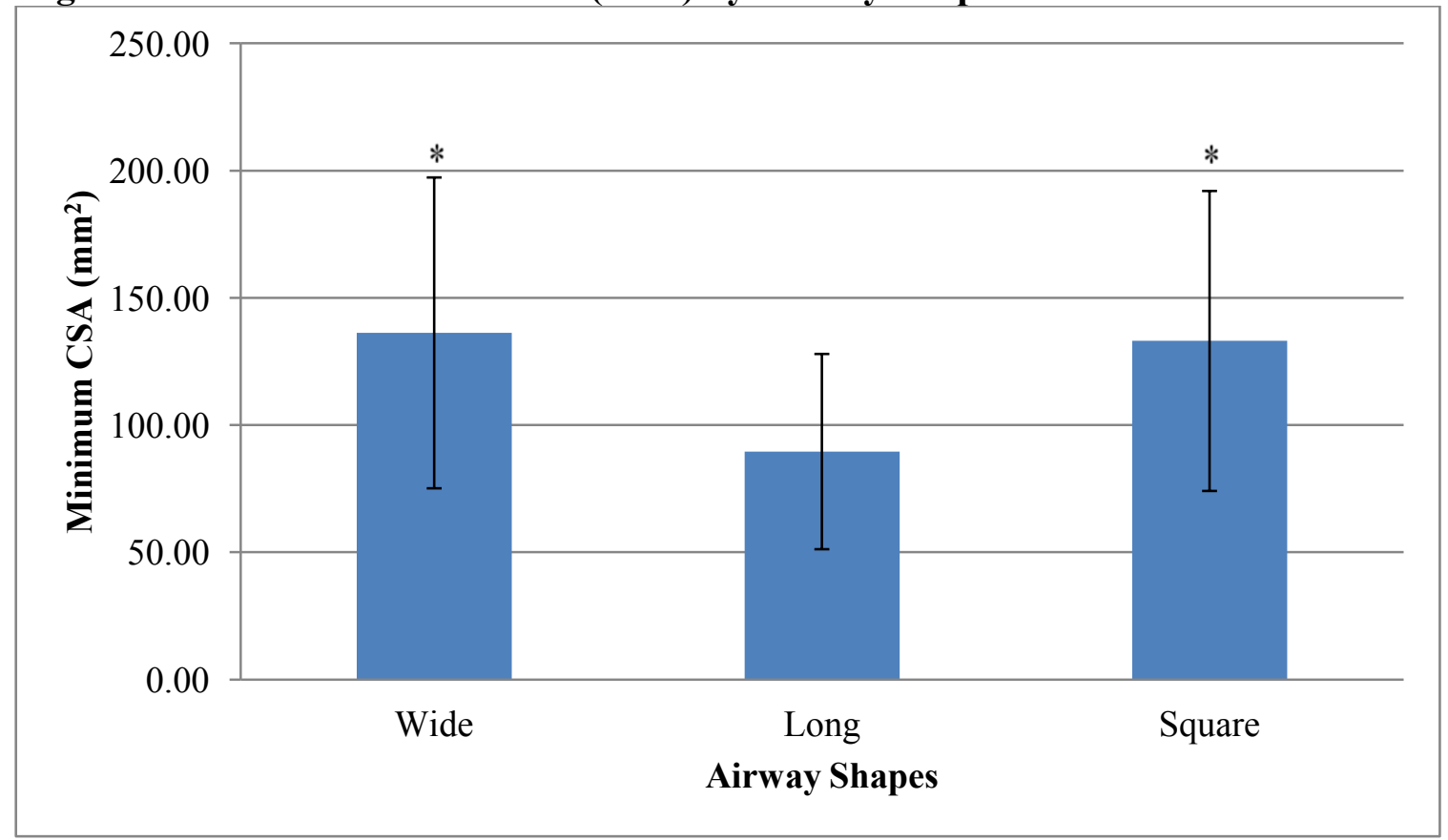

$*=$ Significantly different from Long at $\mathrm{p}<0.01$

Data were analyzed using a one way analysis of variance and a matched pairs Tukey-Kramer test. Significant difference were found in minimum CSA between wide 
and long airway shapes and between square and long airway shapes with a $p<0.01$. No significant differences were found in minimum CSA between wide and square airway shapes.

Table 15. Minimum CSA $\left(\mathrm{mm}^{2}\right)$ Based on Airway Shape Only $(\mathrm{n}=\mathbf{2 7 9})$.

\begin{tabular}{|c|c|c|c|c|c|c|}
\hline & Mean Minimum CSA $\left(\mathrm{mm}^{2}\right)$ & Standard Deviation & Max $\left(\mathrm{mm}^{2}\right)$ & \multicolumn{2}{|l|}{ Min $\left(\mathrm{mm}^{2}\right)$} & \multicolumn{2}{|c|}{} \\
\hline Wide & 136.28 & 61.76 & 327.8 & 12.2 & A & \\
\hline Square & 133.10 & 58.94 & 279.0 & 39.1 & A & \\
\hline Long & 89.63 & 38.37 & 174.6 & 14.2 & & B \\
\hline
\end{tabular}

Groups not connected by the same letter are significantly different.

\section{Airway Volume by Minimum Cross Sectional Area}

Figure 23 shows a bivariate fit of airway volume by minimum CSA. The analysis shows minimum CSA is an increasing function of airway volume. As airway volume increases by one cc, CSA increases by $10.23 \mathrm{~mm}^{2}$. 
Figure 23. Bivariate Fit of Airway Volume by Minimum CSA.

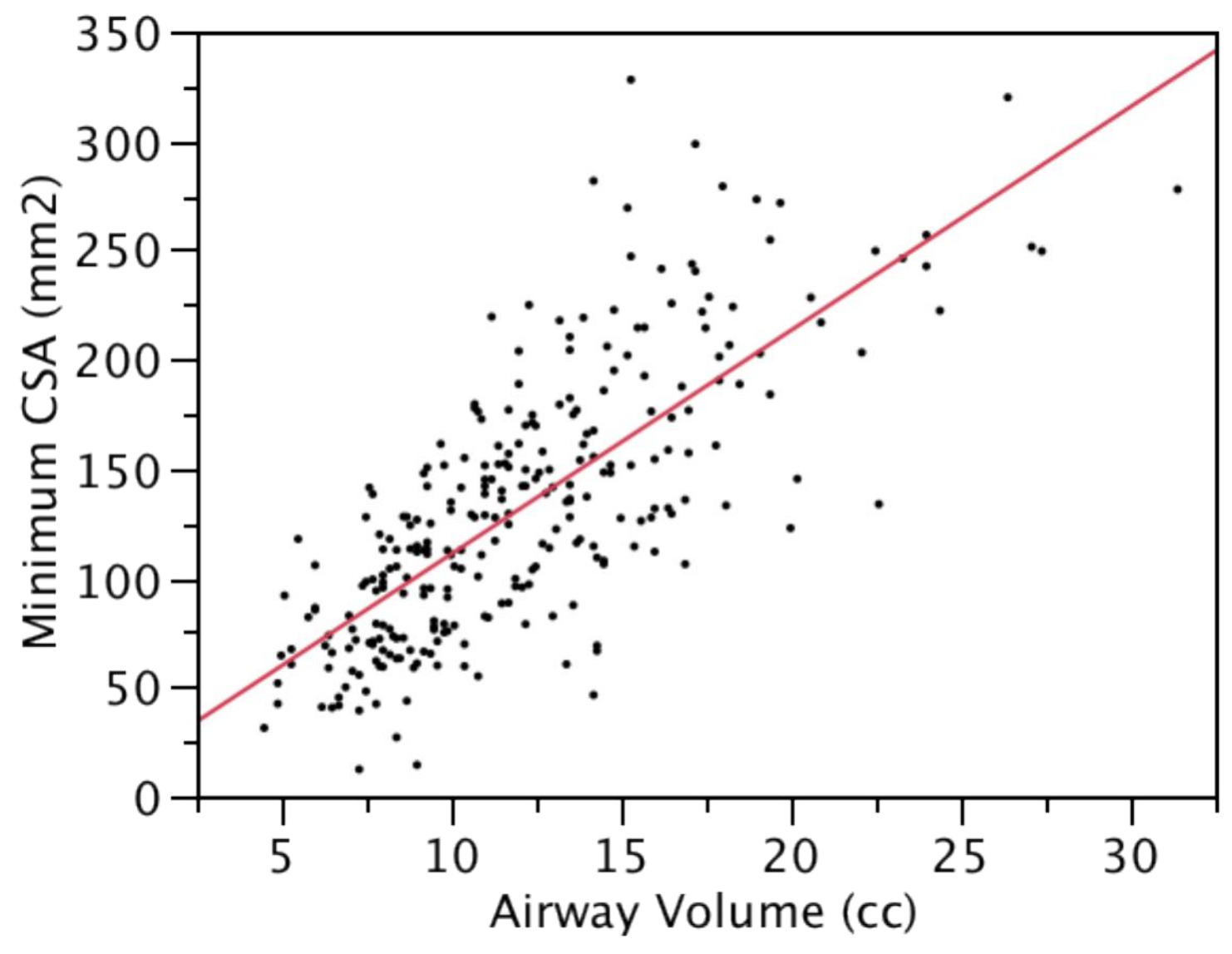

Minimum CSA $\left(\mathrm{mm}^{2}\right)=8.2883169+10.232888 *$ Airway Volume $(\mathrm{cc})$

\section{Reliability of Measurements}

Because one examiner conducted all measurement in this study, a reliability test of measurements was necessary. This test was performed to determine the repeatability of the measures made for the variables in this study. A random sample of ten subjects had the data collection process repeated two weeks after the first assessment. The results displayed a reliability coefficient of 0.99 for both airway volume and minimum CSA in this study. Therefore, the data collected is considered reliable and consistent. 


\section{CHAPTER 5: DISCUSSION}

\section{Introduction}

The purpose of this study was to investigate upper airway dimensions with CBCT to help establish some characteristics of the oropharyngeal airway in adults with all types of malocclusions. For many years, upper airway shape has been of interest because of its connection to obstructive sleep apnea. As such, studies have been conducted both on children and adults evaluating anatomy, flow mechanics, and ventilation utilizing cephalometry, acoustic reflection, and magnetic resonance imaging. ${ }^{45,59,60}$ However, most of the studies were conducted using 2-Dimensional radiography. Information can be lost when 3-Dimensional structures are taken and interpreted using 2-Dimensional images. Aboudara et al. compared the airway volume and area using conventional lateral cephalograms and computed tomography (CT). ${ }^{9}$ The results confirmed much greater individual variability using 2-Dimensional radiographs.

Gender differences were not analyzed in this study because all subjects were adults. Abu Allhaija et al. found no sex differences in pharyngeal dimension among Class I, Class II, and Class III groups. ${ }^{61}$ Results are based on adolescents ages fourteen to seventeen.

\section{Methods and Materials}

As previously mentioned, the purpose of this study was to investigate upper airway dimensions among different skeletal patterns by using cone-beam computed tomography (CBCT). Anteroposterior and vertical skeletal patterns were evaluated both individually and together to determine if the aforementioned effected airway volume, 
minimum cross sectional area (CSA), and airway shape. A total of 279 DICOM files were analyzed in this study using Dolphin imaging 10.5 Premium licensed to West Virginia University School of Dentistry Department of Orthodontics. The subjects were divided into three anteroposterior groups (Class I, Class II, and Class III) with a sample size of ninety-three subjects per group. Subjects were also categorized into three vertical groups (Normodivergent, Hyperdivergent, and Hypodivergent) with a sample size of ninety-three subjects per group. The groups were then subdivided into nine subgroups (Class I Hyperdivergent, Class I Normodivergent, Class I Hypodivergent, etc.) with a sample size of thirty-one patients per subgroup. Airway volume, minimum cross sectional area (CSA), and airway shape were calculated for each subject using Anatomage InVivoDental ${ }^{\mathrm{TM}}$ software version 5.1 licensed to West Virginia University School of Dentistry Department of Orthodontics.

Selection criteria were limited for this research project. The study was limited to subjects in the database at Advanced Dental Imaging on the campus of University of Nevada Las Vegas School of Dentistry. Skeletal ages of the patients comprising the sample were adult patients with a CVM value greater than CVM -4 . The study was limited to 3D cone-beam computed tomography scans on subject"s pre - orthodontic treatment. Most importantly, a good quality DICOM file image was necessary for assessment. Unfortunately the DICOM files from the University of Nevada Las Vegas School of Dentistry did not contain some valuable information. For example, there may have been gender, ethnicity, and medical history differences among the subjects that could not be determined. A total of 1200 DICOM files were analyzed for this study. However, using the above selection criteria, only 279 files were acceptable for analysis. 


\section{Variability of the Sample}

All analyses in this study show a large standard deviation which illustrates a large sampling variability. The large variability is likely due to inherit differences among the sample subjects. For example, not all patients in this study were the same weight, height, or body mass. Additionally, varying degrees of soft tissue thickness (adenoids and tonsils) can change airway dimension measurements. Patients were not excluded from this study solely based on enlarged soft tissues and may have resulted in the large range of airway dimensions seen in this study.

Another cause of sampling variability may be attributed to sample classification. For example, all patients determined to have an ANB angle $>5^{\circ}$ were placed in the group “Class II". However, not all Class II patients have the same relative jaw positions. One may have a retrognathic maxilla with an even greater retrognathic mandible while another may have a normal maxilla with a retrognathic mandible. Both would still be classified as "Class II" but could have very different airway dimensions. Although variability was high, the sample size was adequate and significant differences among the groups and subgroups could be found.

\section{Airway Volume by Anteroposterior Skeletal Pattern}

When assessing airway volume, this study found no significant difference between skeletal Class I and III patients. This is consistent with the results reported by Iwasaki et al. ${ }^{2}$ Although not statistically different, this study did find a tendency for Class III patients to have slightly larger airway volumes than Class I patients. Hong et al. found similar results with the upper part of the pharyngeal space being greater in patients 
with skeletal Class III malocculsions. ${ }^{62}$ They believe the larger airway volume found in Class III patients is due to forward positioning of the mandible.

The present study also found a significant difference between Class II and III patients. Class II patients had smaller airway volumes than Class III patients. This is

consistent with the results reported by Oh et al. ${ }^{63}$ Balteres suggests that this may be due to tongue position. ${ }^{64}$ Class II malocclusions are a consequence of a backward position of the tongue, disturbing the cervical region. If all hard and soft tissues are in a backward position, one can conclude that the oropharyngeal area is small and may result in functional impediment of the airway.

\section{Minimum Cross Sectional Area by Anteroposterior Skeletal Pattern}

This study found a significant difference in minimum CSA between skeletal Class I and Class II patients and between skeletal Class II and Class III patients. Class II patients have a significantly smaller minimum CSA than either Class I or Class III patients. One would expect this result since the present study found minimum CSA is an increasing function of airway volume. Because airway volume is smallest in Class II patients, one would also find minimum CSA smallest in Class II patients.

\section{Airway Shape by Anteroposterior Skeletal Pattern}

When assessing airway shape, this study found no association among the three airway shapes and anteroposterior skeletal pattern. This too is not consistent with Iwasaki et al. which found $84 \%$ of the Class I subjects had square shaped airways while $55 \%$ of Class III subjects had wide shaped airways. ${ }^{2}$ The two were compared and found 
to be significantly different.

It is possible that the difference is due to age of the sample subjects. Jeans et al. reported that the nasopharyngeal airway area increases rapidly until thirteen years of age, and after this period the growth slows down. ${ }^{65}$ Iwasakie $^{\text {e }}$ study was primarily conducted on children seven to nine years of age while this studyees sample was only on adult patients only when airway growth is likely complete. Therefore, the results in this study are probably more consistent and reliable than those where growth may still be a factor.

\section{Airway Volume by Vertical Skeletal Pattern}

The present study found no significant differences in mean airway volume among the three vertical skeletal patterns. However, there is a tendency for patients with hyperdivergent skeletal patterns to have slightly smaller airway volumes than those with normodivergent or hypodivergent skeletal patterns. Joseph et al. reported that the nasopharyngeal airway in hyperdivergent individuals was significantly narrower than in normodivergent individuals. ${ }^{10}$ The relationship between the upper airway volume and the vertical facial pattern may be a result of deficient development of the craniomaxillary complex. Hou et al. suggested that normal-weight obstructive sleep apnea (OSA) patients had a significantly shorter anterior cranial base and maxillary length. ${ }^{66}$ Paoli et al. had found that patients with OSA and a body mass index of 30 had a shorter anterior floor of cranial base. ${ }^{67}$ In their study, the analysis of the craniofacial skeleton demonstrated that the deficient development of the craniomaxillary complex caused the decrease in the upper airway dimensions in hyperdivergent patients. 


\section{Minimum CSA by Vertical Skeletal Pattern}

The present study found no significant difference in mean minimum CSA among the three vertical skeletal patterns. However, patients with hyperdivergent skeletal patterns seem to have slightly smaller airways than those with normodivergent or hypodivergent skeletal patterns. This is consistent with the analysis above comparing airway volume to vertical skeletal pattern.

Currently, no other study has been found comparing mean minimum CSA to vertical skeletal pattern alone. Joseph et al. conducted a cephalometric comparative study of the soft tissue airway dimensions in persons with hyperdivergent and normodivergent facial patterns. ${ }^{10}$ However, this study was conducted using 2-Dimensional lateral cephalometry. They found Class II patients have a narrower anteroposterior pharyngeal dimension when compared to Class I patients. They also found Class II Div 1 patients can have a narrower upper airway dimension without having retrognathia.

\section{Airway Shape by Vertical Skeletal Pattern}

The present study found no association between airway shape and vertical growth pattern. Although no association could be found in either case, one can draw some conclusions from the raw data. The majority of patients, independent of skeletal pattern, tend to have wide airways while the least common airway shape appears to be long. The following figure illustrates the percentage of each airway shape irrespective of skeletal pattern. 
Figure 24. Percentage of each Airway Shape Irrespective of Skeletal Pattern.

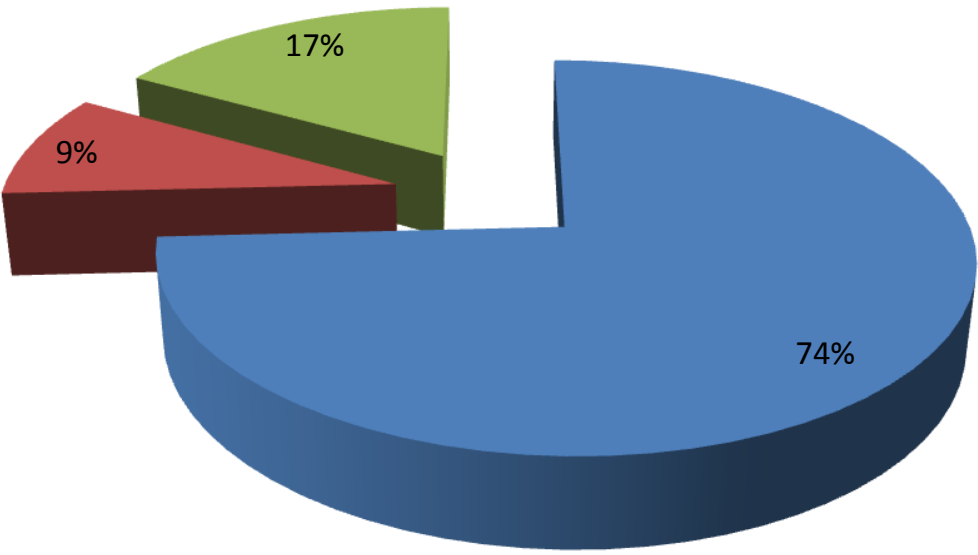

Wide

Long

Square

Again, no other study has been found comparing airway shape to vertical skeletal pattern alone.

\section{Airway Volume by Anteroposterior / Vertical Skeletal Subgroups}

Twelve of thirty-six possible comparison of subgroups were found to have significant differences. Although the generalization is not true for all cases, it appears that subjects with both a hyperdivergent skeletal pattern and/or a Class II skeletal pattern have the smallest airway volumes while those with a normodivergent or hypodivergent skeletal pattern and/or a Class I or Class III skeletal pattern have larger airway volumes. As stated above, Balter's suggests that the Class II skeletal pattern is due to a retruded tongue position resulting in a small oropharyngeal area. Paoli et al. suggests that the hyperdivergent skeletal pattern is a result of deficient development of the craniomaxillary complex which ultimately causes a decrease in the upper airway dimensions. When 
evaluating both anteroposterior and vertical skeletal patterns, both of the aforementioned reasons are likely causes of results seen in this study.

\section{Minimum Cross Sectional Area by Anteroposterior / Vertical Skeletal Subgroups}

Ten of thirty-six possible comparison of subgroups were found to have significant differences. Again, although the generalization is not true for all cases, it appears that subjects with both a hyperdivergent skeletal pattern and/or a Class II skeletal pattern have the smallest minimum CSA values while those with a normodivergent or hypodivergent skeletal pattern and/or a Class I or Class III skeletal pattern have larger minimum CSA values. This is consistent with the analysis above comparing airway volume to anteroposterior and vertical skeletal patterns.

This study found a correction between airway volume and minimum CSA. As airway volume increases by one cc, CSA increases by $10.23 \mathrm{~mm}^{2}$. This suggests the two variables are interdependent. Therefore, when evaluating both anteroposterior and vertical skeletal patterns, both of the reasons listed in the previous section are likely causes of results seen in this study.

\section{Airway Shape by Anteroposterior / Vertical Skeletal Subgroups}

The studies found no association between airway shape and the subgroups. This result was expected since no association was found between airway shape and anteroposterior skeletal patterns alone or between airway shape and vertical skeletal patterns alone. If both groups have no association with airway shape, subdividing the groups and conducting the same analysis should give the same results. As such, no 
association between airway shape and the subgroups could be found.

\section{Airway Volume by Airway Shape}

Significant differences in airway volume were found between wide and long airway shapes and between square and long airway shapes. However, no significant differences in airway volume were found between wide and square airway shapes. Although no significant differences were found between the aforementioned groups, a trend can be seen when evaluating the data. Patients with wide or square airway shapes tend to have the largest airway volumes while patients with long airway shapes tend to have the smallest airway volumes. Iwasaki et al. found patients with wide shaped airways have a lower tongue position, leaving space below the palate. ${ }^{2}$ This is consistent with the results found in this study which show wide shaped airways do have more space below the palate which results in larger airway volumes. Iwasaki also states that higher tongue positions against the palate are seen in long shaped airways. This too is consistent with the results found in this study where long shaped airways have the smallest airway volumes.

\section{Minimum Cross Sectional Area by Airway Shape}

Significant differences in minimum CSA were found between wide and long airway shapes and between square and long airway shapes. No significant differences in minimum CSA were found between wide and square airway shapes. Like airway volume, a trend can be seen when evaluating the above data. Patients with both wide and square airway shapes have a larger minimum CSA when compared to those that have a 
long airway shapes. This is consistent with the analysis above comparing airway volume to airway shape. As previously stated, this study found a correlation between airway volume and minimum CSA. Therefore, when evaluating minimum CSA, one would expect a similar result to airway volume because the two are interdependent.

\section{Airway Volume by Minimum Cross Sectional Area}

Minimum CSA was found to be an increasing function of airway volume. As airway volume increases by one cc, CSA increases by $10.23 \mathrm{~mm}^{2}$. This suggests the two variables are interdependent and may explain why Class III patients have both a larger airway volume and a minimum CSA than Class II patients. Currently, no other study has been found to compare these variables. 


\section{CHAPTER 6: SUMMARY AND CONCLUSIONS}

\section{Summary}

The purpose of this study was to investigate upper airway dimensions among different skeletal malocclusions by using cone-beam computed tomography (CBCT). Anteroposterior and vertical skeletal patterns were evaluated both individually and together to determine if the aforementioned patterns had an effect on airway volume, minimum cross sectional area (CSA), and airway shape.

This study was in collaboration with Dr. James Mah, Associate Clinical Professor at the University of Nevada Las Vegas School of Dentistry. The DICOM files used in this study were taken at an imaging center, Advanced Dental Imaging, and were donated for this study with the intent for research. A total of 279 subjects were divided into three groups according to ANB angle (Class I, II, or III). Group I subjects were patients determined to have a normal skeletal pattern (Class I) with an ANB angle range $0^{\circ}-5^{\circ}$. Group II subjects were patients determined to have a Class II skeletal pattern with an ANB angle $>5^{\circ}$. Group III subjects were patients determined to have a Class III skeletal pattern with an ANB angle $<0^{\circ}$. The vertical dimension was then recorded for each patient by assessing Frankfort Horizontal - Mandibular Plane angle. Patients with mandibular plane angle (FH/MP) of $22^{\circ}$ to $30^{\circ}$ were classified as normodivergent. Patients with mandibular plane angle $>30^{\circ}$ were classified as hyperdivergent and patients with mandibular plane angle $<22^{\circ}$ were classified as hypodivergent. The subjects were then subdivided into nine groups based on both anteroposterior and vertical skeletal patterns.

Airway volume, minimum cross sectional area (CSA), and airway shape were 
calculated for each subject. Statistical tests were then used to determine if there were any significant differences. Based on the results discussed in Chapter IV, the following null hypotheses are able to be accepted:

1. There is no significant difference in airway shape among the three anteroposterior groups (Class I, Class II, and Class III) of untreated adult orthodontic patients.

2. There is no significant difference in airway volume among the three vertical groups (normodivergent, hyperdivergent, and hypodivergent) of untreated adult orthodontic patients.

3. There is no significant difference in minimum CSA among the three vertical groups (normodivergent, hyperdivergent, and hypodivergent) of untreated adult orthodontic patients.

4. There is no significant difference in airway shape among the three vertical groups (normodivergent, hyperdivergent, and hypodivergent) of untreated adult orthodontic patients.

5. There is no significant difference in airway shape among the nine anteroposterior / vertical subgroups (Class I normodivergent, Class I hyperdivergent, Class I hypodivergent, etc.) of untreated adult orthodontic patients.

The following null hypotheses are able to be rejected:

1. There is no significant difference in airway volume among the three anteroposterior groups (Class I, Class II, and Class III) of untreated adult orthodontic patients.

2. There is no significant difference in minimum cross sectional area (CSA) among 
the three anteroposterior groups (Class I, Class II, and Class III) of untreated adult orthodontic patients.

3. There is no significant difference in airway volume among the nine anteroposterior / vertical subgroups (Class I normodivergent, Class I hyperdivergent, Class I hypodivergent, etc.) of untreated adult orthodontic patients.

4. There is no significant difference in minimum CSA among the nine anteroposterior / vertical subgroups (Class I normodivergent, Class I hyperdivergent, Class I hypodivergent, etc.) of untreated adult orthodontic patients.

5. There is no significant difference in airway volume in differently observed airway shapes (wide, long, and square) in untreated adult orthodontic patients.

6. There is no significant difference in minimum CSA in differently observed airway shapes (wide, long, and square) in untreated adult orthodontic patients.

7. There is no correlation in airway volume and minimum cross sectional area (CSA) in untreated adult orthodontic patients.

\section{Conclusions}

Results from this study lead to the following conclusions.

1. Class III patients have the largest airways while Class II patients have the smallest airways.

2. No difference in airway volume exists between Class I and Class III patients as well as Class I and Class II patients. 
3. No difference in minimum cross sectional area exists between Class I and Class III patients as well as Class II and Class III patients.

4. There is no association between airway shape and anteroposterior and/or vertical skeletal patterns.

5. No difference in airway volume or mean minimum cross sectional area exists among normodivergent, hyperdivergent, and hypodivergent patients.

6. When evaluating a patient"s anteroposterior and vertical skeletal patterns, there is a significant difference in airway volume and mean minimum cross sectional area in some differently observed skeletal patterns in untreated adult orthodontic patients. It appears that subjects with both a hyperdivergent skeletal pattern and/or a Class II skeletal pattern have the smallest airways while those with a normodivergent or hypodivergent skeletal patterns and/or a Class I or Class III skeletal patterns have larger airways.

7. Wide airway shapes have the largest airways while long airway shapes have the smallest airways.

8. Minimum CSA is an increasing function of airway volume. As airway volume increases by one cc, CSA increases by $10.23 \mathrm{~mm}^{2}$.

\section{Clinical Implications}

This study explicitly illustrates airway dimensions are affected by both anteroposterior and vertical skeletal patterns. Patients with both a hyperdivergent and a Class II skeletal pattern have the smallest airways and are more likely to develop obstructive sleep apnea than those patients with a normodivergent or hypodivergent 
skeletal pattern and a Class I or Class III skeletal pattern. When designing treatment for patients with obstructive sleep apnea, this research implies the treatment modality should be designed so the mandible does not rotate down and backward. This would make the patient more hyperdivergent thus reducing airway size all the more. 


\section{CHAPTER 7: RECOMMENDATIONS FOR FUTURE RESEARCH}

Only by understanding true airway dimensions and their variations among patients with different skeletal patterns can better treatment modalities be achieved for patients diagnosed with obstructive sleep apnea. Future research can repeat this study to determine if gender, ethnicity, or age result in different outcomes. One can also repeat this study utilizing a true horizontal plane instead of Frankfort Horizontal Plane due the varibliity of this plane.

Ideally, a future investigation could repeat this study on patients diagnosed with obstructive sleep apnea and determine whether the differences observed are similar to this study. However, medical ethics would prevent unnecessarily exposing untreated subjects to a higher dose of radiation from a CBCT machine strictly for research purposes. This is especially important to recognize in the establishment of a control. Perhaps in the future, non-ionizing radiation technologies (e.g. Magnetic Resonance Imaging) will become more practical and inexpensive in the three-dimensional dental research arena. 


\section{REFERENCES}

1. Ciscar MA, Juan G, Martinez V, Ramon M, Lloret T, Minguez J, Armengot M, Marin $\mathrm{J}$, Basterra J. Magnetic resonance imaging of the pharynx in OSA patients and healthy subjects. Eur Respir J 2001 Jan;17(1):79-86.

2. Iwasaki T, Hayasaki H, Takemoto Y, Kanomi R, Yamasaki Y. Oropharyngeal airway in children with class III malocclusion evaluated by cone-beam computed tomography. Am J Orthod Dentofacial Orthop 2009 Sep;136(3):318.e1,9; discussion 318-9.

3. O'Brien LM, Holbrook CR, Mervis CB, Klaus CJ, Bruner JL, Raffield TJ, Rutherford J, Mehl RC, Wang M, Tuell A, et al. Sleep and neurobehavioral characteristics of 5to 7-year-old children with parentally reported symptoms of attentiondeficit/hyperactivity disorder. Pediatrics 2003 Mar;111(3):554-63.

4. Rosen CL. Obstructive sleep apnea syndrome in children: Controversies in diagnosis and treatment. Pediatr Clin North Am 2004 Feb;51(1):153,67, vii.

5. Bacon WH, Krieger J, Turlot JC, Stierle JL. Craniofacial characteristics in patients with obstructive sleep apneas syndrome. Cleft Palate J 1988 Oct;25(4):374-8.

6. Battagel JM, L'Estrange PR. The cephalometric morphology of patients with obstructive sleep apnoea (OSA). Eur J Orthod 1996 Dec;18(6):557-69.

7. Hui DS, Ko FW, Chu AS, Fok JP, Chan MC, Li TS, Choy DK, Lai CK, Ahuja A, Ching AS. Cephalometric assessment of craniofacial morphology in chinese patients with obstructive sleep apnoea. Respir Med 2003 Jun;97(6):640-6.

8. Lowe AA, Santamaria JD, Fleetham JA, Price C. Facial morphology and obstructive sleep apnea. Am J Orthod Dentofacial Orthop 1986 Dec;90(6):484-91.

9. McCrillis J, Haskell J, Haskell B, Brammer M, Chenin D, Scarfe W, Farman A. Obstructive sleep apnea and the use of cone beam computed tomography in airway imaging: A review. Seminars in Orthodontics 2009;15(1):63-9.

10. Joseph AA, Elbaum J, Cisneros GJ, Eisig SB. A cephalometric comparative study of the soft tissue airway dimensions in persons with hyperdivergent and normodivergent facial patterns. J Oral Maxillofac Surg 1998 Feb;56(2):135,9; discussion 139-40.

11. Kirjavainen M, Kirjavainen T. Upper airway dimensions in class II malocclusion. effects of headgear treatment. Angle Orthod 2007 Nov;77(6):1046-53.

12. de Freitas MR, Alcazar NM, Janson G, de Freitas KM, Henriques JF. Upper and lower pharyngeal airways in subjects with class I and class II malocclusions and 
different growth patterns. Am J Orthod Dentofacial Orthop 2006 Dec;130(6):742-5.

13. Samman N, Mohammadi H, Xia J. Cephalometric norms for the upper airway in a healthy hong kong chinese population. Hong Kong Med J 2003 Feb;9(1):25-30.

14. Choi W. Dental computer tomography. 2010.

15. History of Dentistry [Internet]; c2005 [cited 2007 November 1]. Available from: http://www.ada.org.www.libproxy.wvu.edu/public/topics/history/timeline ancient.as p.

16. Moore KE. Obstructive sleep apnea. Surgical Update 2009;22(1).

17. Sleep Disorders: Sleep Apnea [Internet]; c2008 [cited 2007 November/01]. Available from: http://www.webmd.com/sleep-disorders/sleep-apnea/sleep-apnea.

18. Bonham PE, Currier GF, Orr WC, Othman J, Nanda RS. The effect of a modified functional appliance on obstructive sleep apnea. Am J Orthod Dentofacial Orthop 1988 Nov;94(5):384-92.

19. Patel NP, Ahmed M, Rosen I. Split-night polysomnography. Chest 2007 Nov;132(5):1664-71.

20. Cutler MJ, Hamdan AL, Hamdan MH, Ramaswamy K, Smith ML. Sleep apnea: From the nose to the heart. J Am Board Fam Pract 2002 Mar-Apr;15(2):128-41.

21. Szarko J. Obstructive sleep apnea. 2010.

22. Pace B, Lynm C, Glass R. JAMA patient page. breathing problems during sleep. JAMA 2001 Jun 13;285(22):2936.

23. Kaplan NM. The deadly quartet. upper-body obesity, glucose intolerance, hypertriglyceridemia, and hypertension. Arch Intern Med 1989 Jul;149(7):1514-20.

24. Central Sleep Apnea [Internet]; c2010 [cited 2010 February 15]. Available from: http://www.mayoclinic.org/central-sleep-apnea/.

25. Parker J, Kathawlla S, Ravenscraft S, Fox J, Komadina K, Harmon K, Berman T, Cosens B, Feider B. A prospective study evaluating the effectiveness of a mandibular repositioning appliance (PM positioner) for the treatment of moderate obstructive sleep apnea. Sleep 1999;22:230-1.

26. George PT. A modified functional appliance for treatment of obstructive sleep apnea. J Clin Orthod 1987 Mar;21(3):171-5.

27. Clark GT, Arand D, Chung E, Tong D. Effect of anterior mandibular positioning on 
obstructive sleep apnea. Am Rev Respir Dis 1993 Mar;147(3):624-9.

28. The pm positioner and other oral appliances used for treatment of snoring and obstructive sleep apnea [Internet]; c2002 [cited 2007 November 1]. Available from: http://www.pmpositioner.com/treat.html.

29. McNamara JA,Jr. A method of cephalometric evaluation. Am J Orthod 1984 Dec;86(6):449-69.

30. Jacobson A. Radiographic cephalometry: From basics to videoimaging. In: Quintessence Publishing; 1995. .

31. Larsen CS. Bioarchaeology: Interpreting behavior from the human skeleton. Cambridge, MA: Cambridge University Press; 1997. .

32. Kingsley NW. Treatise on oral deformities as a branch of mechanical surgery. Appleton, New York: ; 1880. .

33. Angle EH. Treatment of malocclusion of teeth and fractures of the maxillae. Philadelphia: SS White Dental Mfg. Co.; 1900. .

34. Profitt, W. R. \& Fields, H. W. Contemporary orthodontics. St. Louis: Moseby, Inc.; 2000. .

35. Jamieson A, Guilleminault C, Partinen M, Quera-Salva MA. Obstructive sleep apneic patients have craniomandibular abnormalities. Sleep 1986 Dec;9(4):469-77.

36. Dennison WM. The pierre robin syndrome. Pediatrics 1965 Sep;36(3):336-41.

37. Goodman, R. M., Gorlin, R. J. The face in genetic disorders. St. Louis, MO: Mosby; 1970. .

38. Jones KL. Smith's recognizable patterns of human malformation. 4th ed. ed. Philadelphia: WB Saunders; 1988. .

39. Hayden, G. D., Arnold, G. G. Disorders of the respiratory tract in children. 3rd ed. ed. Philadelphia: WB Saunders; 1977. .

40. Honey OB, Scarfe WC, Hilgers MJ, Klueber K, Silveira AM, Haskell BS, Farman AG. Accuracy of cone-beam computed tomography imaging of the temporomandibular joint: Comparisons with panoramic radiology and linear tomography. Am J Orthod Dentofacial Orthop 2007 Oct;132(4):429-38.

41. Frederiksen NL. Oral radiology: principles and interpretation. Philadelphia: Mosby; 2004. . 
42. Imaging Pulmonary Embolism [Internet]CE Essentials; c2010 [cited 2010 April 7]. Available from:

http://images.google.com/imgres?imgurl=http://www.ceessentials.net/images/pulmo naryEmbolus/image013.jpg\&imgrefurl=http://www.ceessentials.net/article12.html\& $\underline{\text { usg }}=$ wZ6S2E9xAbvz3WWR2iAw3Fzm6E $=\& \mathrm{~h}=802 \& \mathrm{w}=602 \& \mathrm{sz}=48 \& \mathrm{hl}=\mathrm{en} \& \mathrm{start}=16 \& u m=1$ \&itbs $=1 \&$ tbnid $=$ Hvl18EacUlJxM:\&tbnh=143\&tbnw=107\&prev=/images\%3Fq\%3DCT\%2Bimage\%2Bof\%2Bair way\%26um $\% 3 \mathrm{D} 1 \% 26 \mathrm{hl} \% 3 \mathrm{Den} \% 26 \mathrm{sa} \% 3 \mathrm{DN} \% 26 \mathrm{tbo} \% 3 \mathrm{D} 1 \% 26 \mathrm{tbs} \% 3 \mathrm{Disch}: 1$.

43. Baba R, Konno Y, Ueda K, Ikeda S. Comparison of flat-panel detector and imageintensifier detector for cone-beam CT. Comput Med Imaging Graph 2002 MayJun;26(3):153-8.

44. Baba R, Ueda K, Okabe M. Using a flat-panel detector in high resolution cone beam CT for dental imaging. Dentomaxillofac Radiol 2004 Sep;33(5):285-90.

45. Aboudara CA, Hatcher D, Nielsen IL, Miller A. A three-dimensional evaluation of the upper airway in adolescents. Orthod Craniofac Res 2003;6 Suppl 1:173-5.

46. Periago DR, Scarfe WC, Moshiri M, Scheetz JP, Silveira AM, Farman AG. Linear accuracy and reliability of cone beam CT derived 3-dimensional images constructed using an orthodontic volumetric rendering program. Angle Orthod 2008 May; 78(3):387-95.

47. Moshiri M, Scarfe WC, Hilgers ML, Scheetz JP, Silveira AM, Farman AG. Accuracy of linear measurements from imaging plate and lateral cephalometric images derived from cone-beam computed tomography. Am J Orthod Dentofacial Orthop 2007 Oct;132(4):550-60.

48. Honey OB, Scarfe WC, Hilgers MJ, Klueber K, Silveira AM, Haskell BS, Farman AG. Accuracy of cone-beam computed tomography imaging of the temporomandibular joint: Comparisons with panoramic radiology and linear tomography. Am J Orthod Dentofacial Orthop 2007 Oct;132(4):429-38.

49. Rustemeyer P, Streubuhr U, Suttmoeller J. Low-dose dental computed tomography: Significant dose reduction without loss of image quality. Acta Radiol 2004 Dec;45(8):847-53.

50. Scarfe WC, Farman AG, Sukovic P. Clinical applications of cone-beam computed tomography in dental practice. J can Dent Assoc 2006 Feb;72(1):75-80.

51. Healthcare Human Factors Group. Computer tomography radiation safety issues in ontario. Toronto, Centre for Global eHealth Innovation: ; 2006.

52. Frederiksen NL. X rays: What is the risk? Tex Dent J 1995 Feb;112(2):68-72. 
53. Kau CH, Richmond S, Palomo JM, Hans MG. Three-dimensional cone beam computerized tomography in orthodontics. J Orthod 2005 Dec;32(4):282-93.

54. Maal TJ, Plooij JM, Rangel FA, Mollemans W, Schutyser FA, Berge SJ. The accuracy of matching three-dimensional photographs with skin surfaces derived from cone-beam computed tomography. Int J Oral Maxillofac Surg 2008 Jul;37(7):641-6.

55. Hajeer MY, Millett DT, Ayoub AF, Siebert JP. Applications of 3D imaging in orthodontics: Part I. J Orthod 2004 Mar;31(1):62-70.

56. Enciso R, Memon A, Fidaleo DA, Neumann U, Mah J. The virtual craniofacial patient: 3D jaw modeling and animation. Stud Health Technol Inform 2003;94:6571.

57. Muto T, Takeda S, Kanazawa M, Yamazaki A, Fujiwara Y, Mizoguchi I. The effect of head posture on the pharyngeal airway space (PAS). Int J Oral Maxillofac Surg 2002 Dec;31(6):579-83.

58. Li HY, Chen NH, Wang CR, Shu YH, Wang PC. Use of 3-dimensional computed tomography scan to evaluate upper airway patency for patients undergoing sleepdisordered breathing surgery. Otolaryngol Head Neck Surg 2003 Oct;129(4):336-42.

59. Arens R, McDonough JM, Corbin AM, Hernandez ME, Maislin G, Schwab RJ, Pack AI. Linear dimensions of the upper airway structure during development: Assessment by magnetic resonance imaging. Am J Respir Crit Care Med 2002 Jan $1 ; 165(1): 117-22$.

60. Kawashima S, Niikuni N, Chia-hung L, Takahasi Y, Kohno M, Nakajima I, Akasaka M, Sakata H, Akashi S. Cephalometric comparisons of craniofacial and upper airway structures in young children with obstructive sleep apnea syndrome. Ear Nose Throat J 2000 Jul;79(7):499,502, 505-6.

61. Abu Allhaija ES, Al-Khateeb SN. Uvulo-glosso-pharyngeal dimensions in different anteroposterior skeletal patterns. Angle Orthod 2005 Nov;75(6):1012-8.

62. Hong JS, Oh KM, Kim BR, Kim YJ, Park YH. Three-dimensional analysis of pharyngeal airway volume in adults with anterior position of the mandible. Am J Orthod Dentofacial Orthop 2011 Oct;140(4):e161-9.

63. Oh KM, Hong JS, Kim YJ, Cevidanes LS, Park YH. Three-dimensional analysis of pharyngeal airway form in children with anteroposterior facial patterns. Angle Orthod 2011 Nov;81(6):1075-82.

64. Graber T, Neumann B. Removable orthodontic appliances. In: Removable orthodontic appliances. Philadelphia: WB Saunders; 1977. . 
65. Jeans WD, Fernando DC, Maw AR, Leighton BC. A longitudinal study of the growth of the nasopharynx and its contents in normal children. Br J Radiol 1981

Feb;54(638):117-21.

66. Hou HM, Hagg U, Sam K, Rabie AB, Wong RW, Lam B, Ip MS. Dentofacial characteristics of chinese obstructive sleep apnea patients in relation to obesity and severity. Angle Orthod 2006 Nov;76(6):962-9.

67. Paoli JR, Lauwers F, Lacassagne L, Tiberge M, Dodart L, Boutault F. Craniofacial differences according to the body mass index of patients with obstructive sleep apnoea syndrome: Cephalometric study in 85 patients. Br J Oral Maxillofac Surg $2001 \mathrm{Feb} ; 39(1): 40-5$. 


\title{
ABSTRACT \\ A Comparison of Airway Dimensions among Different Skeletal Craniofacial Patterns
}

\author{
Ronnie Sparks, D.D.S., Peter Ngan, D.M.D., Chris Martin, D.D.S., M.S., Thomas \\ Razmus, D.D.S.,M.S., James Mah, D.D.S.,M.S., and Erdogan Gunel, Ph.D.
}

Background and Objectives: Much attention has been given to the association of craniofacial skeletal morphology, upper airway dimension, and respiratory function with patients suffering from obstructive sleep apnea. However, much of the information gathered on the aforementioned has been established with the use of 2-Dimensional lateral cephalometry. The objective of this study was to investigate upper airway dimensions among different skeletal patterns using cone-beam computed tomography (CBCT). Methods: A sample of 279 patients who sought orthodontic treatment at the University of Nevada Las Vegas School of Dentistry Department of Orthodontics was included in this study. Pre-treatment multi-slice CBCT scans of these subjects were divided into three sagittal groups: Class I subjects with an ANB angle $0^{\circ}$ to $5^{\circ}$, Class II subjects with an ANB angle $>5^{\circ}$, and Class III subjects with an ANB angle $<0^{\circ}$. The CBCT scans were also divided into three vertical groups: normodivergent subjects with a mandibular plane angle $22^{\circ}$ to $30^{\circ}$, hyperdivergent subjects with a mandibular plane angle $>30^{\circ}$, and hypodivergent subjects with a mandibular plane angle $<22^{\circ}$. The sagittal and vertical groups were analyzed individually ( 6 groups) and together ( 9 groups) to determine if the various combination of skeletal patterns has any effects on airway volume, minimum cross sectional area (CSA), and airway shape. CBCT scans were analyzed using Dolphin Imaging 10.5 Premium and Anatomage InVivoDental ${ }^{\mathrm{TM}}$ software version 5.1. Data were analyzed using ANOVA, Tukey-Kramer, Student $t$ test, and Wilcoxon/Kruskal-Wallis tests. Results: Significant differences were found among the sagittal groups for airway volume and minimum CSA, $p<.05$. Class III subjects were found to have the largest airway volume and minimum CSA while Class II subjects were found to have the smallest airway volume and minimum CSA. Minimum CSA was found to have an increasing function of airway volume. CSA increased by $10.23 \mathrm{~mm}^{2}$ for every cc increase in airway volume. No significant differences were found among the vertical groups. However, Class II subjects with hyperdivergent skeletal pattern were found to have the smallest airway volume and minimum CSA. No associations were found between the airway shapes and airway volume when evaluating sagittal and/or vertical skeletal patterns. However, wide airway shapes were shown to have the largest airway volume while long airway shapes were shown to have the smallest airways.

Conclusions: Airway dimensions can be affected by craniofacial skeletal pattern. Patients with Class II hyperdivergent skeletal pattern may be more prone to obstructive sleep apnea problems. 


\section{APPENDICES}




\section{Appendix A - IRB Exemption}

IRB PROTOCOL - Details

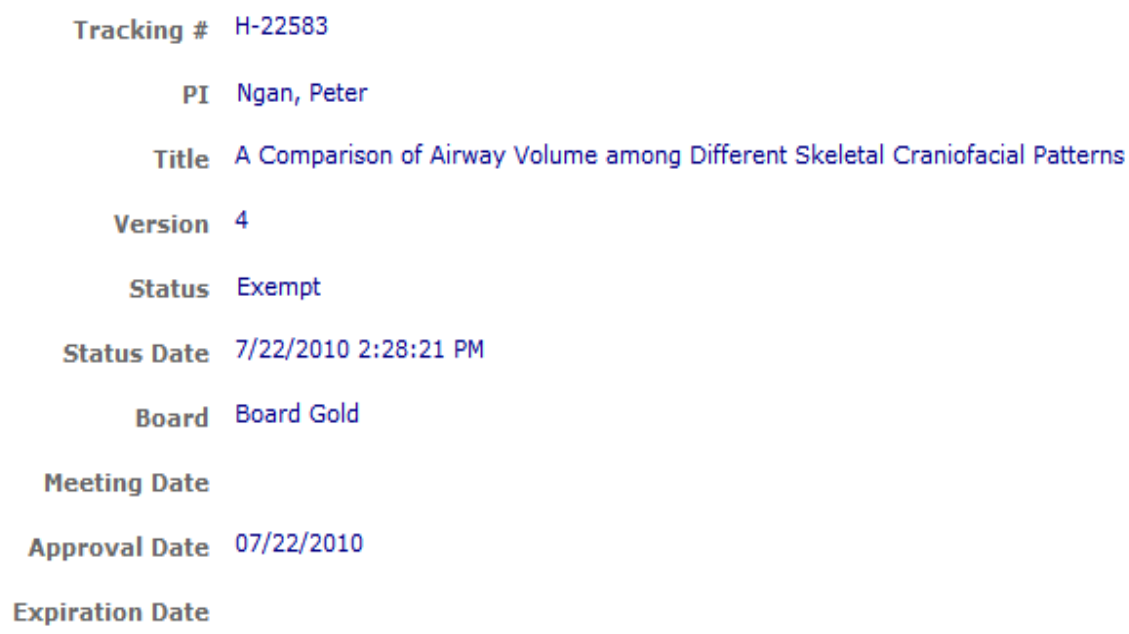




\section{Appendix B - Statistics}

Summary of the Results:

1)Airway Volume by Anteroposterior Skeletal Pattern:

There is a significant difference between Class 2 and Class 3 .

There is no significant difference between Class 1 and Class 2.

There is no significant difference between Class 1 and Class 3 .

2)Minimum CSA by Anteroposterior Skeletal Pattern:

There is a significant difference between Class 1 and Class 2.

There is a significant difference between Class 2 and Class 3.

There is no significant difference between Class 1 and Class 3 .

3)Airway Shape by Anteroposterior Skeletal Pattern:

There is no association between Airway Shape and Sagittal Growth Patterns.

4)Airway Volume by Vertical Skeletal Pattern:

There is no significant difference between Growth Patterns.

5)Minimum CSA by Vertical Skeletal Pattern:

There is no significant difference between Vertical Growth Patterns.

6)Airway Shape by Vertical Skeletal Pattern:

There is no association between Airway Shape and Vertical Growth Patterns.

7) Airway Volume by Anteroposterior / Vertical Skeletal Patterns:

$\begin{array}{lccc}\begin{array}{l}\text { Level } \\ \text { 3hyper }\end{array} & \text { A } & \text { Mean } \\ \text { 1normo } & \text { A } & 13.732258 \\ \text { 3hypo } & \text { A } & & 13.664516 \\ \text { 1hypo } & \text { A } & \text { B } & 13.574194 \\ \text { 3normo } & \text { A } & \text { B } & 12.487097 \\ \text { 2normo } & & \text { B } & 10.461290 \\ \text { 2hypo } & & \text { B } & 10.838710 \\ \text { 2hyper } & & \text { B } & 10.509675 \\ \text { 1hyper } & & \text { B } & 10.348387\end{array}$

Levels not connected by same letter are significantly different. 
8) Minimum CSA by Anteroposterior / Vertical Skeletal Patterns:

\begin{tabular}{|c|c|c|c|c|}
\hline Level & & & & Mean \\
\hline 3hypo & A & & & 152.00645 \\
\hline 1normo & A & & & 148.49677 \\
\hline 3normo & & B & & 141.80000 \\
\hline 3hyper & A & B & & 141.11290 \\
\hline 1hypo & A & B & & 139.07097 \\
\hline 2normo & A & B & $\mathrm{C}$ & 122.59355 \\
\hline 1hyper & & B & $\mathrm{C}$ & 118.37742 \\
\hline 2hypo & & B & $\mathrm{C}$ & 114.94194 \\
\hline 2hyper & & & $\mathrm{C}$ & 105.67097 \\
\hline
\end{tabular}

Levels not connected by same letter are significantly different.

9) Airway Shape by Anteroposterior / Vertical Skeletal Patterns:

Based on the results below there is no association between the Airway shape and the groups.

10)Airway Volume by Airway Shape:

There is a significant difference between Wide and Long.

There is a significant difference between Square and Long.

There is no significant difference between Wide and Square.

11)Minimum CSA by Airway Shape:

There is a significant difference between Wide and Long.

There is a significant difference between Square and Long.

There is no significant difference between Wide and Square.

12)Airway Volume by Minimum CSA:

CSA is an increasing function of Airway Volume. As Airway Volume increases by one cc, CSA increases by $10.23 \mathrm{~mm}^{2}$.

13)Reliability Analysis:

Reliability coefficient for both Airway and Minimum CSA variables are 0.99. 


\section{1)Oneway Analysis of Airway Volume (cc) By Anteroposterior Skeletal}

Pattern.

Quantiles

\begin{tabular}{|c|c|c|c|c|c|c|c|}
\hline Level & Minimum & $10 \%$ & $25 \%$ & Median & $75 \%$ & $90 \%$ & Maximum \\
\hline Class I & 4.9 & 7.04 & 9.1 & 11.7 & 14.4 & 17.44 & 27.1 \\
\hline Class II & 4.9 & 6.7 & 7.95 & 9.9 & 13.45 & 16.12 & 20.6 \\
\hline Class III & 4.5 & 7.94 & 9.35 & 12.4 & 16.15 & 20.62 & 31.4 \\
\hline
\end{tabular}

\section{Oneway Anova Summary of Fit}

$\begin{array}{ll}\text { Rsquare } & 0.054264 \\ \text { Adj Rsquare } & 0.047411 \\ \text { Root Mean Square Error } & 4.362901 \\ \text { Mean of Response } & 12.04695 \\ \text { Observations (or Sum Wgts) } & 279\end{array}$

Analysis of Variance

$\begin{array}{llllll}\text { Source } & \text { DF } & \begin{array}{l}\text { Sum of } \\ \text { Squares }\end{array} & \begin{array}{l}\text { Mean } \\ \text { Square }\end{array} & \text { F Ratio } & \text { Prob }>\text { F } \\ \text { Anteroposterior Skeletal pattern } & 2 & 301.4401 & 150.720 & 7.9181 & 0.0005^{*} \\ \text { Error } & 276 & 5253.6348 & 19.035 & & \\ \text { C. Total } & 278 & 5555.0749 & & & \end{array}$

\begin{tabular}{|c|c|c|c|c|c|}
\hline \multicolumn{6}{|c|}{ Means for Oneway Anova } \\
\hline Level & Number & Mean & Std Error & Lower 95\% & Upper $95 \%$ \\
\hline Class I & 93 & 12.1667 & 0.45241 & 11.276 & 13.057 \\
\hline Class II & 93 & 10.7183 & 0.45241 & 9.828 & 11.609 \\
\hline Class III & 93 & 13.2559 & 0.45241 & 12.365 & 14.147 \\
\hline
\end{tabular}

Means and Std Deviations

$\begin{array}{lllllll}\text { Level } & \text { Number } & \text { Mean } & \text { Std Dev } & \begin{array}{l}\text { Std Err } \\ \text { Mean }\end{array} & \text { Lower 95\% } & \text { Upper 95\% } \\ \text { Class I 93 } & 12.1667 & 4.21293 & 0.43686 & 11.299 & 13.034 \\ \text { Class II 93 } & 10.7183 & 3.59680 & 0.37297 & 9.978 & 11.459 \\ \text { Class III 93 } & 13.2559 & 5.13994 & 0.53299 & 12.197 & 14.314\end{array}$

\section{Means Comparisons}

Comparisons for all pairs using Tukey-Kramer HSD

$\begin{array}{lccl}\text { Level } & & & \text { Mean } \\ \text { Class III } & \text { A } & & 13.255914 \\ \text { Class I } & \text { A } & \text { B } & 12.166667 \\ \text { Class II } & & \text { B } & 10.718280\end{array}$

Levels not connected by same letter are significantly different. 
2)Oneway Analysis of Minimum CSA $\left(\mathrm{mm}^{2}\right)$ By Anteroposterior Skeletal Pattern.

Quantiles

$\begin{array}{lllllll}\text { Level Minimum } & \mathbf{1 0} \% & \mathbf{2 5} \% & \text { Median } & \mathbf{7 5 \%} & \mathbf{9 0} \% & \text { Maximum }\end{array}$

$\begin{array}{llllllll}\text { Class I } & 14.2 & 65.92 & 83.35 & 127.4 & 175.95 & 220.3 & 327.8\end{array}$

$\begin{array}{llllllll}\text { Class II } & 26.8 & 56.36 & 71.05 & 99.4 & 144.85 & 203.16 & 273\end{array}$

$\begin{array}{llllllll}\text { Class III } & 12.2 & 67.46 & 105.55 & 135.8 & 175.45 & 246.54 & 319.7\end{array}$

\section{Oneway Anova Summary of Fit}

Rsquare

Adj Rsquare

Root Mean Square Error

Mean of Response

Observations (or Sum Wgts)
0.044115

0.037189

59.71508

131.5634

279

\section{Analysis of Variance}

$\begin{array}{llllll}\text { Source } & \text { DF } & \text { Sum of Squares } & \text { Mean Square } & \text { F Ratio } & \text { Prob > F } \\ \text { Anteroposterior Skeletal Pattern } & 2 & 45421.6 & 22710.8 & 6.3689 & 0.0020^{*} \\ \text { Error } & 276 & 984185.9 & 3565.9 & & \\ \text { C. Total } & 278 & 1029607.5 & & & \end{array}$

Means for Oneway Anova

Level Number Mean

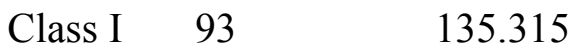

Class II $\quad 93 \quad 114.402$

Class III $93 \quad 144.973$

Std Error Lower 95\% Upper 95\%

$\begin{array}{lll}6.1922 & 123.13 & 147.50\end{array}$

$\begin{array}{lll}6.1922 & 102.21 & 126.59\end{array}$

$\begin{array}{lll}6.1922 & 132.78 & 157.16\end{array}$

\section{Means and Std Deviations}

$\begin{array}{lllllll}\text { Level } & \text { Number } & \text { Mean } & \text { Std Dev } & \begin{array}{l}\text { Std Err } \\ \text { Mean }\end{array} & \text { Lower 95\% } & \text { Upper } \\ \text { Class I 93 } & 135.315 & 61.9392 & 6.4228 & 122.56 & 148.07 \\ \text { Class II 93 } & 114.402 & 54.4213 & 5.6432 & 103.19 & 125.61 \\ \text { Class III 93 } & 144.973 & 62.4462 & 6.4754 & 132.11 & 157.83\end{array}$

\section{Means Comparisons}

Comparisons for all pairs using Tukey-Kramer HSD

\begin{tabular}{|c|c|c|}
\hline Level & & Mean \\
\hline Class III & A & 144.97312 \\
\hline Class I & A & 135.31505 \\
\hline Class II & & 114.40215 \\
\hline
\end{tabular}

Levels not connected by same letter are significantly different. 


\section{3) Airway Shape and Anteroposterior Skeletal Pattern.}

Based on the results below there is no association between the airway shape and anteroposterior skeletal pattern.

\section{Contingency Analysis of Airway Shape By Anteroposterior Skeletal Pattern \\ Contingency Table}

Anteroposterior Skeletal Pattern By Airway Shape

\begin{tabular}{|l|r|r|r|r|}
\hline $\begin{array}{l}\text { Count } \\
\text { Total \% }\end{array}$ & Long & Square & Wide & \\
Col \% & & & & \\
Row \% & & & & \\
\hline Class I & 11 & 15 & 67 & 93 \\
& 3.94 & 5.38 & 24.01 & 33.33 \\
& 44.00 & 31.91 & 32.37 & \\
& 11.83 & 16.13 & 72.04 & \\
\hline Class II & 8 & 15 & 70 & 93 \\
& 2.87 & 5.38 & 25.09 & 33.33 \\
& 32.00 & 31.91 & 33.82 & \\
& 8.60 & 16.13 & 75.27 & \\
\hline Class III & 6 & 17 & 70 & 93 \\
& 2.15 & 6.09 & 25.09 & 33.33 \\
& 24.00 & 36.17 & 33.82 & \\
& 6.45 & 18.28 & 75.27 & \\
\hline & 25 & 47 & 207 & 279 \\
& 8.96 & 16.85 & 74.19 & \\
\hline
\end{tabular}

\section{Tests}

$\begin{array}{rrrr}\mathbf{N} & \text { DF } & \text {-LogLike } & \text { RSquare (U) } \\ 279 & 4 & 0.88401485 & 0.0043\end{array}$

Test

Likelihood Ratio

Pearson
ChiSquare

1.768

1.777
Prob $>$ ChiSq

0.7783

0.7767 


\section{4)Oneway Analysis of Airway Volume (cc) By Vertical Skeletal Pattern.}

\section{Quantiles}

\begin{tabular}{|c|c|c|c|c|c|c|c|}
\hline Level & Minimum & $10 \%$ & $25 \%$ & Median & $75 \%$ & $90 \%$ & Maximum \\
\hline Hyperdivergent & 4.5 & 6.94 & 8.45 & 11.2 & 13.5 & 16.96 & 26.4 \\
\hline Hypodivergent & 4.9 & 7.1 & 8.7 & 12.2 & 14.75 & 17.9 & 27.4 \\
\hline Normodivergent & 5 & 7.7 & 9 & 11 & 14.7 & 18.26 & 31.4 \\
\hline
\end{tabular}

\section{Oneway Anova Summary of Fit}

$\begin{array}{ll}\text { Rsquare } & 0.006717 \\ \text { Adj Rsquare } & -0.00048 \\ \text { Root Mean Square Error } & 4.471229 \\ \text { Mean of Response } & 12.04695 \\ \text { Observations (or Sum Wgts) } & 279\end{array}$

\section{Analysis of Variance}

$\begin{array}{llllll}\text { Source } & \text { DF } & \begin{array}{l}\text { Sum of } \\ \text { Squares }\end{array} & \text { Mean Square } & \text { F Ratio } & \text { Prob > F } \\ \text { Vertical Skeletal Pattern } & 2 & 37.3130 & 18.6565 & 0.9332 & 0.3945 \\ \text { Error } & 276 & 5517.7619 & 19.9919 & & \\ \text { C. Total } & 278 & 5555.0749 & & & \end{array}$

\begin{tabular}{|c|c|c|c|c|c|}
\hline \multicolumn{6}{|c|}{ Means for Oneway Anova } \\
\hline Level & Number & Mean & Std Error & Lower 95\% & Upper $95 \%$ \\
\hline Hyperdivergent & 93 & 11.5301 & 0.46364 & 10.617 & 12.443 \\
\hline Hypodivergent & 93 & 12.2892 & 0.46364 & 11.377 & 13.202 \\
\hline Normodivergent & 93 & 12.3215 & 0.46364 & 11.409 & 13.234 \\
\hline
\end{tabular}

\section{Means and Std Deviations}

$\begin{array}{lllllll}\text { Level } & \text { Number } & \text { Mean } & \text { Std Dev } & \begin{array}{l}\text { Std Err } \\ \text { Mean }\end{array} & \text { Lower 95\% Upper 95\% } \\ \text { Hyperdivergent } & 93 & 11.5301 & 4.07502 & 0.42256 & 10.691 & 12.369 \\ \text { Hypodivergent } 93 & 12.2892 & 4.51554 & 0.46824 & 11.359 & 13.219 \\ \text { Normodivergent 93 } & 12.3215 & 4.79372 & 0.49709 & 11.334 & 13.309\end{array}$

\section{Means Comparisons}

Comparisons for all pairs using Tukey-Kramer HSD

Level

\section{Mean}

Normodivergent

Hypodivergent

Hyperdivergent
A 12.321505

A 12.289247

A 11.530108

Levels not connected by same letter are significantly different. 


\section{5)Oneway Analysis of Minimum CSA $\left(\mathrm{mm}^{2}\right)$ By Vertical Skeletal}

\section{Pattern.}

\section{Quantiles}

$\begin{array}{llllllll}\text { Level } & \text { Minimum 10\% } & \mathbf{2 5 \%} & \text { Median } & \mathbf{7 5 \%} & \mathbf{9 0 \%} & \text { Maximum } \\ \text { Hyperdivergent } & 14.2 & 52.04 & 80.85 & 117.6 & 148.6 & 203.62 & 319.7 \\ \text { Hypodivergent } & 39.1 & 59.4 & 72.1 & 135.1 & 177 & 225.82 & 298.3 \\ \text { Normodivergent } & 12.2 & 70.14 & 93.3 & 125.9 & 171.3 & 225.12 & 327.8\end{array}$

\section{Oneway Anova Summary of Fit}

$\begin{array}{ll}\text { Rsquare } & 0.013364 \\ \text { Adj Rsquare } & 0.006214 \\ \text { Root Mean Square Error } & 60.66802 \\ \text { Mean of Response } & 131.5634 \\ \text { Observations (or Sum Wgts) } & 279\end{array}$

\section{Analysis of Variance \\ Source \\ Vertical Skeletal Pattern 2 \\ Error \\ C. Total \\ DF Sum of Squares \\ $2 \quad 13759.4$ \\ $276 \quad 1015848.1$ \\ $278 \quad 1029607.5$

\author{
Mean Square F Ratio Prob $>$ F \\ $\begin{array}{lll}6879.68 & 1.8692 & 0.1562\end{array}$
} \\ 3680.61}

Means for Oneway Anova

$\begin{array}{llllll}\text { Level } & \text { Number } & \text { Mean } & \text { Std Error } & \text { Lower 95\% } & \text { Upper 95\% } \\ \text { Hyperdivergent } & 93 & 121.720 & 6.2910 & 109.34 & 134.10 \\ \text { Hypodivergent } & 93 & 135.340 & 6.2910 & 122.96 & 147.72 \\ \text { Normodivergent } & 93 & 137.630 & 6.2910 & 125.25 & 150.01\end{array}$

Means and Std Deviations

Level Number Mean

Hyperdivergent 93

Hypodivergent 93

Normodivergent 93
Number Mean Std Dev

121.720

135.340

137.630
56.8924

63.1159

61.8181
Std Err Lower 95\% Upper 95\% Mean

5.8995

6.5448

110.00

133.44

$6.4102 \quad 124.90$

148.34

150.36

\section{Means Comparisons}

Comparisons for all pairs using Tukey-Kramer HSD

Level

Normodivergent

Hypodivergent

Hyperdivergent

\section{Mean}

A 137.63011

A 135.33978

A 121.72043

Levels not connected by same letter are significantly different. 


\section{6) Airway Shape by Vertical Skeletal Pattern.}

Based on the results below there is no association between the airway shape and the vertical skeletal pattern.

\section{Contingency Analysis of Airway Shape By Vertical Skeletal Pattern Contingency Table}

Vertical Skeleteal Pattern By Airway Shape

\begin{tabular}{|l|l|l|l|l|}
\hline $\begin{array}{l}\text { Count } \\
\text { Total \% } \\
\text { Col \% } \\
\text { Row \% }\end{array}$ & Long & Square & Wide & \\
\hline Hyperdivergent & 11 & 17 & 65 & \\
& 3.94 & 6.09 & 23.30 & 33.33 \\
& 44.00 & 36.17 & 31.40 & \\
& 11.83 & 18.28 & 69.89 & \\
\hline Hypodivergent & 6 & 15 & 72 & 93 \\
& 2.15 & 5.38 & 25.81 & 33.33 \\
& 24.00 & 31.91 & 34.78 & \\
\hline Normodivergent & 6.45 & 16.13 & 77.42 & \\
& 8 & 15 & 70 & 93 \\
& 2.87 & 5.38 & 25.09 & 33.33 \\
& 32.00 & 31.91 & 33.82 & \\
\hline & 8.60 & 16.13 & 75.27 & \\
\hline & 25 & 47 & 207 & 279 \\
\hline
\end{tabular}

\section{Tests}

$\begin{array}{llll}\mathbf{N} & \text { DF } & \text {-LogLike } & \text { RSquare (U) } \\ 279 & 4 & 1.0300755 & 0.0050\end{array}$

Test ChiSquare Prob $>$ ChiSq

$\begin{array}{lll}\text { Likelihood Ratio } & 2.060 & 0.7247 \\ \text { Pearson } & 2.067 & 0.7234\end{array}$

$\begin{array}{lll}\text { Pearson } & 2.067 & 0.7234\end{array}$




\section{7)Oneway Analysis of Airway Volume (cc) By Anteroposterior / Vertical Skeletal Patterns.}

\begin{tabular}{|c|c|c|c|c|c|c|c|}
\hline \multicolumn{8}{|c|}{ Quantiles } \\
\hline Level & Minimum & $10 \%$ & $25 \%$ & Median & $75 \%$ & $90 \%$ & Maximum \\
\hline 1hyper & 4.9 & 6.6 & 8.4 & 10.8 & 12.2 & 13.48 & 17.1 \\
\hline 1hypo & 5.5 & 6.42 & 9.4 & 13.5 & 15.4 & 17.52 & 19.4 \\
\hline 1normo & 6 & 7.72 & 9.9 & 12.9 & 16.4 & 22.08 & 27.1 \\
\hline 2hyper & 5.8 & 6.38 & 8 & 9.3 & 13 & 15.74 & 19 \\
\hline 2hypo & 4.9 & 6.2 & 7.6 & 9.6 & 13.9 & 17.8 & 20.6 \\
\hline 2 normo & 5.1 & 6.8 & 8.4 & 10.8 & 13.7 & 15.56 & 17.2 \\
\hline 3hyper & 4.5 & 7.84 & 9.9 & 12.8 & 16.9 & 20.76 & 26.4 \\
\hline 3hypo & 7.5 & 8.04 & 9.4 & 12.5 & 15.2 & 23.14 & 27.4 \\
\hline 3normo & 5 & 7.72 & 8.6 & 10.8 & 13.9 & 18.44 & 31.4 \\
\hline
\end{tabular}

\section{Oneway Anova Summary of Fit}

$\begin{array}{ll}\text { Rsquare } & 0.091529 \\ \text { Adj Rsquare } & 0.064612 \\ \text { Root Mean Square Error } & 4.323332 \\ \text { Mean of Response } & 12.04695 \\ \text { Observations (or Sum Wgts) } & 279\end{array}$

\begin{tabular}{llllll}
$\begin{array}{l}\text { Analysis of Variance } \\
\text { Source }\end{array}$ & DF & $\begin{array}{l}\text { Sum of } \\
\text { Squares }\end{array}$ & \multicolumn{3}{l}{ Mean Square F Ratio Prob > F } \\
Anteroposterior\&Verical 8 & 508.4517 & 63.5565 & 3.4003 & $0.0010^{*}$ \\
Error & 270 & 5046.6232 & 18.6912 & & \\
C. Total & 278 & 5555.0749 & & &
\end{tabular}

\begin{tabular}{|c|c|c|c|c|c|}
\hline \multicolumn{6}{|c|}{ Means for Oneway Anova } \\
\hline Level & Number & Mean & Std Error & Lower 95\% & Upper $95 \%$ \\
\hline 1hyper & 31 & 10.3484 & 0.77649 & 8.820 & 11.877 \\
\hline 1hypo & 31 & 12.4871 & 0.77649 & 10.958 & 14.016 \\
\hline 1normo & 31 & 13.6645 & 0.77649 & 12.136 & 15.193 \\
\hline 2hyper & 31 & 10.5097 & 0.77649 & 8.981 & 12.038 \\
\hline 2hypo & 31 & 10.8065 & 0.77649 & 9.278 & 12.335 \\
\hline 2 normo & 31 & 10.8387 & 0.77649 & 9.310 & 12.367 \\
\hline 3hyper & 31 & 13.7323 & 0.77649 & 12.204 & 15.261 \\
\hline 3hypo & 31 & 13.5742 & 0.77649 & 12.045 & 15.103 \\
\hline 3normo & 31 & 12.4613 & 0.77649 & 10.933 & 13.990 \\
\hline
\end{tabular}

Std Error uses a pooled estimate of error variance 


\section{Means and Std Deviations}

$\begin{array}{lllllll}\text { Level } & \text { Number } & \text { Mean } & \text { Std Dev } & \text { Std Err Mean } & \text { Lower 95\% } & \text { Upper 95\% } \\ \text { 1hyper } & 31 & 10.3484 & 2.68500 & 0.48224 & 9.364 & 11.333 \\ \text { 1hypo } & 31 & 12.4871 & 3.81888 & 0.68589 & 11.086 & 13.888 \\ \text { 1normo } & 31 & 13.6645 & 5.17646 & 0.92972 & 11.766 & 15.563 \\ \text { 2hyper } & 31 & 10.5097 & 3.34897 & 0.60149 & 9.281 & 11.738 \\ \text { 2hypo } & 31 & 10.8065 & 4.27839 & 0.76842 & 9.237 & 12.376 \\ \text { 2normo } & 31 & 10.8387 & 3.17571 & 0.57037 & 9.674 & 12.004 \\ \text { 3hyper } & 31 & 13.7323 & 4.99696 & 0.89748 & 11.899 & 15.565 \\ \text { 3hypo } & 31 & 13.5742 & 5.06188 & 0.90914 & 11.717 & 15.431 \\ \text { 3normo } & 31 & 12.4613 & 5.42535 & 0.97442 & 10.471 & 14.451\end{array}$

\section{Means Comparisons}

\section{Comparisons for each pair using Student's t}

Level

3hyper

1normo A

3hypo A

1hypo A B

3normo A B

2normo B

2hypo B

2hyper B

1hyper
Mean

13.732258

13.664516

13.574194

12.487097

12.461290

10.838710

10.806452

10.509677

10.348387

Levels not connected by same letter are significantly different.

The study found the following:

a) There is a significant difference between Class I Normodivergent patients and Class I Hyperdivergent patients.

b) There is no significant difference between Class I Normodivergent patients and Class I Hypodivergent patients.

c) There is a significant difference between Class I Normodivergent patients and Class II Hyperdivergent patients.

d) There is a significant difference between Class I Normodivergent patients and Class II Hypodivergent patients.

e) There is a significant difference between Class I Normodivergent patients and Class II Normodivergent patients.

f) There is no significant difference between Class I Normodivergent patients and Class III Hyperdivergent patients.

g) There is no significant difference between Class I Normodivergent patients and Class III Hypodivergent patients.

h) There is no significant difference between Class I Normodivergent patients and Class III Normodivergent patients. 
i) There is no significant difference between Class II Normodivergent patients and Class II Hyperdivergent patients.

j) There is no significant difference between Class II Normodivergent patients and Class I Hypodivergent patients.

k) There is no significant difference between Class II Normodivergent patients and Class II Hyperdivergent patients.

1) There is no significant difference between Class II Normodivergent patients and Class II Hypodivergent patients.

m) There is a significant difference between Class II Normodivergent patients and Class III Hyperdivergent patients.

n) There is a significant difference between Class II Normodivergent patients and Class III Hypodivergent patients.

o) There is no significant difference between Class II Normodivergent patients and Class III Normodivergent patients

p) There is no significant difference between Class III Normodivergent patients and Class I Hyperdivergent patients.

q) There is no significant difference between Class III Normodivergent patients and Class I Hypodivergent patients.

r) There is no significant difference between Class III Normodivergent patients and Class II Hyperdivergent patients.

s) There is no significant difference between Class III Normodivergent patients and Class II Hypodivergent patients.

t) There is no significant difference between Class III Normodivergent patients and Class III Hyperdivergent patients.

u) There is no significant difference between Class III Normodivergent patients and Class III Hypodivergent patients.

v) There is no significant difference between Class I Hyperdivergent patients and Class I Hypodivergent patients.

w) There is no significant difference between Class I Hyperdivergent patients and Class II Hyperdivergent patients

$\mathrm{x})$ There is no significant difference between Class I Hyperdivergent patients and Class II Hypodivergent patients.

y) There is a significant difference between Class I Hyperdivergent patients and Class III Hyperdivergent patients.

z) There is a significant difference between Class I Hyperdivergent patients and Class III Hypodivergent patients.

aa) There is no significant difference between Class II Hyperdivergent patients and Class I Hypodivergent patients.

bb) There is no significant difference between Class II Hyperdivergent patients and Class II Hypodivergent patients.

cc) There is a significant difference between Class II Hyperdivergent patients and Class III Hypodivergent patients.

dd) There is no significant difference between Class III Hyperdivergent patients and Class I Hypodivergent patients.

ee) There is a significant difference between Class III Hyperdivergent patients and Class II Hyperdivergent patients 
ff) There is a significant difference between Class III Hyperdivergent patients and Class II Hypodivergent patients

gg) There is no significant difference between Class III Hyperdivergent patients and Class III Hypodivergent patients.

hh) There is no significant difference between Class I Hypodivergent patients and Class II Hypodivergent patients.

ii) There is no significant difference between Class I Hypodivergent patients and Class III Hypodivergent patients.

jj) There is a significant difference between Class II Hypodivergent patients and Class III Hypodivergent patients. 


\section{8) Oneway Analysis of Minimum CSA $\left(\mathrm{mm}^{2}\right)$ By Anteroposterior / Vertical Skeletal Patterns.}

\section{Quantiles}

\begin{tabular}{|c|c|c|c|c|c|c|c|}
\hline Level & Minimum & $10 \%$ & $25 \%$ & Median & $75 \%$ & $90 \%$ & Maximum \\
\hline 1hyper & 14.2 & 44.84 & 72.1 & 116.8 & 155.2 & 186.62 & 243.4 \\
\hline 1hypo & 43.5 & 57.48 & 73.4 & 151.3 & 183.7 & 216.94 & 298.3 \\
\hline 1 normo & 66.4 & 80.06 & 110.3 & 125.9 & 179.3 & 265.54 & 327.8 \\
\hline 2hyper & 26.8 & 46.04 & 76.1 & 99.4 & 131.5 & 149.02 & 273 \\
\hline 2hypo & 39.1 & 53.16 & 64.7 & 86.1 & 161.1 & 217.78 & 241.2 \\
\hline 2 normo & 41.4 & 60.6 & 82.2 & 101 & 153.7 & 212.66 & 240.1 \\
\hline 3hyper & 31.1 & 66.78 & 105 & 129.1 & 167.2 & 241.38 & 319.7 \\
\hline 3hypo & 59.1 & 66.24 & 109.1 & 148 & 185.5 & 248.64 & 279 \\
\hline 3 normo & 12.2 & 65.9 & 100.4 & 135.8 & 169.4 & 250.3 & 281.5 \\
\hline
\end{tabular}

\section{Oneway Anova Summary of Fit}

Rsquare

Adj Rsquare

Root Mean Square Error

Mean of Response

Observations (or Sum Wgts)
0.064975

0.03727

59.71255

131.5634

279

\section{Analysis of Variance}

$\begin{array}{llllll}\text { Source } & \text { DF } & \begin{array}{l}\text { Sum of } \\ \text { Squares }\end{array} & \begin{array}{l}\text { Mean } \\ \text { Square }\end{array} & \begin{array}{l}\text { F } \\ \text { Ratio }\end{array} & \begin{array}{l}\text { Prob }> \\ \text { F }\end{array} \\ \text { Anteroposterior\&Vertical } & 8 & 66898.7 & 8362.33 & 2.3453 & 0.0188^{*} \\ \text { Error } & 270 & 962708.8 & 3565.59 & & \\ \text { C. Total } & 278 & 1029607.5 & & & \end{array}$

\section{Means for Oneway Anova}

\begin{tabular}{|c|c|c|c|c|c|}
\hline Level & Number & Mean & Std Error & Lower 95\% & Upper 95\% \\
\hline 1hyper & 31 & 118.377 & 10.725 & 97.26 & 139.49 \\
\hline 1hypo & 31 & 139.071 & 10.725 & 117.96 & 160.19 \\
\hline 1normo & 31 & 148.497 & 10.725 & 127.38 & 169.61 \\
\hline 2hyper & 31 & 105.671 & 10.725 & 84.56 & 126.79 \\
\hline 2hypo & 31 & 114.942 & 10.725 & 93.83 & 136.06 \\
\hline 2 normo & 31 & 122.594 & 10.725 & 101.48 & 143.71 \\
\hline 3hyper & 31 & 141.113 & 10.725 & 120.00 & 162.23 \\
\hline 3hypo & 31 & 152.006 & 10.725 & 130.89 & 173.12 \\
\hline 3normo & 31 & 141.800 & 10.725 & 120.69 & 162.91 \\
\hline
\end{tabular}

Std Error uses a pooled estimate of error variance 


$\begin{array}{lllllll}\begin{array}{l}\text { Means and Std Deviations } \\ \text { Level }\end{array} & \text { Number } & \text { Mean } & \text { Std Dev } & \begin{array}{l}\text { Std Err } \\ \text { Mean }\end{array} & \text { Lower 95\% } & \text { Upper 95\% } \\ \text { 1hyper } & 31 & 118.377 & 53.7087 & 9.646 & 98.68 & 138.08 \\ \text { 1hypo } & 31 & 139.071 & 64.4683 & 11.579 & 115.42 & 162.72 \\ \text { 1normo } & 31 & 148.497 & 65.0676 & 11.686 & 124.63 & 172.36 \\ \text { 2hyper } & 31 & 105.671 & 46.9716 & 8.436 & 88.44 & 122.90 \\ \text { 2hypo } & 31 & 114.942 & 60.7248 & 10.906 & 92.67 & 137.22 \\ \text { 2normo } & 31 & 122.594 & 55.1385 & 9.903 & 102.37 & 142.82 \\ \text { 3hyper } & 31 & 141.113 & 64.5657 & 11.596 & 117.43 & 164.80 \\ \text { 3hypo } & 31 & 152.006 & 60.3439 & 10.838 & 129.87 & 174.14 \\ \text { 3normo } & 31 & 141.800 & 63.8084 & 11.460 & 118.39 & 165.21\end{array}$

\section{Means Comparisons}

\section{Comparisons for each pair using Student's t}

\section{Level}

3hypo

1normo

3normo

3hyper

1 hypo

2normo

1hyper

2hypo

2hyper

\section{Mean}

152.00645

148.49677

141.80000

141.11290

139.07097

122.59355

118.37742

114.94194

105.67097

Levels not connected by same letter are significantly different.

The study found the following:

a) There is a significant difference in minimum CSA between Class I Normodivergent patients and Class I Hyperdivergent patients.

b) There is no significant difference in minimum CSA between Class I Normodivergent patients and Class I Hypodivergent patients.

c) There is a significant difference in minimum CSA between Class I Normodivergent patients and Class II Hyperdivergent patients.

d) There is a significant difference in minimum CSA between Class I Normodivergent patients and Class II Hypodivergent patients.

e) There is no significant difference in minimum CSA between Class I Normodivergent patients and Class II Normodivergent patients.

f) There is no significant difference in minimum CSA between Class I Normodivergent patients and Class III Hyperdivergent patients.

g) There is no significant difference in minimum CSA between Class I Normodivergent patients and Class III Hypodivergent patients.

h) There is no significant difference in minimum CSA between Class I Normodivergent patients and Class III Normodivergent patients. 
i) There is no significant difference in minimum CSA between Class II Normodivergent patients and Class I Hyperdivergent patients.

j) There is no significant difference in minimum CSA between Class II Normodivergent patients and Class I Hypodivergent patients.

k) There is no significant difference in minimum CSA between Class II Normodivergent patients and Class II Hyperdivergent patients.

1) There is no significant difference in minimum CSA between Class II Normodivergent patients and Class II Hypodivergent patients.

m) There is no significant difference in minimum CSA between Class II Normodivergent patients and Class III Hyperdivergent patients.

n) There is no significant difference in minimum CSA between Class II Normodivergent patients and Class III Hypodivergent patients.

o) There is no significant difference in minimum CSA between Class II Normodivergent patients and Class III Normodivergent patients.

p) There is no significant difference in minimum CSA between Class III Normodivergent patients and Class I Hyperdivergent patients.

q) There is no significant difference in minimum CSA between Class III Normodivergent patients and Class I Hypodivergent patients.

r) There is a significant difference in minimum CSA between Class III Normodivergent patients and Class II Hyperdivergent patients.

s) There is a significant difference in minimum CSA between Class III Normodivergent patients and Class II Hypodivergent patients.

t) There is no significant difference in minimum CSA between Class III Normodivergent patients and Class III Hyperdivergent patients.

u) There is no significant difference in minimum CSA between Class III Normodivergent patients and Class III Hypodivergent patients.

v) There is no significant difference in minimum CSA between Class I Hyperdivergent patients and Class I Hypodivergent patients.

w) There is no significant difference in minimum CSA between Class I Hyperdivergent patients and Class II Hyperdivergent patients.

$\mathrm{x})$ There is no significant difference in minimum CSA between Class I Hyperdivergent patients and Class II Hypodivergent patients.

y) There is no significant difference in minimum CSA between Class I Hyperdivergent patients and Class III Hyperdivergent patients.

z) There is no significant difference in minimum CSA between Class I Hyperdivergent patients and Class III Hypodivergent patients.

aa) There is no significant difference in minimum CSA between Class II Hyperdivergent patients and Class I Hypodivergent patients.

bb) There is no significant difference in minimum CSA between Class II Hyperdivergent patients and Class II Hypodivergent patients.

cc) There is a significant difference in minimum CSA between Class II Hyperdivergent patients and Class III Hypodivergent patients.

dd) There is no significant difference in minimum CSA between Class III Hyperdivergent patients and Class I Hypodivergent patients.

ee) There is a significant difference in minimum CSA between Class III Hyperdivergent patients and Class II Hyperdivergent patients. 
ff) There is no significant difference in minimum CSA between Class III Hyperdivergent patients and Class II Hypodivergent patients.

gg) There is no significant difference in minimum CSA between Class III Hyperdivergent patients and Class III Hypodivergent patients.

hh) There is no significant difference in minimum CSA between Class I Hypodivergent patients and Class II Hypodivergent patients.

ii) There is no significant difference in minimum CSA between Class I Hypodivergent patients and Class III Hypodivergent patients.

jj) There is a significant difference in minimum CSA between Class II Hypodivergent patients and Class III Hypodivergent patients. 


\section{9) Contingency Analysis of Airway Shape By Anteroposterior / Vertical}

Skeletal Patterns.

\section{Contingency Table}

Anteroposterior/Vertical By Airway Shape

\begin{tabular}{|c|c|c|c|c|}
\hline $\begin{array}{l}\text { Count } \\
\text { Total \% } \\
\text { Col \% } \\
\text { Row \% }\end{array}$ & Long & Square & Wide & \\
\hline 1hyper & $\begin{array}{l}6 \\
2.15 \\
24.00 \\
19.35\end{array}$ & \begin{tabular}{|l}
7 \\
2.51 \\
14.89 \\
22.58 \\
\end{tabular} & \begin{tabular}{|l|}
18 \\
6.45 \\
8.70 \\
58.06 \\
\end{tabular} & \begin{tabular}{|l|}
31 \\
11.11
\end{tabular} \\
\hline 1hypo & $\begin{array}{l}2 \\
0.72 \\
8.00 \\
6.45 \\
\end{array}$ & \begin{tabular}{|l|}
5 \\
1.79 \\
10.64 \\
16.13 \\
\end{tabular} & \begin{tabular}{|l|}
4 \\
8.60 \\
11.59 \\
77.42 \\
\end{tabular} & \begin{tabular}{|l|}
31 \\
11.11
\end{tabular} \\
\hline 1 normo & $\begin{array}{l}3 \\
1.08 \\
12.00 \\
9.68 \\
\end{array}$ & \begin{tabular}{|l|}
3 \\
1.08 \\
6.38 \\
9.68 \\
\end{tabular} & \begin{tabular}{|l}
25 \\
8.96 \\
12.08 \\
80.65 \\
\end{tabular} & \begin{tabular}{|l|}
31 \\
11.11
\end{tabular} \\
\hline 2hyper & $\begin{array}{l}2 \\
0.72 \\
8.00 \\
6.45 \\
\end{array}$ & \begin{tabular}{|l|}
5 \\
1.79 \\
10.64 \\
16.13 \\
\end{tabular} & \begin{tabular}{|l|}
24 \\
8.60 \\
11.59 \\
77.42 \\
\end{tabular} & \begin{tabular}{|l|}
31 \\
11.11
\end{tabular} \\
\hline 2hypo & $\begin{array}{l}4 \\
1.43 \\
16.00 \\
12.90 \\
\end{array}$ & $\begin{array}{l}5 \\
1.79 \\
10.64 \\
16.13 \\
\end{array}$ & \begin{tabular}{|l|}
22 \\
7.89 \\
10.63 \\
70.97 \\
\end{tabular} & \begin{tabular}{|l}
31 \\
11.11
\end{tabular} \\
\hline 2normo & $\begin{array}{l} \\
0.72 \\
8.00 \\
6.45 \\
\end{array}$ & $\begin{array}{l}5 \\
1.79 \\
10.64 \\
16.13 \\
\end{array}$ & \begin{tabular}{|l}
4 \\
8.60 \\
11.59 \\
77.42 \\
\end{tabular} & \begin{tabular}{|l|}
31 \\
11.11
\end{tabular} \\
\hline 3hyper & $\begin{array}{l}3 \\
1.08 \\
12.00 \\
9.68\end{array}$ & $\begin{array}{l}5 \\
1.79 \\
10.64 \\
16.13\end{array}$ & \begin{tabular}{|l|}
23 \\
8.24 \\
11.11 \\
74.19
\end{tabular} & \begin{tabular}{|l|}
31 \\
11.11
\end{tabular} \\
\hline 3hypo & $\begin{array}{l}0 \\
0.00 \\
0.00 \\
0.00 \\
\end{array}$ & \begin{tabular}{|l|}
5 \\
1.79 \\
10.64 \\
16.13 \\
\end{tabular} & \begin{tabular}{|l|}
66 \\
9.32 \\
12.56 \\
83.87 \\
\end{tabular} & \begin{tabular}{|l|}
31 \\
11.11
\end{tabular} \\
\hline 3normo & \begin{tabular}{|l|}
3 \\
1.08 \\
12.00 \\
9.68 \\
\end{tabular} & $\begin{array}{l}7 \\
2.51 \\
14.89 \\
22.58 \\
\end{array}$ & \begin{tabular}{|l|}
1 \\
7.53 \\
10.14 \\
67.74 \\
\end{tabular} & \begin{tabular}{|l|}
31 \\
11.11
\end{tabular} \\
\hline & \begin{tabular}{|l|}
55 \\
8.96 \\
\end{tabular} & \begin{tabular}{|l}
47 \\
16.85
\end{tabular} & \begin{tabular}{|l|}
207 \\
74.19
\end{tabular} & 279 \\
\hline
\end{tabular}




\section{Tests}

N

279

DF

16

-LogLike

6.9711234
RSquare (U)

0.0339

\section{Test}

Likelihood Ratio

\section{ChiSquare}

13.942

11.973

Prob $>$ ChiSq

Pearson

Warning: $20 \%$ of cells have expected count less than 5 , ChiSquare suspect. 


\section{Multivariate}

\section{Correlations}

$\begin{array}{lll} & \begin{array}{l}\text { Airway } \\ \text { Volume-1 } \\ \text { Airway }\end{array} & \begin{array}{l}\text { Airway } \\ \text { Volume-2 } \\ \text { Volume-1 }\end{array} \\ \begin{array}{lll}\text { Airway } \\ \text { Volume-2 }\end{array} & 0.99000 & 0.9978 \\ & & 1.0000\end{array}$

Cronbach's $\alpha$

$\begin{array}{ll} & \boldsymbol{\alpha} \\ \text { Entire set } & 0.9989\end{array}$

Plot Alpha

Multivariate

Correlations

Minimum Minimum

CSA-1 CSA-2

Minimum $\quad 1.0000 \quad 0.9996$

CSA-1

$\begin{array}{lll}\text { Minimum } & 0.9996 & 1.0000\end{array}$

CSA-2

Cronbach's $\alpha$

$\begin{array}{ll} & \boldsymbol{\alpha} \\ \text { Entire set } & 0.9996\end{array}$

Plot Alpha

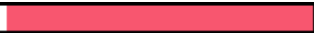


10)Oneway Analysis of Airway Volume (cc) By Airway Shape

Quantiles

\begin{tabular}{|c|c|c|c|c|c|c|c|}
\hline Level & Minimum & $10 \%$ & $25 \%$ & Median & $75 \%$ & $90 \%$ & Maximum \\
\hline Long & 4.9 & 5.3 & 7.5 & 9 & 10.95 & 13.54 & 14.2 \\
\hline Square & 5 & 7.38 & 8.8 & 11 & 13.9 & 16.72 & 27.4 \\
\hline Wide & 4.5 & 7.3 & 9 & 11.7 & 15 & 18.12 & 31.4 \\
\hline
\end{tabular}

\section{Oneway Anova Summary of Fit}

Rsquare

Adj Rsquare

Root Mean Square Error

Mean of Response

Observations (or Sum Wgts)
0.041034

0.034085

4.393311

12.04695

279

Analysis of Variance

$\begin{array}{llllll}\text { Source } & \text { DF } & \text { Sum of Squares } & \text { Mean Square } & \text { F Ratio } & \text { Prob > F } \\ \text { Airway Shape } & 2 & 227.9497 & 113.975 & 5.9051 & 0.0031^{*} \\ \text { Error } & 276 & 5327.1252 & 19.301 & & \\ \text { C. Total } & 278 & 5555.0749 & & & \end{array}$

$\begin{array}{llllll}\text { Means for Oneway Anova } & & & \\ \text { Level } & \text { Number } & \text { Mean } & \text { Std Error } & \text { Lower 95\% } & \text { Upper 95\% } \\ \text { Long } & 25 & 9.2840 & 0.87866 & 7.554 & 11.014 \\ \text { Square } & 47 & 11.7553 & 0.64083 & 10.494 & 13.017 \\ \text { Wide } & 207 & 12.4469 & 0.30536 & 11.846 & 13.048\end{array}$

Means and Std Deviations

$\begin{array}{lllllll}\text { Level } & \text { Number } & \text { Mean } & \text { Std Dev } & \begin{array}{l}\text { Std Err } \\ \text { Mean }\end{array} & \text { Lower 95\% } & \text { Upper 95\% } \\ \text { Long } & 25 & 9.2840 & 2.57515 & 0.51503 & 8.221 & 10.347 \\ \text { Square } & 47 & 11.7553 & 4.35190 & 0.63479 & 10.478 & 13.033 \\ \text { Wide } & 207 & 12.4469 & 4.56707 & 0.31743 & 11.821 & 13.073\end{array}$

\section{Means Comparisons}

Comparisons for each pair using Student's t

Level

Wide A

Square A

Long

A

$\mathrm{B}$

Mean

12.446860

11.755319

9.284000

Levels not connected by same letter are significantly different. 
11)Oneway Analysis of Minimum CSA $\left(\mathrm{mm}^{2}\right)$ By Airway Shape

Quantiles

\begin{tabular}{|c|c|c|c|c|c|c|c|}
\hline Level & Minimum & $10 \%$ & $25 \%$ & Median & $75 \%$ & $90 \%$ & Maximum \\
\hline Long & 14.2 & 50.12 & 61.65 & 76.1 & 111.9 & 147.52 & 174.6 \\
\hline Square & 39.1 & 60.62 & 86.1 & 127.7 & 167.2 & 224.82 & 279 \\
\hline Wide & 12.2 & 65.02 & 92.7 & 127.8 & 174.4 & 224.06 & 327.8 \\
\hline
\end{tabular}

\section{Oneway Anova Summary of Fit}

Rsquare

Adj Rsquare

Root Mean Square Error

Mean of Response

Observations (or Sum Wgts)
0.047278

0.040374

59.61622

131.5634

279

\section{Analysis of Variance}

$\begin{array}{llllll}\text { Source } & \text { DF } & \text { Sum of Squares } & \text { Mean Square } & \text { F Ratio } & \text { Prob > F } \\ \text { Airway Shape } & 2 & 48677.6 & 24338.8 & 6.8481 & 0.0013^{*} \\ \text { Error } & 276 & 980929.8 & 3554.1 & & \\ \text { C. Total } & 278 & 1029607.5 & & & \end{array}$

$\begin{array}{llllll}\begin{array}{l}\text { Means for Oneway Anova } \\ \text { Level }\end{array} & \text { Number } & \text { Mean } & \text { Std Error } & \text { Lower 95\% } & \text { Upper 95\% } \\ \text { Long } & 25 & 89.628 & 11.923 & 66.16 & 113.10 \\ \text { Square } & 47 & 133.104 & 8.696 & 115.99 & 150.22 \\ \text { Wide } & 207 & 136.278 & 4.144 & 128.12 & 144.44\end{array}$

Means and Std Deviations

$\begin{array}{lllllll}\text { Level } & \text { Number } & \text { Mean } & \text { Std Dev } & \text { Std Err Mean } & \text { Lower 95\% } & \text { Upper 95\% } \\ \text { Long } & 25 & 89.628 & 38.3717 & 7.6743 & 73.79 & 105.47 \\ \text { Square } & 47 & 133.104 & 58.9418 & 8.5975 & 115.80 & 150.41 \\ \text { Wide } & 207 & 136.278 & 61.7615 & 4.2927 & 127.81 & 144.74\end{array}$

\section{Means Comparisons}

Comparisons for all pairs using Tukey-Kramer HSD

\begin{tabular}{|c|c|c|}
\hline Level & & Mean \\
\hline Wide & A & 136.27826 \\
\hline Square & A & 133.10426 \\
\hline Long & & 89.62800 \\
\hline
\end{tabular}

Levels not connected by same letter are significantly different. 


\section{2)Bivariate Fit of Airway Volume by Minimum CSA.}

CSA is an increasing function of Airway Volume. As Airway Volume increases by one cc, CSA increases by $10.23 \mathrm{~mm} 2$.

\section{Linear Fit}

Minimum CSA $(\mathrm{mm} 2)=8.2883169+10.232888 *$ Airway Volume $(\mathrm{cc})$

\section{Summary of Fit}

$\begin{array}{ll}\text { RSquare } & 0.564956 \\ \text { RSquare Adj } & 0.563386 \\ \text { Root Mean Square Error } & 40.21263 \\ \text { Mean of Response } & 131.5634 \\ \text { Observations (or Sum Wgts) } & 279\end{array}$

$\begin{array}{lllll}\text { Analysis of Variance } & & \\ \text { Source } & \text { DF } & \text { Sum of Squares } & \text { Mean Square } & \text { F Ratio } \\ \text { Model } & 1 & 581683.0 & 581683 & 359.7173 \\ \text { Error } & 277 & 447924.5 & 1617 & \text { Prob }>\text { F } \\ \text { C. Total } & 278 & 1029607.5 & & <.0001^{*}\end{array}$

\section{Parameter Estimates}

$\begin{array}{lllll}\text { Term } & \text { Estimate } & \text { Std Error } & \text { t Ratio } & \text { Prob }>|\mathbf{t}| \\ \text { Intercept } & 8.2883169 & 6.931254 & 1.20 & 0.2328 \\ \text { Airway Volume (cc) } & 10.232888 & 0.539532 & 18.97 & <.0001^{*}\end{array}$




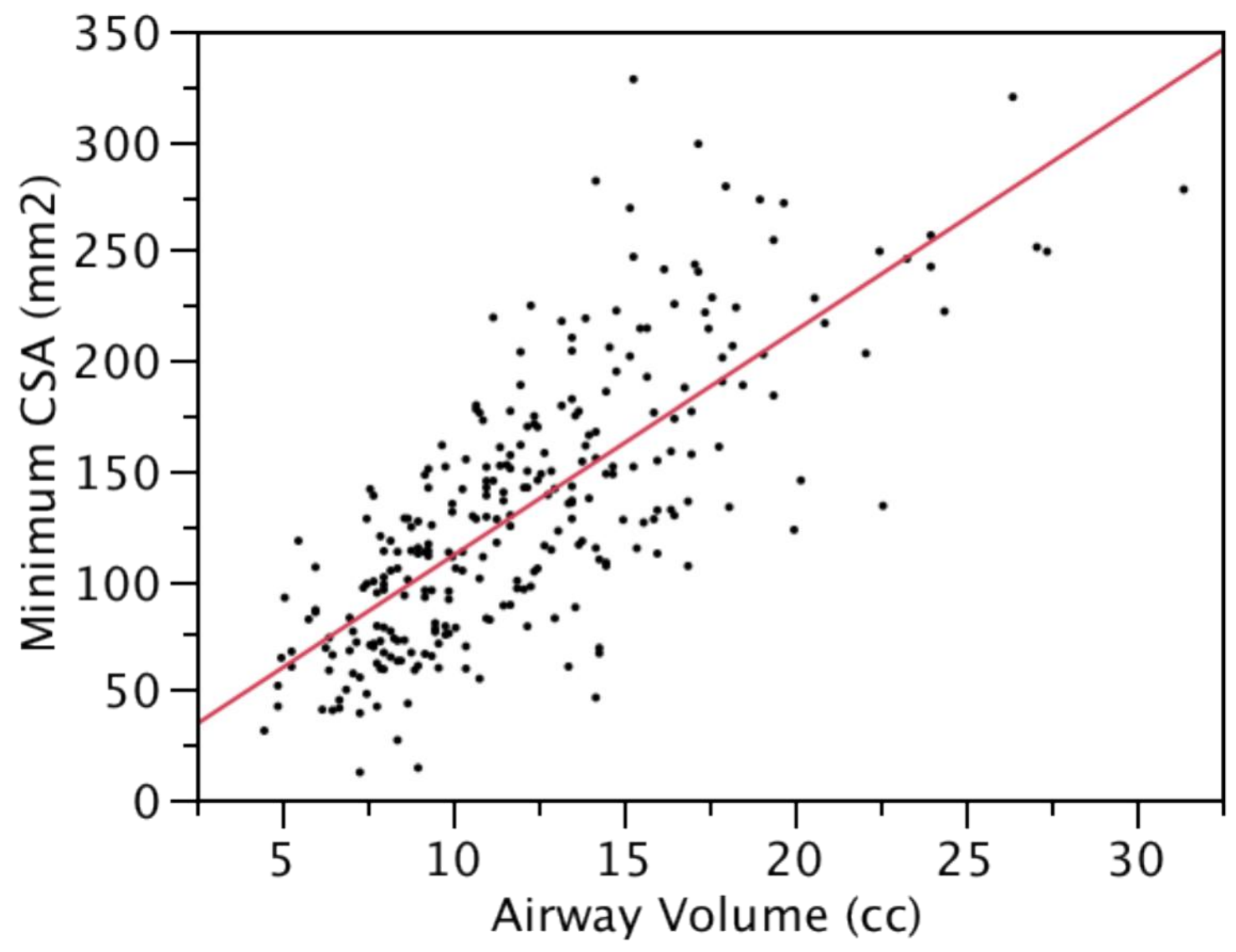




\section{CURRICULUM VITAE}

Name: $\quad$ Ronnie J. Sparks, D.D.S.

Date of Birth: $\quad$ June 8, 1984

Place of Birth: $\quad$ Charleston, West Virginia

\section{Education:}

August 2002 - May 2005: West Virginia Wesleyan College

Buckhannon, West Virginia

Bachelor of Science, Biology

August 2005 - May 2009: West Virginia University School of Dentistry

Morgantown, West Virginia

Doctorate of Dental Surgery

Highest Graduate Class of 2009

July 2009 - Present: $\quad$ West Virginia University School of Dentistry

Department of Orthodontics

Morgantown, West Virginia

Masters of Science (anticipated May 2009)

\section{Professional Memberships:}

August 2005 - May 2009: American Student Dental Association

May 2009 - Present: $\quad$ American Dental Association

July 2009 - Present: $\quad$ American Association of Orthodontists

\section{Publications:}

R. Sparks, R. Greene, P. Ngan, and M. Hurst. 2008. A Comparative Survey of Current Treatments Offered to Patients with Sleep Apnea in the Ruby Memorial Hospital Sleep Center. Abstract accepted at the $87^{\text {th }}$ General Session \& Exhibition of the International Association for Dental Research, Miami, Fl. 2009 


\title{
A Comparison of Airway Dimensions among Different Skeletal Craniofacial Patterns
}

\author{
Ronnie J. Sparks, D.D.S.
}

Thesis Submitted to the

School of Dentistry at West Virginia University

In partial fulfillment of the requirements

For the degree of Master of Science

\section{APPROVAL OF EXAMINING COMMITTEE}

Peter Ngan, D.M.D., Chairman

Chris Martin, D.D.S., M.S.

\section{Date}

Thomas Razmus, D.D.S., M.S. 